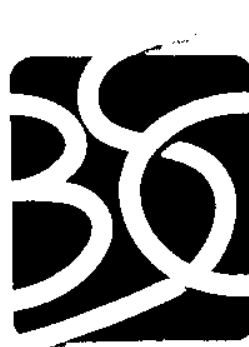

BECHTEL

SAIC CONPAYLC
QA: QA

MDL-NBS-HS-000005 REV 01

September 2004

NOTICE OF OPEN CHANGE DOCUMENTS - THIS DOCUMENT IS IMPACTED BY THE LISTED CHANGE DOCUMENT AND CANNOT BE USED WITHOUT IT.

1) ACN-001, DATED 02/24/2005

\title{
Conceptual Model and Numerical Approaches for Unsaturated Zone Flow and Transport
}

Prepared for:

U.S. Department of Energy

Office of Civilian Radioactive Waste Management

Office of Repository Development

1551 Hillshire Drive

Las Vegas, Nevada $89134-6321$

Prepared by:

Bechtel SAIC Company, LLC

1180 Town Center Drive

Las Vegas, Nevada 89144

Under Contract Number

DE-AC28-01RW12101 


\section{DISCLAIMER}

This report was prepared as an account of work sponsored by an agency of the United States Government. Neither the United States Government nor any agency thereof, nor any of their employees, nor any of their contractors, subcontractors or their employees, makes any warranty, express or implied, or assumes any legal liability or responsibility for the accuracy, completeness, or any third party's use or the results of such use of any information, apparatus, product, or process disclosed, or represents that its use would not infringe privately owned rights. Reference herein to any specific commercial product, process, or service by trade name, trademark, manufacturer, or otherwise, does not necessarily constitute or imply its endorsement, recommendation, or favoring by the United States Government or any agency thereof or its contractors or subcontractors. The views and opinions of authors expressed herein do not necessarily state or reflect those of the United States Government or any agency thereof. 
QA: QA

Conceptual Model and Numerical Approaches for Unsaturated

Zone Flow and Transport

MDL-NBS-HS-000005 REV 01

September 2004 


\section{OCRWM Model Signature Page/Change History}

\section{Type of Mathematical Model}

$\bigotimes$ Process Model

Abstraction Model

System Model

Describe Intended Use of Model

Provides conceptual models for UZ models documented in other Scientific Analyses/Model Reports

\section{Title}

Conceptual Model and Numerical Approaches for UZ Flow and Transport

4. D! (including Rev. No., if applicable):

MDL-NBS-HS-000005 REV 01

\begin{tabular}{|c|c|c|c|}
\hline \multirow[t]{2}{*}{$\begin{array}{l}\text { 5. Total Appendices } \\
\text { Two }\end{array}$} & 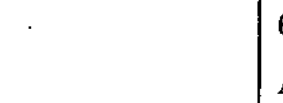 & \multicolumn{2}{|c|}{$\begin{array}{l}\text { 6. No. of Pages in Each Appendix } \\
\text { A-4, B-4 }\end{array}$} \\
\hline & Printed Name & Signature & Date \\
\hline 7. Originator & H.H. Liu & & \\
\hline $\begin{array}{l}\text { 8. Independent Technical } \\
\text { Reviewer }\end{array}$ & J. Houseworth & & \\
\hline 9. Checker & J. Geller & & \\
\hline 10. QER & K. McFall & & \\
\hline 11. Responsible Manager/Lead & H.H. Liu/Y.S. Wu & & \\
\hline 12. Responsible Manager & M. Zhu & & \\
\hline
\end{tabular}

\begin{tabular}{|l|l|}
\hline \multicolumn{2}{|c|}{ Change History } \\
\hline 14. Revision No. & \multicolumn{1}{|c|}{ 15. Description of Change } \\
\hline REV 00 01 & Initial Issue \\
\hline & $\begin{array}{l}\text { Increased transparency in response to the regulatory-focused } \\
\text { evaluation performed by the Regulatory Integration Team. } \\
\text { Entire model documentation was revised. Side bars are not } \\
\text { used because the changes were too extensive to use Step } \\
\text { 5.8f)1) per AP-SIII.10Q, REV 02, ICN 07. The revision was } \\
\text { also used for addressing Key Technical Issue Agreement } \\
\text { TEF 2.13. }\end{array}$ \\
\hline
\end{tabular}




\section{CONTENTS}

Page

ACRONYMS AND ABBREVIATIONS ........................................................................ xiii

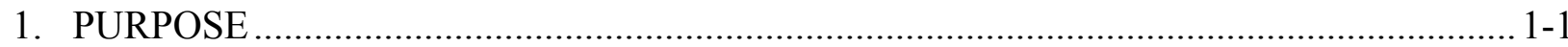

2. QUALITY ASSURANCE ............................................................................... 2-1

3. USE OF SOFTWARE .......................................................................................... $3-1$

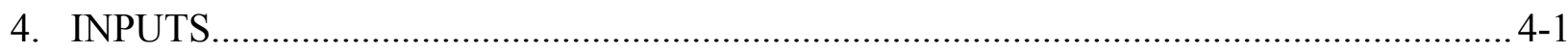

4.1 DIRECT INPUT ….................................................................................. 4-1

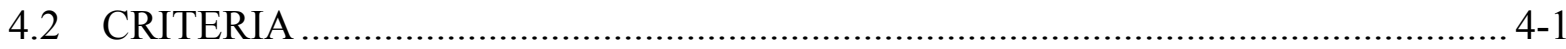

4.3 CODES, STANDARDS, AND REGULATIONS ................................................ 4-4

5. ASSUMPTIONS ................................................................................................

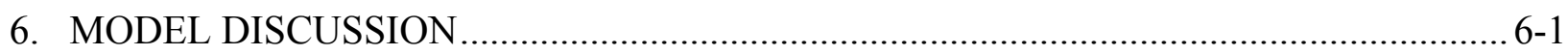

6.1 CONCEPTUAL MODEL OF FLOW …........................................................... $6-2$

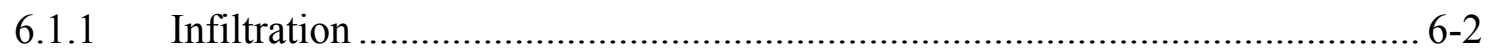

6.1.2. Fracture and Matrix Flow Component.................................................... 6-3

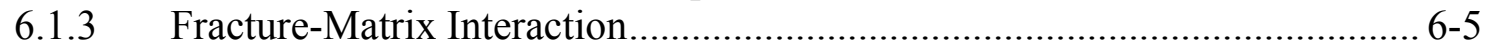

6.1.4 Perched Water ..................................................................................... 6-7

6.1.5 Effects of Major Faults .................................................................... 6-9

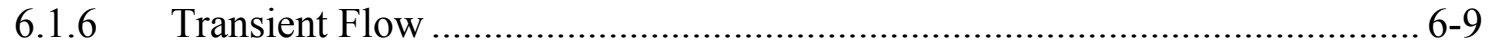

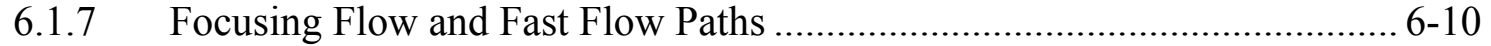

6.1.8 Gas Flow Process ................................................................................ 6-11

6.1.9 Summary and Further Discussions ..................................................... 6-12

6.2 CONCEPTUAL MODEL OF TRANSPORT .................................................... 6-13

6.2.1 Advective Transport....................................................................... 6-13

6.2.2 Matrix Diffusion and Potential Scale-Dependency of Effective

Fracture and Matrix Sorption............................................................... 6-17

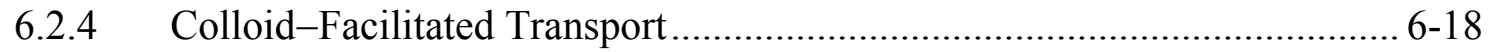

6.2.5 Other Transport Issues and Processes...................................................... 6-18

6.2.6 Summary and Further Discussions ............................................................. 6-19

6.3 NUMERICAL APPROACHES .................................................................... $6-20$

6.3.1 Available Numerical Schemes ........................................................... 6-20

6.3.1.1 Continuum Approaches .......................................................... 6-20

6.3.1.1.1 Basic Physical and Numerical Principles................... 6-20

6.3.1.1.2 Effective Continuum Approach .............................. 6-21

6.3.1.1.3 Dual-Continua Approaches.................................... 6-22

6.3.1.1.4 Multiple Interacting Continua Approach .................. 6-22

6.3.1.2 Discrete Fracture-Network Approaches ...................................... 6-22

6.3.2 Assessment of Numerical Approaches ................................................ 6-23 


\section{CONTENTS (Continued)}

Page

6.3.3 Consistency between Continuum-Approach-Based Simulation Results and Field Observations................................................................ 6-24

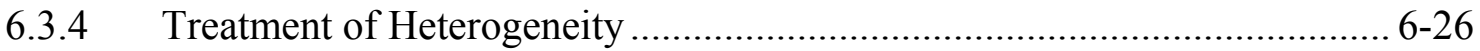

6.3.5 van Genuchten Relations for Modeling Unsaturated Flow in

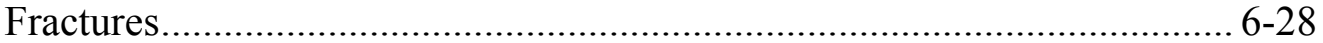

6.3.6 Special Issues for Flow and Transport Modeling ..................................... 6-32

6.3.6.1 Gas Flow ........................................................................... 6-32

6.3.6.2 Particle-Tracking Algorithm for Chemical Transport...................6-33

6.3.6.3 Dispersion in Fractures............................................................ 6-33

6.3.6.4 Use of the Dual-Continua Approach for Modeling Radionuclide Transport ............................................................. 6-34

6.3.7 Active Fracture Model ...................................................................... 6-34

6.3.7.1 Active Fracture Concept..................................................... 6-34

6.3.7.2 Constitutive Relations ............................................................ 6-36

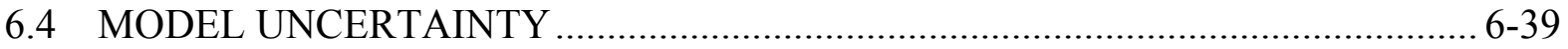

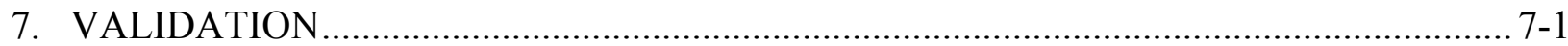

7.1 MODEL VALIDATION ACTIVITIES ............................................................... $7-1$

7.2 CONSISTENCY BETWEEN AFM AND FRACTAL FLOW BEHAVIOR IN UNSATURATED SYSTEMS ….................................................................... 7-3

7.2.1 Evidence of Fractal Flow-Patterns in Unsaturated or Multiphase Flow Systems ........................................................................... 7-3

7.2.2 Fractal Dimension................................................................................. 7-5

7.2.3 Consistency of the AFM and a Fractal Flow Pattern ................................. 7-6

7.3 COMPARISON WITH A FILM-FLOW MODEL .................................................. $7-9$

7.3.1 Film-Flow Model .............................................................................. 7-10

7.3.2 Model Comparison................................................................................. $7-15$

7.4 EVALUATION OF THE AFM WITH CARBON-14 AND MINERAL

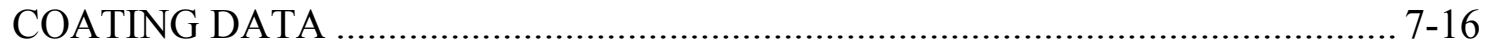

7.4.1 Model validation with Carbon-14 Data ................................................ 7-16

7.4.2 Model Validation with Mineral Coating Data ........................................... 7-20

7.5 VALIDATION SUMMARY ..................................................................... 7-21

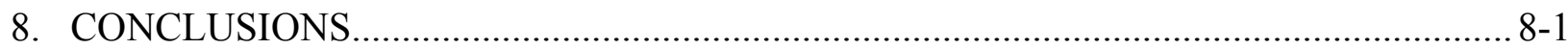

8.1 CONCEPTUAL MODEL AND NUMERICAL APPROACHES ............................ 8-1

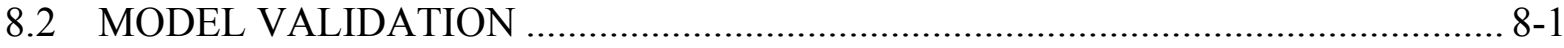

8.3 HOW THE ACCEPTANCE CRITERIA ARE ADDRESSED ................................. 8-2

9. INPUTS AND REFERENCES ......................................................................... 9-1

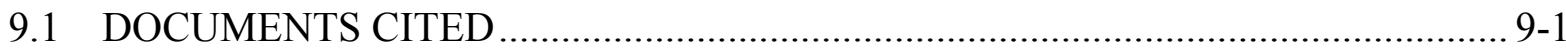

9.2 CODES, STANDARDS, REGULATIONS, AND PROCEDURES ....................... 9-10

9.3 SOURCE DATA, LISTED BY DATA TRACKING NUMBER ........................... 9-10

9.4 OUTPUT DATA, LISTED BY DATA TRACKING NUMBER .......................... 9-11

9.5 SOFTWARE CITED .............................................................................. $9-12$ 


\section{CONTENTS (Continued)}

Page

APPENDIX A-DATA POINT VALUES IN FIGURES 7-3 AND 7-4 _................................. A-1

APPENDIX B-DATA POINT VALUES IN FIGURE 7-1 ................................................ B-1 


\section{INTENTIONALLY LEFT BLANK}




\section{FIGURES}

Page

6-1. A Simplified Schematic Showing Conceptualized Water Flow through Yucca Mountain

6-2. Comparison Between Observed and Simulated Chloride Concentration

Distribution for Borehole USW SD-9.

6-3. A Simplified Schematic for Water Flow in Fractures Characterized by Fingering Flow at Different Scales.

6-4. A Simplified Schematic for Flow Patterns Within and Near a Perched Water Body Characterized by Strong Lateral Flow Within the Perched Water Body and the Associated Fault-Dominated Flow

6-5. A Simplified Schematic Showing Conceptual Model of Unsaturated Zone Flow Focusing in Yucca Mountain

6-6. Effective Matrix Diffusion Coefficient as a Function of Test Scale. RD Refers to the Effective Coefficient Value (Estimated from Field Data) Divided by the Corresponding Local Value

6-7. Schematic Diagram of One-Dimensional Column of Gridblock, Modeled as (a) ECM, (b) Dual-Porosity with One Matrix Gridblock, (c) Dual-Permeability with One Matrix Gridblock per Fracture Gridblock, and (d) MINC with Three Matrix Gridblocks per Fracture Gridblock.....

6-8. Comparison Between Simulated Seepage Rates as a Function of Time and Field Observations Collected from Alcove 8/Niche 3 Tests

6-9. Comparison Between Simulated Seepage Rates as a Function of Time and Field Observations Collected from Alcove 1 Tests

6-10. Comparison of Simulated Matrix and Fracture Flux (m/s) at the Repository Horizon in Cases A, B, and C

6-11. A Computationally Generated Fracture Network

6-12. Fit of the van Genuchten Model to the Simulated Capillary Pressure-Effective Saturation Relations

6-13. Comparison Between Simulated Relative Permeability-Effective Saturation

Relations. The Curves Predicted Using the van Genuchten (VG) Relations, the Brooks-Corey (BC) Relations, and a New Relation (Equation 6-10) with the $m$ Values Determined from 6-12.

6-14. Capillary Pressure Curves of Fracture Continuum for $\gamma=0,0.5$ and $0.9 \ldots \ldots \ldots \ldots \ldots \ldots \ldots \ldots . . .6-37$

6-15. Relative Permeability Curves of Fracture Continuum for $\gamma=0,0.5$ and 0.9 ............... 6-38

7-1. Relation Between N and 1 (Appendix B). The Data Points Correspond to Observed Values for the Tptpmn Unit.

7-2. Schematic Showing Demonstration of "Box" Counting Procedure for Several Box Sizes, with the Shaded Areas Containing Saturation and Active Flow.

7-3. Match of Equation 7-18b to Surface Transmissivity-Film Thickness Measurements

7-4. Matches of Equation 7-18 to (a) Film Thickness and (b) Surface Transmissivity-Film Thickness 


\section{FIGURES (Continued)}

7-5. Match of Equation 7-18b to Surface Transmissivity-Film Thickness

Measurements

7-6. Comparison Between Relative Permeability-Saturation Relations Calculated

Using the AFM with $\mathrm{m}=0.633$ (DTN: LB0205REVUZPRP.001 [DIRS 159525]) for Several $\gamma$ Values (Solid Red Lines) and Relations Calculated from the Film-Flow Model with $\lambda$ Values (Dashed Lines)

7-7. Comparisons Between Simulated Water Travel Times (Ages) for Rock Matrix at Boreholes (a) USW UZ-1 and (b) USW SD-12, as well as the Corresponding Carbon-14 Ages for Several $\gamma$ Values.

7-8. Simulated Average Portion of Active Fracture for the Relevant Model Layers (tsw32 to tsw38) as a Function of Infiltration Rate and $\gamma$ 


\section{TABLES}

Page

3-1. Qualified Software Used in This Report.................................................................. 3-1

4-1. Project Requirements and Acceptance Criteria Applicable to This

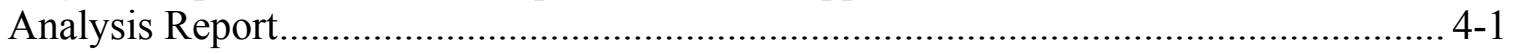

6-1. FEPs Addressed in This Model Report.................................................................. 6-1

7-1. Scientific Notebooks ........................................................................................... 7-2

7-2. Data Tracking Numbers for Input Data Used .......................................................... 7-2 


\section{INTENTIONALLY LEFT BLANK}




\section{ACRONYMS AND ABBREVIATIONS}

\begin{tabular}{|c|c|}
\hline AFM & active fracture model \\
\hline $\mathrm{CHn}$ & Calico Hills nonwelded hydrogeologic unit \\
\hline DLA & diffusion-limited-aggregation \\
\hline ECM & effective continuum method \\
\hline ESF & Exploratory Studies Facility \\
\hline FEP & feature, event, and process \\
\hline MINC & multiple interacting continua \\
\hline PTn & Paintbrush nonwelded hydrogeologic unit \\
\hline QA & quality assurance \\
\hline QARD & Quality Assurance Requirements and Description \\
\hline $\begin{array}{l}\text { TCW } \\
\text { TDMS } \\
\text { TSPA } \\
\text { TSw } \\
\text { TWP }\end{array}$ & $\begin{array}{l}\text { Tiva Canyon welded hydrogeologic unit } \\
\text { Technical Data Management System } \\
\text { Total System Performance Assessment } \\
\text { Topopah Spring welded hydrogeologic unit } \\
\text { technical work plan }\end{array}$ \\
\hline $\mathrm{UZ}$ & unsaturated zone \\
\hline
\end{tabular}




\section{INTENTIONALLY LEFT BLANK}




\section{PURPOSE}

The purpose of this model report is to document the conceptual and numerical models used for modeling unsaturated zone (UZ) fluid (water and air) flow and solute transport processes. This work was planned in Technical Work Plan for: Unsaturated Zone Flow Model and Analysis Report Integration (BSC 2004 [DIRS 169654], Sections 1.2.5, 2.1.1, 2.1.2 and 2.2.1). The conceptual and numerical modeling approaches described in this report are mainly used for models of UZ flow and transport in fractured, unsaturated rock under ambient conditions. Developments of these models are documented in the following model reports:

- UZ Flow Model and Submodels

- Radionuclide Transport Models under Ambient Conditions.

Conceptual models for flow and transport in unsaturated, fractured media are discussed in terms of their applicability to the UZ at Yucca Mountain. The rationale for selecting the conceptual models used for modeling of UZ flow and transport is documented. Numerical approaches for incorporating these conceptual models are evaluated in terms of their representation of the selected conceptual models and computational efficiency; and the rationales for selecting the numerical approaches used for modeling of UZ flow and transport are discussed.

This report also documents activities to validate the active fracture model (AFM) based on experimental observations and theoretical developments. The AFM is a conceptual model that describes the fracture-matrix interaction in the UZ of Yucca Mountain. These validation activities are documented in Section 7 of this report regarding use of an independent line of evidence to provide additional confidence in the use of the AFM in the UZ models. The AFM has been used in UZ flow and transport models under both ambient and thermally disturbed conditions. Developments of these models are documented in the following model reports:

- UZ Flow Model and Submodels

- Radionuclide Transport Models under Ambient Conditions

- Particle Tracking Model and Abstraction of Transport Processes

- Drift Scale Radionuclide Transport

- Mountain-Scale Coupled Processes (TH/THC/THM)

- Drift-Scale THC Seepage Model

- Multiscale Thermohydrologic Model

- Drift-Scale Coupled Processes (DST and TH Seepage) Models

- Drift Scale THM Model

The model validation activities reported in this report were planned in the TWPs (BSC 2004 [DIRS 169654], Section 2.2.1; BSC 2002 [DIRS 160819], Section I-1-3) and there was a deviation from the TWPs in this report. The currently available data from the large-infiltration-plot test at Alcove 8/Niche three have not been used for model validation because they are not suitable for validating the AFM. The currently available data were obtained under testing conditions corresponding to high fracture saturations. In this case, simulation results are not sensitive to the AFM parameters. 
Caveats and limitations include use of the van Genuchten relation for the active fracture continuum, use of porous-medium equivalence for describing flow and transport in fracture networks, and the assumption of steady-state liquid flow in the UZ. More discussions on these caveats and limitations are presented in Section 6 of this report. 


\section{QUALITY ASSURANCE}

Development of this model report and the supporting modeling activities have been determined to be subject to the requirements in Quality Assurance Requirements and Description (DOE 2004 [DIRS 171539]). Approved quality assurance (QA) procedures identified in the technical work plan (TWP) (BSC 2004 [DIRS 169654], Section 4) have been used to conduct and document the activities described in this model report. The TWP also identifies the methods used to control the electronic management of data (BSC 2004 [DIRS 169654], Section 8.4) during the modeling and documentation activities.

This model report describes the conceptual model of flow and transport in the UZ and the numerical approaches for its implementation. The UZ is part of the natural barrier classified in the Q-List (BSC 2004 [DIRS 168361]) as "Safety Category," because of the barrier's importance to waste isolation, as defined in AP-2.22Q, Classification Analyses and Maintenance of the Q-List. The results of this report are important to the demonstration of compliance with the postclosure performance objectives prescribed in 10 CFR 63.114 [DIRS 156605]. The report contributes to performance assessment; the conclusions do not directly impact engineered features important to preclosure safety, as defined in AP-2.22Q. 


\section{INTENTIONALLY LEFT BLANK}




\section{USE OF SOFTWARE}

The software programs used in this study are listed in Table 3-1. These are appropriate for the intended application and were used only within the range of validation. They were obtained from Software Configuration Management, and qualified under LP-SI.11Q-BSC, Software Management.

Table 3-1. Qualified Software Used in This Report

\begin{tabular}{|l|l|l|l|l|l|}
\hline Software Name & Version & $\begin{array}{c}\text { Software } \\
\text { Nracking } \\
\text { Number (STN) }\end{array}$ & \multicolumn{1}{|c|}{ Platform } & \multicolumn{1}{|l|}{ Operating System } & $\begin{array}{l}\text { DIRS Reference } \\
\text { Number }\end{array}$ \\
\hline TOUGH2 & 1.4 & $10007-1.4-01$ & $\begin{array}{l}\text { SUN ULTRASPARC, } \\
\text { DEC ALPHA }\end{array}$ & $\begin{array}{l}\text { SUNOS 5.5.1, OSF1 } \\
\text { V4.0, OSF1 V5.1 }\end{array}$ & $\begin{array}{l}\text { LBNL 2000 } \\
\text { [DIRS 146496] }\end{array}$ \\
\hline T2R3D & 1.4 & $10006-1.4-00$ & $\begin{array}{l}\text { SUN, DEC ALPHA, } \\
\text { PC }\end{array}$ & $\begin{array}{l}\text { UNIX, WINDOWS } \\
\text { 95/98/NT 4.0 }\end{array}$ & $\begin{array}{l}\text { LBNL 1999 } \\
\text { [DIRS 146654] }\end{array}$ \\
\hline infil2grid & 1.7 & $10077-1.7-00$ & PC, DEC ALPHA & $\begin{array}{l}\text { DOS V4.00.1111, } \\
\text { OSF1 V4.0 }\end{array}$ & $\begin{array}{l}\text { LBNL 2002 } \\
\text { [DIRS 154793] }\end{array}$ \\
\hline
\end{tabular}

DIRS = Document Input Reference System; STN=software tracking number

Standard Excel spreadsheets and display graphics programs (Excel 97 SR-1 and Tecplot V7.0) were also used but are not subject to software QA requirements. All information needed to reproduce the work using these standard software programs is included in this report, with references specified. 


\section{INTENTIONALLY LEFT BLANK}




\section{INPUTS}

\subsection{DIRECT INPUT}

This report describes conceptual models and numerical approaches for UZ flow and transport. No data from the Technical Data Management System (TDMS) are used as direct input in this report, and no output data tracking numbers were used as direct input by the downstream technical products. Data used for model validation are presented in Section 7.

\subsection{CRITERIA}

The general requirements to be satisfied by the total system performance assessment (TSPA) are stated in 10 CFR 63.114 [DIRS 156605]. Technical requirements to be satisfied by the TSPA are identified in the Yucca Mountain Project Requirements Document (Canori and Leitner 2003 [DIRS 166275]). The acceptance criteria that will be used by the Nuclear Regulatory Commission (NRC) to determine whether the technical requirements have been met are identified in Yucca Mountain Review Plan, Final Report (YMRP) (NRC 2003 [DIRS 163274]). The pertinent requirements and criteria for this report are summarized in Table 4-1.

Table 4-1. Project Requirements and Acceptance Criteria Applicable to This Analysis Report

\begin{tabular}{|c|c|c|c|}
\hline $\begin{array}{l}\text { Requirement } \\
\text { Number }^{\mathrm{a}}\end{array}$ & Requirement Title ${ }^{a}$ & 10 CFR 63 Link & $\begin{array}{l}\text { YMRP Acceptance } \\
\text { Criteria } b\end{array}$ \\
\hline PRD -002/T-015 & $\begin{array}{l}\text { Requirements for Performance } \\
\text { Assessment }\end{array}$ & $\begin{array}{l}10 \text { CFR } 63.114(\mathrm{a})-(\mathrm{c}) \\
\text { and }(\mathrm{e})-(\mathrm{g})\end{array}$ & $\begin{array}{l}2.2 \cdot 1 \cdot 3 \cdot 6.3 \text {, criteria } 1 \text { to } 4 \\
2 \cdot 2 \cdot 1 \cdot 3.7 .3 \text {, criteria } 1 \text { to } 5\end{array}$ \\
\hline
\end{tabular}

${ }^{a}$ Canori and Leitner (2003 [DIRS 166275])

${ }^{\mathrm{b}} \mathrm{NRC}(2003$ [DIRS 163274]).

The acceptance criteria identified in Sections 2.2.1.3.6.3 and 2.2.1.3.7.3 of the YMRP (NRC 2003 [DIRS 163274]) are included below. In cases where subsidiary criteria are listed in the YMRP for a given criterion, only the subsidiary criteria addressed by this scientific analysis are listed below. Explanation of how this report meets the acceptance criteria below is given in Section 8.3.

Note that the acceptance criteria in Table 4-1 are different from those identified in the TWP (BSC 2004 [DIRS169654], Table 3-1). After the TWP was completed, the applicability of acceptance criteria for the report are reevaluated and additional criteria applicable to this report are identified and included in Table 4-1.

Acceptance Criteria from Section 2.2.1.3.6, Flow Paths in the Unsaturated Zone.

Acceptance Criterion 1, System Description and Model Integration Are Adequate.

(1) Total system performance assessment adequately incorporates, or bounds, important design features, physical phenomena, and couplings, and uses consistent and appropriate assumptions throughout the flow paths in the unsaturated zone abstraction process. Couplings include thermal-hydrologic-mechanical-chemical effects as appropriate; 
(2) The aspects of geology, hydrology, geochemistry, physical phenomena, and couplings that may affect flow paths in the unsaturated zone are adequately considered. Conditions and assumptions in the abstraction of flow paths in the unsaturated zone are readily identified and consistent with the body of data presented in the description;

(3) The abstraction of flow paths in the unsaturated zone uses assumptions, technical bases, data, and models that are appropriate and consistent with other related U.S. Department of Energy abstractions. For example, the assumptions used for flow paths in the unsaturated zone are consistent with the abstractions of quality and chemistry of water contacting waste packages and waste forms, climate and infiltration, and flow paths in the saturated zone (Sections 2.2.1.3.3, 2.2.1.3.5 and 2.2.1.3.8 of the Yucca Mountain Review Plan, respectively). The descriptions and technical bases are transparent and traceable to site and design data.

(4) The bases and justification for modeling assumptions and approximations of radionuclide transport in the unsaturated zone are consistent with those used in model abstractions for flow paths in the unsaturated zone and thermal-hydrologicmechanical-chemical effects;

(9) Guidance in NUREG-1297 (Altman et al. 1988 [DIRS 103597]) and NUREG-1298 (Altman et al. 1988 [DIRS 103750]), or other acceptable approaches for peer review and data qualification is followed.

\section{Acceptance Criterion 2: Data Are Sufficient for Model Justification.}

(6) Accepted and well-documented procedures are used to construct and calibrate numerical models;

(7) Reasonably complete process-level conceptual and mathematical models are used in the analyses. In particular: (i) mathematical models are provided that are consistent with conceptual models and site characteristics; and (ii) the robustness of results from different mathematical models is compared;

\section{Acceptance Criterion 3: Data Uncertainty is Characterized and Propagated Through the Model Abstraction.}

(1) Models use parameter values, assumed ranges, probability distributions, and bounding assumptions that are technically defensible, reasonably account for uncertainties and variabilities, and do not result in an under-representation of the risk estimate;

(6) Uncertainties in the characteristics of the natural system and engineered materials are considered. 


\section{Acceptance Criterion 4, Model Uncertainty is Characterized and Propagated Through the Model Abstraction.}

(1) Alternative modeling approaches of features, events, and processes, consistent with available data and current scientific understanding, are investigated. The results and limitations are appropriately considered in the abstraction;

(3) Consideration of conceptual model uncertainty is consistent with available site characterization data, laboratory experiments, field measurements, natural analog information and process-level modeling studies; and the treatment of conceptual model uncertainty does not result in an under-representation of the risk estimate;

Acceptance Criteria from Section 2.2.1.3.7, Radionuclide Transport in the Unsaturated Zone).

\section{Acceptance Criterion 1: System Description and Model Integration Are Adequate.}

(1) Total system performance assessment adequately incorporates important design features, physical phenomena, and couplings, and uses consistent and appropriate assumptions throughout the radionuclide transport in the unsaturated zone abstraction process;

(2) The description of the aspects of hydrology, geology, geochemistry, design features, physical phenomena, and couplings, that may affect radionuclide transport in the unsaturated zone, is adequate. For example, the description includes changes in transport properties in the unsaturated zone, from water-rock interaction. Conditions and assumptions in the total system performance assessment abstraction of radionuclide transport in the unsaturated zone are readily identified, and consistent with the body of data presented in the description;

(3) The abstraction of radionuclide transport in the unsaturated zone uses assumptions, technical bases, data, and models that are appropriate and consistent with other related U.S. Department of Energy abstractions. For example, the assumptions used for radionuclide transport in the unsaturated zone are consistent with the abstractions of radionuclide release rates and solubility limits and flow paths in the unsaturated zone (Sections 2.2.1.3.4 and 2.2.1.3.6 of the Yucca Mountain Review Plan). The descriptions and technical bases provide transparent and traceable support for the abstraction of radionuclide transport in the unsaturated zone;

(5) Sufficient data and technical bases for the inclusion of features, events, and processes, related to radionuclide transport in the unsaturated zone in the total system performance assessment abstraction, are provided; and

(6) Guidance in NUREG-1297 (Altman et al. 1988 [DIRS 103597]) and NUREG-1298 (Altman et al. 1988 [DIRS 103750]), or other acceptable approaches for peer review and data qualification is followed. 


\section{Acceptance Criterion 3: Data Uncertainty is Characterized and Propagated Through the} Model Abstraction.

(1) Models use parameter values, assumed ranges, probability distributions, and bounding assumptions that are technically defensible, reasonably account for uncertainties and variabilities, and do not result in an under-representation of the risk estimate;

\section{Acceptance Criterion 4: Model Uncertainty is Characterized and Propagated Through the Model Abstraction.}

(1) Alternative modeling approaches of features, events, and processes are considered and are consistent with available data and current scientific understanding, and the results and limitations are appropriately considered in the abstraction;

(2) Conceptual model uncertainties are adequately defined and documented, and effects on conclusions regarding performance are properly assessed.

(3) Consideration of conceptual model uncertainty is consistent with available site characterization data, laboratory experiments, field measurements, natural analog information and process-level modeling studies; and the treatment of conceptual model uncertainty does not result in an under-representation of the risk estimate; and

(4) Appropriate alternative modeling approaches are consistent with available data and current scientific knowledge, and appropriately consider their results and limitations, using tests and analyses that are sensitive to the processes modeled. For example, for radionuclide transport through fractures, the U.S. Department of Energy adequately considers alternative modeling approaches, to develop its understanding of fracture distributions and ranges of fracture flow and transport properties in the unsaturated zone.

\subsection{CODES, STANDARDS, AND REGULATIONS}

No codes or standards, other than those identified in the Project Requirements Documents (Canori and Leitner 2003 [DIRS 166275], Table 2-3) and determined to be applicable in Table 4-1, were used in this model report. 


\section{ASSUMPTIONS}

The UZ is a complex hydrogeological system involving a number of important processes relating to fluid flow and solute transport. The assumptions made to develop conceptual model and numerical approaches for these processes are presented in Section 6. This report does not include assumptions used in the absence of direct confirming data or evidence to perform the model activity. Per AP-SIII.10Q, Models, only the latter assumptions need to be presented in this section. 


\section{INTENTIONALLY LEFT BLANK}




\section{MODEL DISCUSSION}

This section discusses the conceptual model and numerical approaches used to describe flow and transport processes in the UZ. These processes are closely related to the hydrogeologic features of the UZ, which consists of heterogeneous volcanic rocks. These rocks have been welded and fractured to varying degrees, and are divided into hydrogeologic units (Montazer and Wilson 1984 [DIRS 100161], pp. 9-20) based roughly on the degree of welding. Beginning from the land surface, they are the Tiva Canyon welded (TCw), the Paintbrush nonwelded (PTn), the Topopah Spring welded (TSw), the Calico Hills nonwelded $(\mathrm{CHn})$, and the Crater Flat undifferentiated hydrogeologic units (Figure 6-1). The welded units typically have low matrix porosities and high fracture densities, whereas the nonwelded units have relatively high matrix porosities and low fracture densities (Montazer and Wilson 1984 [DIRS 100161], pp. 8-9). Water in the UZ moving downward through these units is considered to be partitioned between fractures ("fracture flow") and the rock matrix ("matrix flow"), as described subsequently in this model report.

The conceptual model of flow and transport processes is a framework to explain these processes in the UZ. The current conceptual model is based, to a great extent, on the ideas originally presented by Montazer and Wilson (1984 [DIRS 100161], pp. 36-49), and has been developed through the evaluation of collected data and the results of modeling studies. A detailed discussion of the conceptual model is presented in Sections 6.1 and 6.2. Different numerical approaches are available for modeling flow and transport in unsaturated fractured rocks. Section 6.3 briefly reviews the numerical approaches and provides an assessment of these approaches based on the conceptual model and other practical considerations. The AFM is also documented in this section and validated in Section 7.

This report addresses the features, events, and processes (FEPs) listed in Table 6-1 that were taken from the license application FEP List (DTN: MO0407SEPFEPLA.000 [DIRS 170760]). The selected FEPs are those associated with the subject matter of this report. The cross-reference for each FEP to the relevant sections of this report is also given in Table 6-1.

Note that in addition to FEPs in Table 6-1, the FEP Diffusion in the UZ (FEP number 2.2.08.05.0A) is also identified in the TWP (BSC 2004 [169654], Table 2.1.5-1). This FEP is not included in this report because the general diffusion process in the $\mathrm{UZ}$ is not the key element of the conceptual model for UZ flow and transport.

Table 6-1. FEPs Addressed in This Model Report

\begin{tabular}{|l|l|l|}
\hline \multicolumn{1}{|c|}{ FEP No. } & \multicolumn{1}{|c|}{ FEP Name } & \multicolumn{1}{c|}{ Relevant Sections of this Report } \\
\hline 2.2.07.02.0A & $\begin{array}{l}\text { Unsaturated groundwater flow in } \\
\text { geosphere }\end{array}$ & Sections 6.1 and 7 \\
\hline 2.2.07.04.0A & $\begin{array}{l}\text { Focusing of unsaturated flow } \\
\text { (fingers, weeps) }\end{array}$ & Sections 6.1.7, 6.3.7 and 7 \\
\hline 2.2.07.08.0A & Fracture flow in the UZ & Section 6.1 \\
\hline 2.2.08.08.0B & Matrix diffusion in the UZ & Section 6.2.2 \\
\hline 2.2.08.09.0B & Sorption in the UZ & Section 6.2.3 \\
\hline 2.2.08.10.0B & Colloidal transport in the UZ & Section 6.2.4 \\
\hline
\end{tabular}




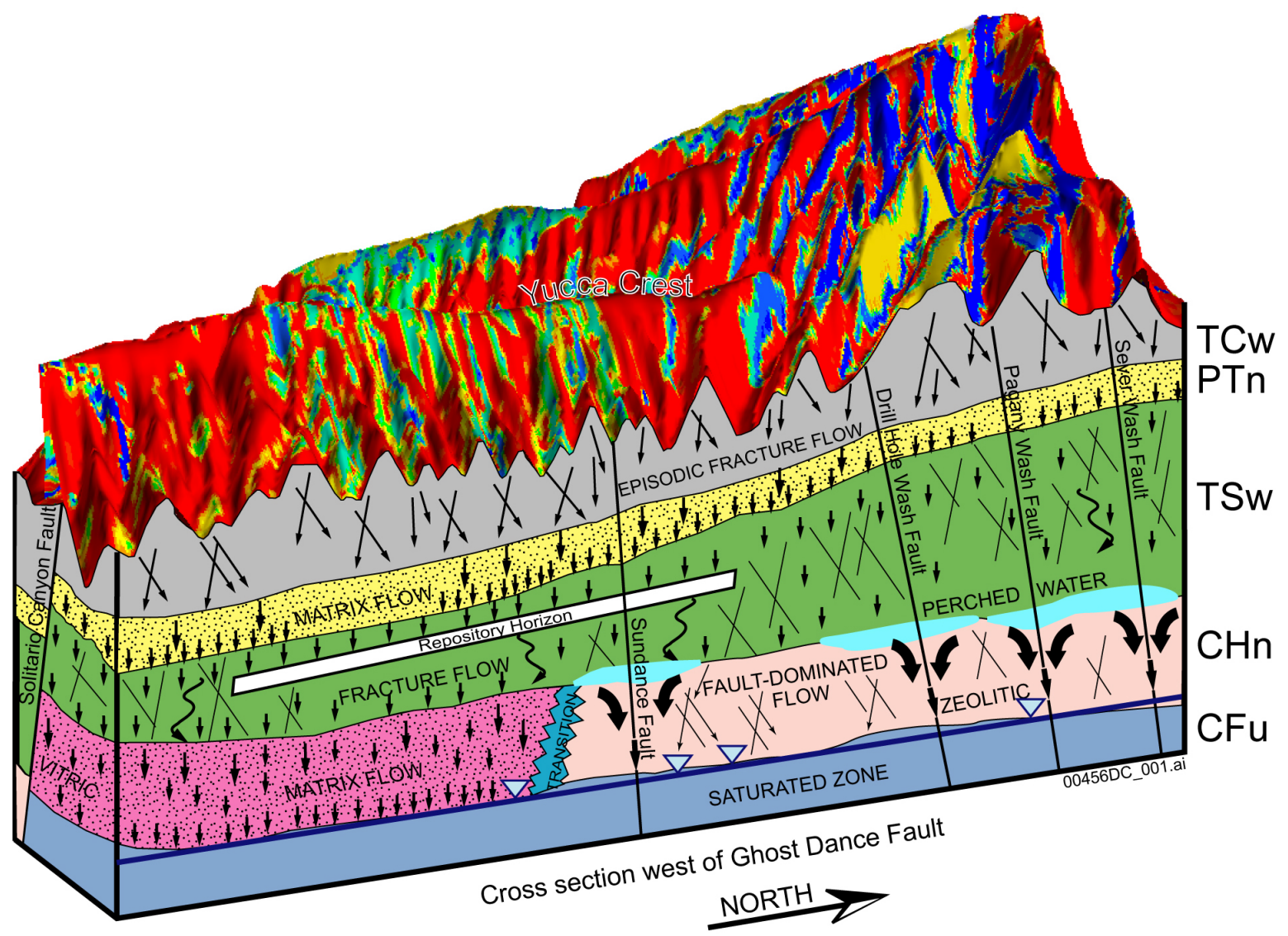

NOTE: The blue and red colors on the land surface approximately correspond to high and low infiltration rates, respectively, while the other colors approximately correspond to infiltration rates in between.

Figure 6-1. A Simplified Schematic Showing Conceptualized Water Flow through Yucca Mountain

\subsection{CONCEPTUAL MODEL OF FLOW}

This subsection documents the conceptual model of flow used for modeling transport and flow within the UZ at Yucca Mountain. The conceptual model is presented by addressing important flow issues and processes.

\subsubsection{Infiltration}

Infiltration process refers to the penetration of liquid water (from precipitation) through the ground surface and to a depth where it can no longer be withdrawn by evaporation or transpiration by plants. Percolation process refers to vertical and lateral flow of liquid water within the UZ. Infiltration is the ultimate source of percolation flux at the repository horizon and provides the water for flow and transport mechanisms that may move radionuclides from the repository to the water table. Infiltration is spatially and temporally variable because of the nature of the storm events that supply precipitation (Hevesi et al. 1994 [DIRS 125315]) and variation in soil cover and topography. Infiltration is believed to be high on sideslopes and ridgetops where bedrock crops are exposed, and fracture flow in the bedrock is able to move moisture away from zones of active evaporation (Flint et al. 1994 [DIRS 103135]). 
Significant precipitation (and infiltration) occurs only every few years (Flint et al. 1996 [DIRS 100147], pp. 46-50). In these years, the amount of infiltration still varies greatly, depending on storm amplitudes, durations, or frequencies. In very wet years, infiltration pulses may infiltrate into Yucca Mountain during a relatively short time period. A more detailed discussion of infiltration at Yucca Mountain is documented in a report describing simulation of net infiltration for modern and potential future climates (BSC 2004 [DIRS 170007]).

\subsubsection{Fracture and Matrix Flow Component}

This subsection describes fracture and matrix flow component in various geologic layers (including the TCw, PTn, TSw and $\mathrm{CHn}$ ) in the UZ.

As a result of the relatively high density of interconnected fractures and low matrix permeabilities in the $\mathrm{TCw}$, infiltration pulses are expected to move rapidly through the fracture system with little attenuation (Bodvarsson et al. 1999 [DIRS 120055], p. 10). This is partially supported by pneumatic sensors in the TCw showing little attenuation of the barometric signal in monitoring boreholes compared with the barometric signal observed at the land surface (Rousseau et al. 1999 [DIRS 102097], p. 89). In this unit, the gas flow paths are considered to be similar to those of liquid water.

Once the unsaturated flow leaves the $\mathrm{TCw}$ and enters the PTn, totally different processes are evident. Because the PTn has relatively high matrix permeabilities and porosities, and low fracture densities, the predominant fracture flow in the $\mathrm{TCw}$ is expected to convert to dominant matrix flow within the PTn. The measured properties for the PTn and other units are documented in BSC (2004 [DIRS 170038], Tables 7 and 8). Pneumatic data are consistent with the notion that fracturing within the PTn is limited; the pneumatic signal is propagated predominantly through the high-storage matrix, leading to significant attenuation (Ahlers et al. 1999 [DIRS 109715], p. 49). Similarly, much of the water flow occurs in the relatively high-porosity matrix in this unit. As a result, the PTn greatly attenuates infiltration pulses such that liquid-water flow below the PTn is approximately in steady state. This interpretation is consistent with the results of a modeling study by Wang and Narasimhan (1993 [DIRS 106793], pp. 354-361).

The dominance of matrix flow in the PTn unit and the attenuation effects are supported by field tests conducted in the same unit. Salve et al. (2003 [DIRS 164470]) performed water release tests along a fault within the PTn unit. Water was released under constant-head conditions from a 0.3-m interval within a borehole that crosses the fault. A total of $193 \mathrm{~L}$ of water during seven distinct events was released over two weeks between October 21, 1998, and November 5, 1998. Between November 30, 1999, and December 2, 1999, an additional $136 \mathrm{~L}$ of water were introduced into the same interval during three distinct events lasting 4 to 7 hours (Salve et al. 2003 [DIRS 164470]). It was observed that during the first release test, the wetting front advanced slowly as a result of significant matrix imbibition. It was also found that water that imbibed into the matrix was retained for periods extending to at least a few months for the given test conditions. Based on these observations and considering that water release rates used in the tests were much larger than water percolation rates under ambient conditions, it is concluded that the dry porous PTn matrix is capable of attenuating episodic percolation fluxes in localized areas 
(such as around faults) where fast flow would otherwise be expected to dominate (Salve et al. 2003 [DIRS 164470], p. 282).

In an early conceptual model of Yucca Mountain, Montazer and Wilson (1984 [DIRS 100161], pp. 45-48) indicated that significant lateral flow occurs within the PTn unit. The contrast in hydraulic properties at internal layer contacts within the PTn could cause lateral flow. Additionally, the transient flow of water from the $\mathrm{TCw}$ unit to the PTn unit promotes air entrapment, which could further reduce the vertical liquid flux into the PTn. Montazer and Wilson (1984 [DIRS 100161], p. 47) also showed that vertical heterogeneities within the PTn unit may result in a much larger effective permeability of the unit in the direction of dip, compared with the effective permeability in the direction normal to the bedding plane. They argued that the combination of this factor and capillary barrier effects might introduce considerable lateral flow within the unit. A fine grid simulation reported by $\mathrm{Wu}$ et al. (2002 [DIRS 161058]) favors the existence of lateral flow within the PTn resulting from capillary barrier effects. This conceptual model was further supported by the fact that the sitescale UZ flow model, considering lateral flow mechanisms within the PTn, better matches the observed chloride data within the UZ [UZ Flow Models and Submodels (BSC 2004 [DIRS 169861], Section 6.5.2)], as shown in Figure 6-2.

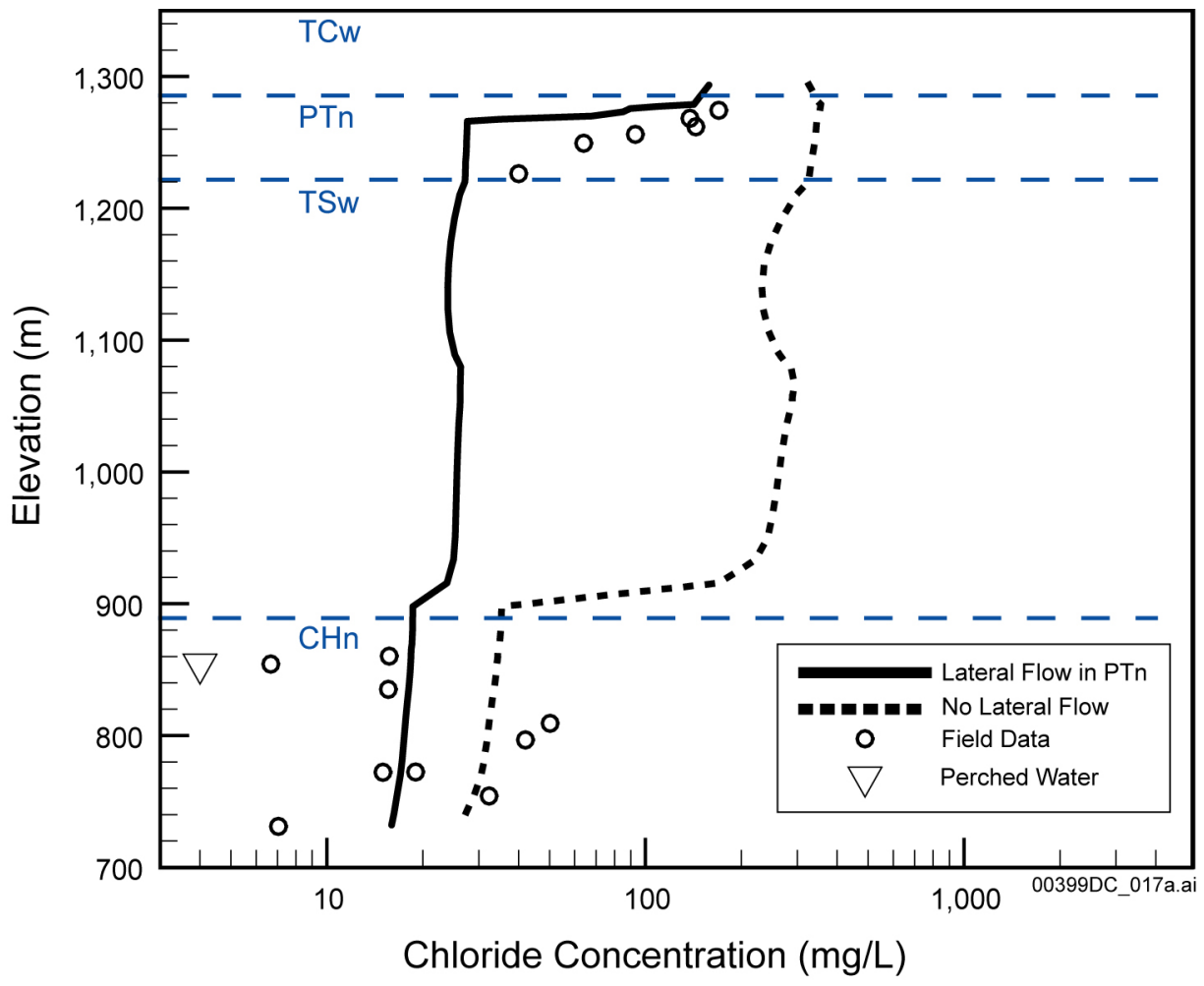

Source: BSC 2004 [DIRS 169861], Figure 6.5-3.

NOTE: The simulations were performed with the site-scale UZ flow model with and without lateral flow mechanism in the PTn. Some simulation results were removed from the original figure.

Figure 6-2. Comparison Between Observed and Simulated Chloride Concentration Distribution for Borehole USW SD-9 
Because of its high fracture density and low matrix permeability, water flow in the TSw (below the PTn) is considered to be primarily through the fractures. Assuming a unit hydraulic gradient, the matrix percolation rate will be the same as the matrix hydraulic conductivity. Using matrix saturated hydraulic conductivities determined from permeabilities measured in core samples from the TSw, the calculated matrix percolation rate is a small fraction of the average infiltration rate currently estimated (Pruess et al. 1999 [DIRS 117112], p. 283). Therefore, the remainder of the flow must be distributed in the fracture network. Calcite-coating data show that most of the deposition is found within the fractures in the welded units (Paces et al. 1998 [DIRS 107408], p. 37), supporting the hypothesis that fracture water flow is a major flow mechanism within TSw. The calcite coating is a signature of liquid-water flow history. Carbon-14 $\left({ }^{14} \mathrm{C}\right)$ ages of the perched water bodies below the TSw unit ranges from 3,500 to 11,000 years (Yang et al. 1996 [DIRS 100194], p. 34), again suggesting a fracture-dominated flow within the TSw. The water travel times from the ground surface to the perched water zone are much longer for the liquid water flowing in the matrix (Bandurraga and Bodvarsson 1999 [DIRS 103949], p. 40, Table 3). Because of the small matrix permeabilities, the perched water bodies would be expected to have much older ages if they result from matrix water flow within the TSw unit.

The occurrence of perched water bodies, reported from a number of boreholes at the lower portion of the TSw and the upper portion of the CHn (Wu et al. 1999 [DIRS 117167], pp. 159-163), indicates that the layers of the TSw basal vitrophyre and the CHn serve as barriers to vertical flow and cause lateral flow. The main hydrogeologic units below the repository are the CHn and Crater Flat undifferentiated hydrogeologic units. Both of these units have vitric and zeolitic components that differ by the degree of hydrothermal alteration (Flint 1998 [DIRS 100033], pp. 29-33). The zeolitic rocks have low matrix permeabilities and some fracture permeability, and therefore a relatively small amount of water may flow through the zeolitic units, with most of the water flowing laterally in perched water bodies and then vertically down faults (Figure 6-1). On the other hand, similar to the PTn unit, the vitric units have relatively high matrix porosity and permeability, and, therefore, mostly porous-medium flow predominates. Fracture flow is believed to be limited in these units.

\subsubsection{Fracture-Matrix Interaction}

The transfer of water between fractures and the rock matrix, denoted by fracture-matrix interaction, is likely to be limited within welded units at Yucca Mountain (Bodvarsson et al. 1999 [DIRS 120055], p. 13). The chloride concentration data indicate that perched water was recharged mainly from fracture water, with a small degree of interaction with matrix water (Yang et al. 1996 [DIRS 100194], p. 55). Studies by Ho (1997 [DIRS 100584], pp. 401-412) evaluate methods of incorporating the conceptual model of fracture-matrix interaction into a dual-permeability model. He shows that the calibration with observed matrix saturation and water-potential data is improved using techniques that reduce the fracture-matrix interaction significantly.

The limited fracture-matrix interaction at the Yucca Mountain site is consistent with many other independent laboratory tests as well as theoretical and numerical studies. In a number of laboratory experiments, Glass et al. (1996 [DIRS 139237], pp. 6-7) demonstrated that gravity-driven fingering flow is a common flow mechanism in individual fractures. This mechanism can reduce the wetted area in a single fracture to fractions as low as 0.01 to 0.001 of 
the total fracture area. However, most of their studies were conducted in analogue fractures without interaction with the matrix. Imbibition in the matrix can increase wetted areas of fingering flow patterns in individual fractures, as shown in a numerical study of Abdel-Salam and Chrysikopoulos (1996 [DIRS 132960], pp. 1537-1538). In their study, they investigated unsaturated flow in a quasi-three-dimensional fracture-matrix system (with spatially variable apertures accounting for matrix imbibition). They showed that fingering flow occurs in a fracture, but matrix imbibition will reduce the degree of fingering. Therefore, while fingering flow in individual fractures is an important mechanism for reducing fracture-matrix interaction, its effects may not be as significant as shown in individual fracture experiments that do not incorporate matrix imbibition.

In a theoretical study, Wang and Narasimhan (1993 [DIRS 106793], pp. 329-335) indicated that the wetted area in a fracture under unsaturated flow conditions is generally smaller than the geometric interface area between fractures and matrix, even when fingering flow does not occur. This results from the assumption that liquid water in an unsaturated fracture occurs as saturated segments that cover a portion of the fracture-matrix interface area. On the other hand, in a recent laboratory experiment study, Tokunaga and Wan (1997 [DIRS 139195]) demonstrated that water film flow could be important in unsaturated fractures. However, note that in their experiments, water film flow becomes important only when the matrix is nearly saturated and water flow occurs from matrix to fractures, as indicated by the conditions of their experiment. Therefore, at this point, we can hypothesize that liquid water generally exists as saturated segments around contact points in unsaturated fractures. The distribution of liquid water in this form will reduce the fracture-matrix interaction (as compared to the case in which the whole geometric interface area is considered to contribute to flow and transport between fractures and matrix).

Liu et al. (1998 [DIRS 105729], p. 2645) suggested that in unsaturated, fractured rocks, fingering flow occurs at both a single fracture scale and a connected fracture-network scale (Figure 6-3). This is supported in a study of Kwicklis and Healy (1993 [DIRS 100587], pp. 4097-4099). They used numerical simulations to investigate liquid water flow in a simple, unsaturated fracture network and found that a large portion of the connected fracture network played no role in conducting the flow when the fractures do not have uniform apertures. The fingering flow at a network scale has important effects on large-scale flow and transport, and significantly contributes to the reduction of fracture-matrix interaction.

Studies also showed that fracture coating might have important effects on fracture-matrix interaction. Thoma et al. (1992 [DIRS 139189]) performed experiments on actual coated and uncoated tuff fractures and observed that the low-permeability coatings inhibited matrix imbibition considerably. In contrast, fracture coatings may in some cases increase the fracture-matrix interaction when microfractures develop in the coatings (Sharp et al. 1996 [DIRS 139240], p. 1331). Therefore, fracture coating may or may not result in fracture-matrix interaction reduction. Coating effects are not considered in modeling flow and transport in the $\mathrm{UZ}$ at Yucca Mountain. 


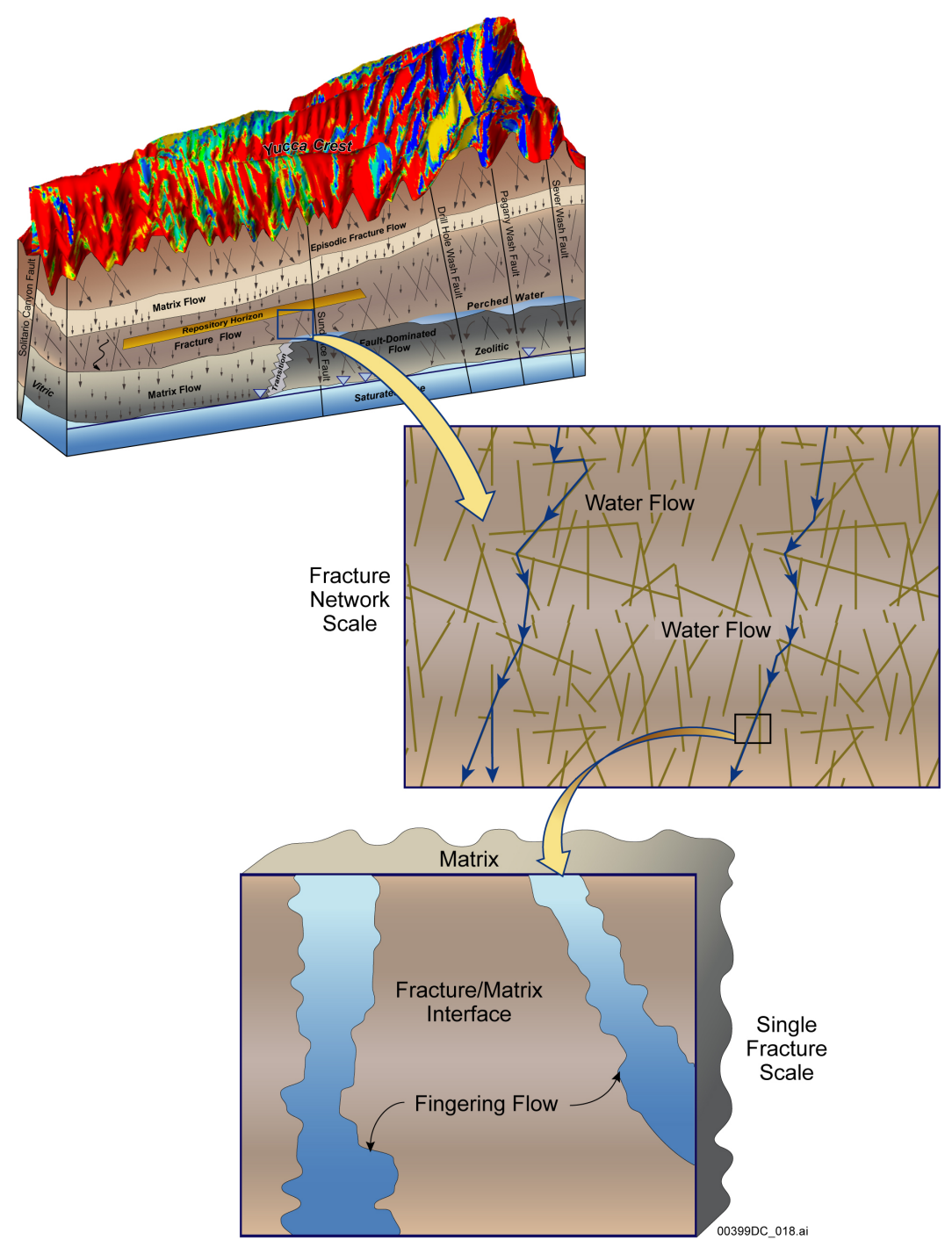

Figure 6-3. A Simplified Schematic for Water Flow in Fractures Characterized by Fingering Flow at Different Scales

Although several mechanisms exist for limiting fracture-matrix interaction in the UZ, as discussed above, fingering flow at a fracture network scale is considered to be the key mechanism (Liu et al. 1998 [DIRS 105729]; Glass et al. 1996 [DIRS 139237], pp. 6-7). The AFM based on this mechanism (Liu et al. 1998 [DIRS 105729]) is used for modeling fracture-matrix interaction. This model is documented in Section 6.3 of this report.

\subsubsection{Perched Water}

Perched water is the groundwater in saturated zones that is above or not directly connected to the static water table (Freeze and Cherry 1979 [DIRS 101173], p. 45), and may occur when large permeability differences exist between geologic units. Perched water zones at Yucca Mountain were reported from a number of boreholes at the lower portion of the TSw and the upper portion of the $\mathrm{CHn}$. The field tests indicated that perched water zones with very different water volumes 
exist at Yucca Mountain (Bodvarsson et al. 1999 [DIRS 120055], p. 14; Wu et al. 1999 [DIRS 117167]).

The presence of perched water has important implications for the travel times and flow paths of water through the UZ at Yucca Mountain (Figure 6-4). First, perched water ${ }^{14} \mathrm{C}$ data indicates that apparent age estimates of perched water bodies range from approximately 3,500 to 11,000 years (Yang et al. 1996 [DIRS 100194], p. 34), suggesting dominant fracture flow in the TSw unit (Section 6.1.2). Second, the occurrence of perched water bodies indicates that the layers of the TSw basal vitrophyre and the $\mathrm{CHn}$ serve as barriers to vertical flow and cause lateral flow. Portions of the Calico Hills formation have been extensively altered to zeolites, creating the perched water bodies observed within this unit (Bodvarsson et al. 1999 [DIRS 120055], pp. 14-15).

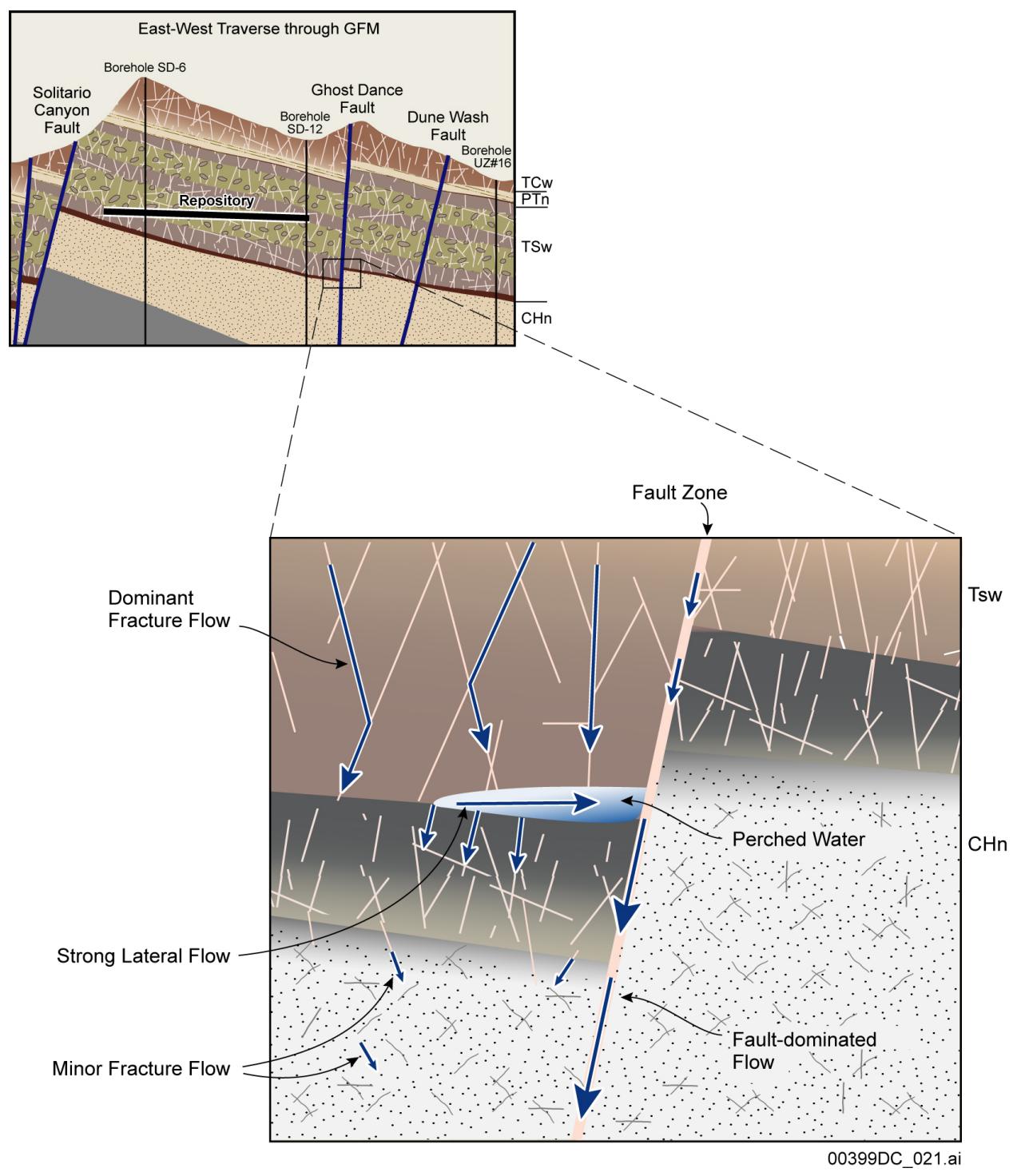

Figure 6-4. A Simplified Schematic for Flow Patterns within and near a Perched Water Body Characterized by Strong Lateral Flow within the Perched Water Body and the Associated Fault-Dominated Flow 


\subsubsection{Effects of Major Faults}

Numerous strike-slip and normal faults with varying amounts of displacement exist at Yucca Mountain. It is important to understand how major faults affect the flow processes in the UZ at Yucca Mountain.

A fault can act as a fast-flow conduit for vertical liquid-water flow. In this case, transient liquid-water flow may occur within the fault as a result of temporally variable infiltration. Note that major faults cut through the PTn, and the damping effect of the PTn is significantly reduced. However, if occurring, this transient flow along the major faults is expected to carry only a small amount of water and may not be a significant liquid-flow mechanism for the UZ at Yucca Mountain, as will be discussed in Section 6.1.7. It is reasonable to assume that recharge through alluvial channels and the associated faults and other potential fast pathways above the repository is minimal compared to the overall recharge flux. Note that faults intercepting the perched water bodies below the repository, however, can correspond to significant vertical liquid-water flow (see Figure 6-4).

A fault can also act as a barrier for lateral liquid-water flow. Where a fault zone is highly fractured, the corresponding coarse openings will create a capillary barrier for lateral flow. Alternatively, a fault can displace the surrounding geologic units, such that a unit with low permeability faces one with relatively high permeability in a fault zone. In this case, the fault will act as a permeability barrier to the lateral flow within the units with relatively high permeability. Montazer and Wilson (1984 [DIRS 100161], p. 20) conceptualized that permeability would vary along faults, with higher permeability in the brittle, welded units and lower permeability in the nonwelded units where gouge or sealing material may be produced. Whereas a fault sealed with gouge or other fine-grained material would have much higher capillary suction, it will also have low permeability, retarding the movement of liquid water.

In summary, because lateral flow is hypothesized to be insignificant above the repository and significant focusing infiltration near faults may not occur (Section 6.1.7), faults conduct only a small amount of water and are not considered to contribute significantly to the large-scale percolation pattern from the surface to the repository level. Below the repository, low-permeability layers in the $\mathrm{CHn}$ channel some flow to faults acting as conduits to the water table.

\subsubsection{Transient Flow}

Flow in the $\mathrm{UZ}$ is time dependent or transient, mainly resulting from the temporal variation in the infiltration flux at the surface. The temporal variation of the infiltration may be approximated as occurring over short intervals characterized by changes in weather, resulting in episodic transient flows, or over much longer time periods corresponding to climate change.

However, as discussed in Section 6.1.2, the PTn greatly attenuates episodic infiltration pulses such that liquid-water flow below the PTn is considered to be approximately in steady state. This is supported by the modeling study of Wang and Narasimhan (1993 [DIRS 106793], pp. 354-361). The attenuation is a result of matrix flow in the PTn and the relatively large storage that mainly results from the relatively low matrix saturation in this unit. On the other hand, longer-term climate change has a more pronounced influence on flow pattern within the 
mountain than episodic infiltration, and ultimately impacts the entire flow field in the UZ (DOE 1998 [DIRS 100550], pp. 3-115 and 3-116). However, previous modeling studies suggest that use of steady-state flow fields is a good approximation for modeling radionuclide transport in the UZ associated with climate changes (DOE 1998 [DIRS 100550], p. 3-116). The reason for this is that the change in flow in the fractures, which dominates the flux in most hydrogeologic units, responds relatively quickly to a change in infiltration (DOE 1998 [DIRS 100550], p. 3-116). Thus, it is reasonable to assume flow to be in steady state for modeling liquid-water flow in the UZ.

It is expected that flow through isolated fast flow paths that by-pass the PTn unit may exhibit a strong transient character for the lack of a significant attenuation mechanism. However, these isolated flow paths are believed to carry only a small amount of water. More discussions of this issue are given in the next subsection.

\subsubsection{Focusing Flow and Fast Flow Paths}

Flow focusing refers to the occurrence of a significant amount of water flowing through a very small area and/or zone. Depending on geological conditions and the magnitude of the flux, flow focusing leading to fast flow pathways across the PTn may occur. A number of samples obtained from the Exploratory Studies Facility (ESF) arguably show bomb-pulse signatures of Cl-36 (BSC 2004 [DIRS 170004], Section 6.14). (Note that the UZ flow model captures the fast-flow component associated with bomb-pulse signatures of Cl-36 (BSC 2004 [DIRS 169861], Appendix H) in order to be conservative.) They are generally associated with localized fault structures that cut through the PTn, and these pathways are likely responsible for the presence of bomb-pulse signatures of Cl-36 within the TSw at the repository horizon. However, for the following reasons, these fast and transient flow paths actually carry only a small amount of water: (1) bomb-pulse signatures were arguably found in only a few locations in the ESF (BSC 2004 [DIRS 170004], Section 6.14.2), (2) these discrete fast paths are not associated with large catchment areas involving large volumes of infiltrating water, and (3) bomb-pulse tracers (e.g., Cl-36, and C-14) are not detected in perched water.

The above arguments support a conceptual model that focused flow does not significantly occur above the TSw layer. The potential for flow focusing below the PTn unit has been demonstrated using numerical studies (based on the heterogeneous continuum approach) by Bodvarsson et al. (2003 [DIRS 163443]). Along the line of thinking of Bodvarsson et al. (2003 [DIRS 163443]), Liu et al. (1998 [DIRS 105729]) and Glass et al. (1996 [DIRS 139237]), the following conceptual model of unsaturated flow focusing (Figure 6-5) is suggested. In this conceptual model, infiltration is dispersed in the near surface and also in the low effective permeability PTn layer. From there, water begins to be focused in the TSw layer and continues into fewer discrete flow pathways on through the Calico Hills vitric and Calico Hills zeolitic layers. These discrete flow pathways, which likely occur in fractures as in Figure 6-3, then deliver percolating water to the groundwater. Whereas this focused flow pattern below the PTn unit has a critical impact on the percolation distribution above the repository and radionuclide transport from the repository to water table, details of this focused flow pattern is not well understood.

While focused flow occurs in the TSw and below, the distribution of focused flow paths is relatively uniform, and focused flow paths are not limited to major faults, as supported by spatial 
uniformity of many related field observations (Bodvarsson et al. 1999 [DIRS 120055], p. 13). For example, average measured matrix saturations suggest relatively uniform values for most of the units, and in situ water potential measurements also show little variability within the TSw for different boreholes. It was also observed that temperatures within the TSw unit are fairly uniform (Bodvarsson et al. 1999 [DIRS 120055], p. 13).

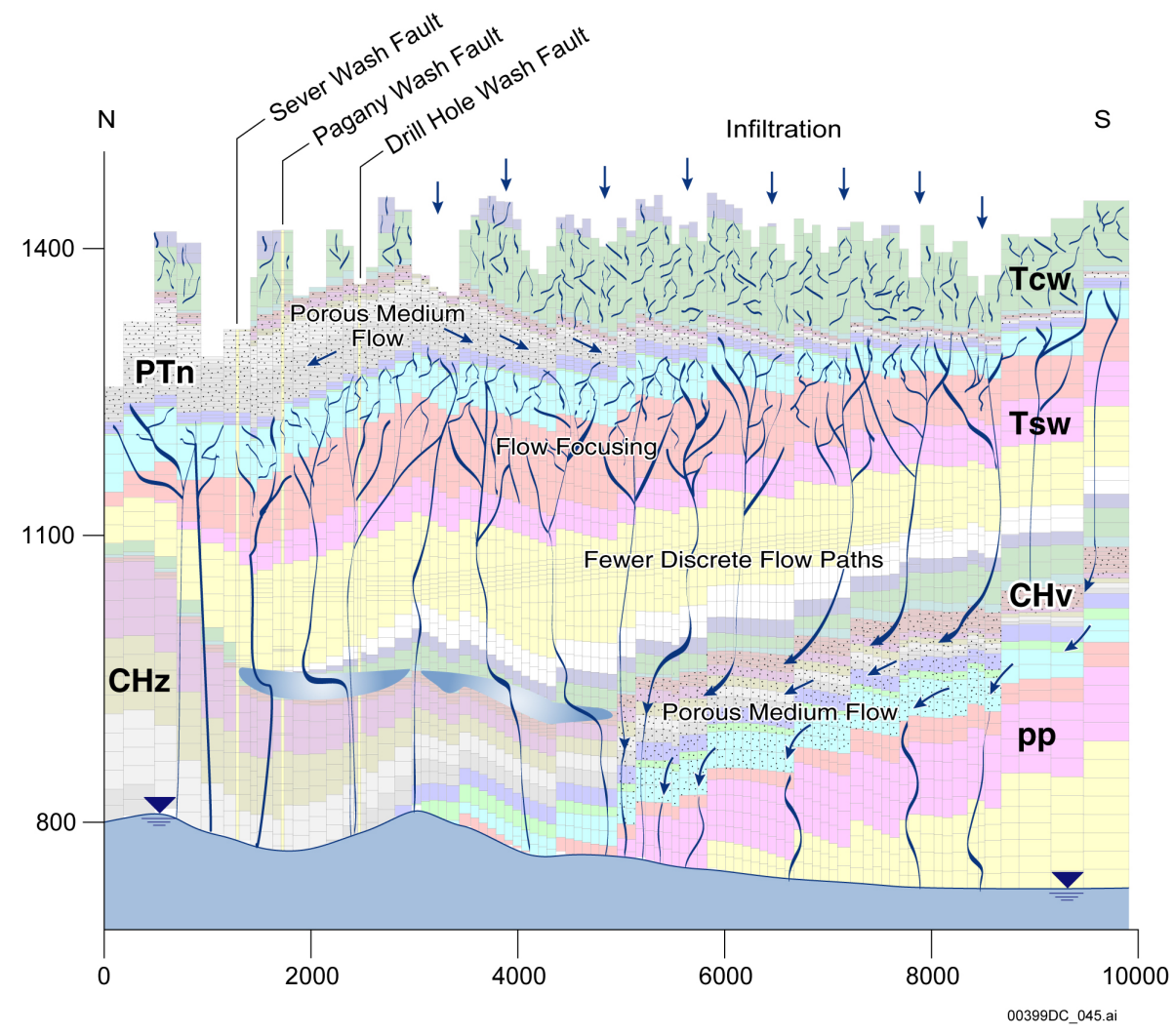

NOTE: Blue zones correspond to saturated zone and perched water bodies. Axes units are meters and PP represents hydrogeologic units PP1 through PP4 that are part of the CHn (BSC 2004 [DIRS 169855], Table 6-5).

Figure 6-5. A Simplified Schematic Showing Conceptual Model of Unsaturated Zone Flow Focusing in Yucca Mountain

\subsubsection{Gas Flow Process}

Gas (air) flow at Yucca Mountain mainly depends on the characteristics of fracture networks. The fractures are generally much more permeable than the matrix because of both their larger absolute permeability and lower liquid saturation. In the welded units, this is particularly true, but in the PTn, the permeability of the fracture continuum is closer to that of the matrix continuum, because of lower liquid saturation and larger pore sizes in the PTn matrix. Little data exist on gas flow below the bottom of the TSw, though high liquid saturation and low permeability likely will significantly reduce gas flow.

The ambient gas-flow processes occurring at Yucca Mountain include barometric pumping, wind, and density-driven flow. Barometric pumping is the response of subsurface pneumatic pressure to changes in atmospheric pressure. Because this is a transient process, both the 
permeability and storage of the media affect the subsurface response. In the welded units, this translates into little change in the pneumatic pressure signal with depth (Rousseau et al. 1999 [DIRS 102097], pp. 89-97). The PTn, however, attenuates and lags the pressure signal. Ahlers et al. (1999 [DIRS 109715], p. 58) showed a strong correlation between the PTn thickness and pneumatic response below the PTn. They also showed that faults are fast pathways for gas flow but affect subsurface response only at a relatively local scale (Ahlers et al. 1999 [DIRS 109715], pp. 47 and 59-66).

Gas flow occurs under ambient conditions as a result of density- and wind-driven processes (Weeks 1987 [DIRS 100612]). Density-driven flow occurs in the area of low elevation and is a consequence of the differences between the density of dry air in the atmosphere and wet air in the mountain. The wet air is lighter and rises in response to the pressure exerted by the heavier dry air, causing flow within the mountain from the lower elevations toward the crest. Wind-driven flow occurs because of the higher pressure exerted on the windward side of the mountain and the lower pressure in the lee of the crest. Thus, wind-driven flow will also promote flow toward the crest. Measurement of air-flow in an open borehole near the crest of Yucca Mountain shows that density- and wind-driven flow occurs mainly in the $\mathrm{TCW}$ (Thorstenson et al. 1990 [DIRS 100831], p. 262).

\subsubsection{Summary and Further Discussions}

Based on the discussions of flow issues and processes in the UZ (Sections 6.1.1 through 6.1.8), a conceptual model of flow in the UZ is constructed. Infiltration is mainly characterized by high spatial and temporal variabilities. Infiltration pulses move rapidly through the fractures in the $\mathrm{TCw}$ unit with little attenuation by the matrix. Because of the expected attenuation effects of the PTn unit, the liquid-water flow processes below this unit are considered to be approximately in steady state, under ambient conditions. Considerable lateral flow in the PTn occurs, and fracture liquid-water flow is dominant in welded units and matrix flow in nonwelded units. Fracture-matrix interaction in the welded units is limited. The existence of perched water bodies introduces three-dimensional lateral flow within the UZ. Major faults do not act as flow paths to significantly alter the percolation pattern from the surface to the repository level. Below the repository, low-permeability layers in the $\mathrm{CHn}$ may channel some flow to faults that can act as conduits to the water table.

It is instructive to compare the current conceptual model of flow in the UZ with other conceptual models published in the literature. Since the mid-1980s, the prevailing view of the UZ at Yucca Mountain has been that, under ambient conditions, water flow mainly occurs through the rock matrix even in the welded, densely fractured TSw unit (Wang and Narasimhan 1993 [DIRS 106793], pp. 327-339; Peters and Klavetter 1988 [DIRS 100604]; Nitao and Buscheck 1991 [DIRS 102860]). Based on capillary theory, it was believed that under unsaturated conditions, liquid water would essentially be excluded from fractures because of strong capillarity in the matrix. However, with more and more data available for characterizing the site, it has become evident that unsaturated flow in the welded units is primarily through the fractures, as discussed in Section 6.1.2 of this report.

While the current conceptual model is based to a great extent on the model originally presented by Montazer and Wilson (1984 [DIRS 100161], pp. 36-49), the major differences between these 
two models are the roles of the structural features, or faults, in conducting liquid water through the UZ. Montazer and Wilson (1984 [DIRS 100161], pp. 50-51) hypothesized that the combination of dipping beds, permeability layering, and capillary-barrier effects results in significant lateral flow within the PTn toward the bounding structural features. Most of the infiltrated water is transmitted downward to the water table along structural features (Montazer and Wilson 1984 [DIRS 100161], p. 51). As discussed in Sections 6.1.2, 6.1.5 and 6.1.7, more recent studies indicate that faults are not likely to act as flow paths to significantly alter the flow pattern above the repository level in the UZ.

In a recent study, Pruess (1999 [DIRS 104250]) proposed a conceptual model for flow in the UZ. While the details of his conceptual model can be found in Pruess (1999 [DIRS 104250]), key elements of the model can be summarized as follows (Pruess 1999 [DIRS 104250], p. 1041):

1. Most of the water flow in thick UZs of fractured rock proceeds by way of episodic, transient, and localized flow through fractures.

2. Liquid-water flow can remain localized even in the presence of dispersive effects that would tend to cause lateral spreading.

3. Several mechanisms combine to severely reduce the effects of matrix imbibition.

While both the model of Pruess (1999 [DIRS 104250]) and the current conceptual model consider the fracture-matrix interaction to be limited in the UZ, and only a portion of fractures to be active in conducting liquid water, they are different in their description of time-dependent character of fracture flow. Pruess hypothesizes that fracture flow paths in unsaturated, fractured rocks are transient (Pruess 1999 [DIRS 104250], p. 1041). As discussed in Sections 6.1.2, 6.1.6, and 6.1.7, the current conceptual model hypothesizes that liquid-water flow below the PTn unit is approximately in steady state.

\subsection{CONCEPTUAL MODEL OF TRANSPORT}

This subsection documents the conceptual model used for modeling transport within the UZ of Yucca Mountain. The conceptual model is presented by addressing important transport issues and processes. Note that transport is closely tied to flow processes, because water is the principal medium in which solutes are transported through the UZ.

\subsubsection{Advective Transport}

Advective transport (advection) refers to the movement of dissolved or colloidal materials within the bulk flow of fluid (Fetter 1993 [DIRS 102009], p. 47). Transport is strongly related to liquid water flow through advection, and advective transport pathways coincide with flow pathways discussed in Section 6.1. In welded units, advection through fractures is expected to dominate transport behavior, mainly because liquid water largely flows through fracture networks in these units. Advection is also an important mechanism for transport between fractures and matrix, especially at interfaces between nonwelded and welded units. At these interfaces, transitions occur between dominant fracture flow and dominant matrix flow. Liquid-water flow paths below the repository are critical to potential radionuclide transport resulting from advection. Perched water results in lateral transport of the radionuclides. Dominant fracture flow in the 
zeolitic components of the $\mathrm{CHn}$ provides relatively short travel times for transport to the water table, whereas the dominant matrix flow in the vitric components provides much longer travel times.

\subsubsection{Matrix Diffusion and Potential Scale-Dependency of Effective Matrix Diffusion Coefficient}

Matrix diffusion refers to solute transport from fracture networks into the surrounding matrix blocks resulting from molecular diffusion (Neretnieks 1993 [DIRS 123099], pp. 47-48). Mass transfer between fractures and the tuff matrix plays an important role in transport within the UZ. Because flow velocity in the matrix is much slower than in fractures, transfer of radionuclides from fractures to the matrix can significantly retard the overall transport of radionuclides from the repository to the water table. The transfer can result from advection, dispersion, and diffusion processes. Where fracture flow is dominant, the advection from fractures to the matrix is not important, because only a relatively small amount of water flows into the matrix, with the rest flowing through fractures. In this case, matrix diffusion is a major mechanism for mass transfer between fractures and the matrix. On the other hand, the diffusion process in the matrix is more important than dispersion due to the slow pore velocity in the matrix. Therefore, diffusion is probably the most important physical process in the matrix, contributing to the retardation of radionuclide transport when fracture flow is dominant.

The effective matrix diffusion coefficient (molecular diffusion coefficient in free water multiplied by matrix tortuosity) is a key parameter for describing matrix diffusion. Matrix diffusion coefficient values measured from small rock samples in the laboratory are generally used for modeling field-scale solute transport in fractured rock (e.g., Moridis et al. 2003 [DIRS 161902]). Recently, several research groups have independently found that effective matrix-diffusion coefficients much larger than laboratory measurements are needed to match field-scale tracer-test data (Shapiro 2001 [DIRS 162132]; Neretnieks 2002 [DIRS 162140]; Liu et al. 2003 [DIRS 162470]; BSC 2004 [DIRS 169861], Section 7.6).

Effective matrix-diffusion-coefficient values have been estimated from a number of field test sites characterized by different rock types. To compile these values (corresponding to different tracers) as a function of the test scale, a matrix-diffusion-coefficient ratio, $\mathrm{RD}$, is defined as an effective coefficient value (estimated from field data) divided by a local value from laboratory measurements. It is an indicator of scale dependency that is expected to exist when RD is a function of the test scale.

Figure 6-6 shows the relationship between values for RD, determined from a number of sites by different research groups (Maloszewski and Zuber 1993 [DIRS 101460]; Jardine et al. 1999 [DIRS 169950]; Becker and Shapiro 2000 [DIRS 169947]; Callahan et al. 2000 [DIRS 156648]; Shapiro 2001 [DIRS 162132]; Neretnieks 2002 [DIRS 162140]; Liu et al. 2003 [DIRS 162470]; BSC 2004 [DIRS 169861], Section 7.6), and the corresponding test scales. Jardine et al. (1999 [DIRS 169950]) performed and analyzed a carefully designed tracer test in fractured shale bedrock. They were able to obtain breakthrough curves from wells with different distances to the source. However, the same parameters were used to match all the breakthrough curves for a given tracer. As indicated in their Figure 9, the breakthrough curves from wells about $6 \mathrm{~m}$ from the source are reasonably matched, but the curve from the well $17 \mathrm{~m}$ from the source is not. A 
larger effective matrix-diffusion-coefficient value seems to be needed to match the data from the latter well, an indication of a possible increase in the coefficient with scale. Therefore, in Figure 6-6, the fitted effective matrix diffusion is considered to correspond to a test scale of $6 \mathrm{~m}$ only. Note that, as indicated by Jardine et al. (1999 [DIRS 169950]), their intentions were not to rigorously model all of the processes contributing to solute transport in the system, but, rather, to test the importance of matrix diffusion.

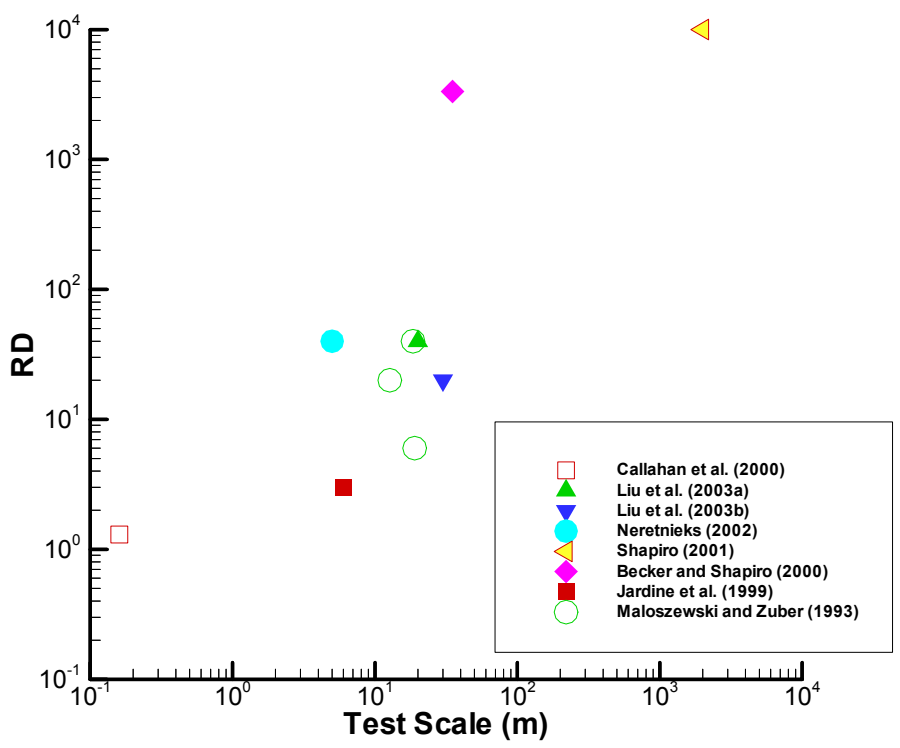

Source: Liu et al. 2004 [DIRS 169948], Figure 1.

Figure 6-6. Effective Matrix Diffusion Coefficient as a Function of Test Scale. RD Refers to the Effective Coefficient Value (Estimated from Field Data) Divided by the Corresponding Local Value

Neretnieks (2002 [DIRS 162140]) reported matches to tracer test data collected from the Äspö site with a test scale of $5 \mathrm{~m}$ and found a need for a factor 30 times larger for the fracture-matrix interface area (or effective matrix-diffusion coefficient) than expected. The increase in fracture-matrix interface area is equivalent to the increase in effective diffusion coefficient (for a given interface area in a model). He also indicated that nine other research groups had also independently evaluated the tracer test data from the site using different modeling approaches. Nearly all the groups found the need for a factor 30-50 times larger effective fracture-matrix interface area (or effective matrix-diffusion coefficient) than expected. In Figure 6-6, a representative RD value of 40 is used for the Äspö test site.

Liu et al. (2003 [DIRS 162470]) and BSC (2004 [DIRS 169861], Section 7.6) presented model analyses of two different field test data, collected in the UZ of Yucca Mountain. Unlike studies reported by other researchers mentioned in this subsection, Liu et al. (2003 [DIRS 162470]) and BSC (2004 [DIRS 169681], Section 7.6) matched both the flow field (characterized by water travel time and/or seepage into subsurface openings) and tracer breakthrough curves. They reported that increased fracture-matrix interface areas (or effective matrix diffusion coefficients) 
were needed for both tests. The data of Callahan et al. (2000 [DIRS 156648]) were also collected for the rock matrix in the UZ of Yucca Mountain.

Becker and Shapiro (2000 [DIRS 169947]) and Shapiro (2001 [DIRS 162132]) reported analyses of tracer test data from fractured crystalline rock at the Mirror Lake site. Becker and Shapiro (2000 [DIRS 169947]) showed that laboratory measurement of the effective diffusion coefficient should be replaced by the coefficient in free water (corresponding to $\mathrm{RD}=3,333$ ) to match the bromide data in their Test $\mathrm{C}$ with a test scale of about $36 \mathrm{~m}$. However, they were not able to match all the breakthrough curves for different tracers, and argued that advective transport processes contribute to this discrepancy. An alternative explanation may be that a simple model used by those authors cannot capture all the importance processes (such as effects of subsurface heterogeneity), even when matrix diffusion is a dominant process. Nevertheless, the value of $\mathrm{RD}=3,333$ is included in Figure 6-6. Shapiro (2001 [DIRS 162132]) found that 3-5 orders of magnitude greater than the estimates of the matrix-diffusion coefficient from laboratory experiments were needed to match the tracer data observed at a kilometer scale. His analysis probably provides the first estimate for kilometer-scale effective diffusion coefficient. A representative value of Shapiro (2001 [DIRS 162132]) for RD (1.0E+4) is used in Figure 6-6. Figure 6-6 also includes analyses results of Maloszewski and Zuber (1993 [DIRS 101460]) for three different sites.

Although some uncertainties exist, the data shown in Figure 6-6 seem to strongly suggest that the effective matrix diffusion coefficient, like permeability and dispersivity, increases with test scale. A number of researchers have attempted to explain why the effective coefficient determined from field data is larger than the corresponding laboratory value (Shapiro 2001 [DIRS 162132]; Neretnieks 2002 [DIRS 162140]; Liu et al. 2003 [DIRS 162470]; BSC 2004 [DIRS 169681], Section 7.6).

Shapiro (2001 [DIRS 162132]) suggested that kilometer-scale "effective matrix diffusion" is not a diffusive process, but actually an advective process between high and low permeability zones, resulting in a significantly large "effective diffusion coefficient." While this may be a plausible explanation, further confirmation is still needed. For example, Liu et al. (2003 [DIRS 162470]; BSC 2004 [DIRS 169861], Section 7.6) used a dual-permeability model involving both fast flow in fractures and slow flow in the matrix (as well as the advective transport between the two) and still found the need to use increased effective diffusion coefficients for matching the tracer test data. Neretnieks (2002 [DIRS 162140]) argued that existence of fracture in-filling creates relatively large areas for solute to diffuse into rock matrix, which, together with the process of diffusion into stagnant water, contributes to the need for increasing the effective diffusion coefficient to match the data. Wu et al. (2001 [DIRS 156399]) and Liu et al. (2003 [DIRS 162470]) indicated that the existence of many small-scale fractures (which considerably increase the fracture-matrix interface area, but are not considered in numerical models) may be the major reason for the relatively large effective diffusion coefficient calculated from field data. While these suggested mechanisms seem to be reasonable for field-scale solute transport in fractured rock, they cannot be directly used to explain why the effective diffusion coefficient increases with test scale because they are not able to relate the effective matrix diffusion coefficient to the corresponding test scale. 
Liu et al. (2004 [DIRS 169948]) proposed a fractal-based explanation for the scale-dependent behavior of the effective diffusion coefficient. Considering that both fracture roughness and fracture-network geometry can be characterized by fractals, Liu et al. (2004 [DIRS 169948]) hypothesize that a solute travel path within a fracture network is fractal, rather than a straight line (as assumed in common numerical or analytic models). Based on this hypothesis, Liu et al. (2004 [DIRS 169948]) were able to show that RD is a power function of test scale and increases with test scale.

Although the potential scale-dependency and the preliminary explanation of Liu et al. (2004 [DIRS 169948]) need to be confirmed by more investigations, the use of core-scale matrix diffusion coefficients in the site-scale UZ transport models likely underestimates radionuclide transport time in the UZ, as discussed above, and therefore the corresponding simulation results for radionuclide transport processes are likely to be conservative in terms of estimating performance of the repository.

\subsubsection{Fracture and Matrix Sorption}

Sorption is an important process involved in reactive transport. Sorption refers to a combination of chemical interactions between dissolved solutes and the solid phases (immobile rock matrix or colloids) (Fetter 1993 [DIRS 102009], p. 117). The strength of the sorptive behavior is a function of chemical element, the rock type involved in the interaction, and the geochemical conditions of the water contacting the rock (Domenico and Schwartz 1990 [DIRS 100569], pp. 440-443). Sorption, for example, can act to retard the movement of radionuclides in the groundwater. Reactive chemicals, which are strongly sorbed to rock matrix, are relatively immobile. On the other hand, sorptive interactions may enhance solute transport if the aqueous species sorbs to colloids (Fetter 1993 [DIRS 102009], pp. 149-150). (Colloid-facilitated transport will be discussed in Section 6.2.4.) Generally, sorption is a reversible process; however, in some cases, sorption can be irreversible, as will be discussed in the next section.

The importance of sorption in the different rock types is not only a function of the sorptive strength, but also the degree of contact that solutes have with the rock matrix during transport through the UZ. Zeolitic tuff generally has a larger sorptive strength than vitric tuff, but has a relatively small matrix flow component because of its low matrix permeability (DOE 1998 [DIRS 100550], p. 3-118). Sorption in the zeolitic tuff, thus, may not be able to effectively retard solute transport, along with small molecular diffusion coefficients corresponding to insignificant matrix diffusion.

The surfaces of fractures, often lined with minerals differing from the bulk of the rock matrix, may be capable of sorbing many of the radionuclides that may be released from the potential repository (Triay et al. 1997 [DIRS 100422], p. 173). However, characterizing distributions of the fracture-lining minerals and sorptive interactions with these minerals has been limited. Also, the fracture minerals have a relatively small volume and surface area relative to the bulk rock matrix. For these reasons, a conservative assumption in modeling radionuclide transport is that no sorptive interaction with fracture surfaces occurs, and that sorptive interactions are only possible for radionuclides in matrix blocks.

Numerous rock-water chemical interactions may influence radionuclide transport. Sorption, representing the combination of these interactions, is characterized by a "sorption" or 
distribution coefficient $\left(\mathrm{K}_{\mathrm{d}}\right)$. In general, for a given radionuclide and rock type, this coefficient is not a constant, but depends on the temporally and spatially varied chemical composition of both the aqueous and solid phases (Domenico and Schwartz 1990 [DIRS 100569], pp. 442-443), the latter affecting underlying interactions. As a conservative approach to model radionuclide transport through the $\mathrm{UZ}$, a minimum bound for $\mathrm{K}_{\mathrm{d}}$ can be used. The minimum $\mathrm{K}_{\mathrm{d}}$ represents the smallest reasonable ratio of radionuclides attached to the solid phase versus dissolved in the aqueous phase.

\subsubsection{Colloid-Facilitated Transport}

Radionuclide transport in the UZ at Yucca Mountain may be facilitated by colloidal transport processes. Colloids are particles that are small enough to become suspended (and thus transportable) in a liquid (Fetter 1993 [DIRS 102009], p. 149), and can interact with radionuclides through sorption mechanisms. Unlike sorption of radionuclides to the rock matrix, however, radionuclides sorbed on colloids are potentially mobile. Therefore, colloids can facilitate radionuclide transport through the $\mathrm{UZ}$ at a faster rate than the aqueous phase alone (de Marsily 1986 [DIRS 100439], pp. 270-271). Another form of colloidal radionuclides occurs when the radionuclide is an integral component of the colloid structure. In this case, the radionuclide is irreversibly bound to the colloid (DOE 1998 [DIRS 100550], p. 3-105).

The colloid-facilitated transport is controlled by several processes, including advection of colloids, matrix diffusion and dispersion of colloids, sorption of radionuclides on colloids, radioactive decay of radionuclides, and filtration of colloid particles. Advective radionuclide transport paths coincide with liquid-water flow paths below the repository. The advective transport through fractures is enhanced by reduced matrix diffusion and matrix sorption. Colloid particles themselves are not expected to experience any significant matrix diffusion because of the very low diffusion coefficients associated with colloids. Colloids may not be able to move through some of the rock matrix, particularly the welded and zeolitic rock types, because of the large colloid size relative to the matrix pore size. However, movement through the more permeable nonwelded vitric rock in the Calico Hills may be possible. The restriction of matrix particle size on movement of colloid particles is described as a filtration process (de Marsily 1986 [DIRS 100439], pp. 271-272). Filtration of colloids generally means the retention of colloids moving with the suspending fluids in pores, channels, and fracture apertures that are too small or dry to allow passage of the colloids. Obviously, the colloid-facilitated transport becomes a more important transport mechanism for radionuclides that strongly sorb onto the solid phase.

\subsubsection{Other Transport Issues and Processes}

Radioactive decay is a process that affects the concentration of radionuclides during transport through the UZ. For simple decay, radionuclide concentration decreases exponentially with time (de Marsily 1986 [DIRS 100439], p. 265), creating stable decay products. Chain-decay adds another layer of complexity because of the growth of new radionuclides created from the decay of a parent radionuclide. One aspect of potential significance with respect to chain-decay is that daughter products may have significantly different sorption behavior than the parent radionuclide, and, therefore, exhibit different transport behavior. 
Dispersion is a transport mechanism caused by localized variations in flow velocity (de Marsily 1986 [DIRS 100439], pp. 234-235 and 244). However, it is not expected to play an important role in the UZ transport. An important reason that dispersion is secondary is the explicitly modeled variations in transport velocity caused by the fracture-matrix system. (See Section 6.3.6.3 for further discussion.) In the rock matrix, dispersion is also considered to be minor compared with diffusion because of the low pore velocity in the matrix. Dispersive flux is proportional to pore velocity (de Marsily 1986 [DIRS 100439], pp. 236-238).

The presence of perched water may serve as a mechanism to dilute liquid-phase solute concentrations in the UZ. In the TSw unit above perched water, solutes are expected to be carried primarily by many flow channels within active fractures (see Section 6.1.3 and Figure 6-3). Once they arrive at perched water zones, these solutes may mix with perched water, resulting in a decrease in chemical concentrations. The degree of dilution depends on the residence time of the solutes in the perched water; longer residence time corresponds to a larger degree of mixing within the perched water and therefore a larger degree of dilution. The relevant observations and modeling studies suggest that a large degree of mixing occurs in the perched water zones (Sonnenthal and Bodvarsson 1999 [DIRS 117127], pp. 118 and 151). Sonnenthal and Bodvarsson (1999 [DIRS 117127], p. 118) observed that chloride concentrations in water samples collected during hydraulic tests in the perched water bodies are not very variable because the water is probably well-mixed. Their modeling exercise also showed that perched water compositions are best matched by a mixture of Pleistocene age water with variable amounts of modern water (Sonnenthal and Bodvarsson 1999 [DIRS 117127], p. 151).

\subsubsection{Summary and Further Discussions}

Based on the discussions of transport issues and processes for the UZ (Sections 6.2.1 through 6.2.5), a conceptual model of transport in the UZ can be summarized as follows: (1) advective transport pathways coincide with flow pathways; (2) matrix diffusion is a major mechanism for mass transfer between fractures and matrix, and is expected to contribute to the retardation of radionuclide transport when fracture flow is dominant; and (3) sorption may retard the movement of radionuclides in the UZ, but this retardation is limited by reduced fracture-matrix interfacial area resulting from fingering flow in fractures. However, sorptive interactions may enhance radionuclide transport if the aqueous species sorbs to colloids that are subsequently transported through the UZ. Dispersion is not expected to be a major transport mechanism in the UZ.

Because flow is a major driving force for transport, the conceptual model of transport in the UZ is closely tied to the conceptual model of flow. Alternative conceptual models of flow give rise to different transport behavior from that discussed above. If the liquid-water flow primarily occurs in the matrix-as hypothesized by Wang and Narasimhan (1993 [DIRS 106793], pp. 327-339), Peters and Klavetter (1988 [DIRS 100604]) and Nitao and Buscheck (1991 [DIRS 102860])-matrix diffusion will be insignificant for UZ transport, and colloid-facilitated transport may not need to be considered, given that it mainly occurs in fractures. In contrast, if most liquid-water flows through structural features (Montazar and Wilson 1984 [DIRS 100161], p. 51) or very sparse flow paths (Pruess 1999 [DIRS 104250]), transport will be primarily determined by flow in fractures, and the effects of the matrix, such as matrix diffusion and matrix sorption, become insignificant. However, as discussed in Section 6.1.9 of this report, 
liquid-water flow in the $\mathrm{UZ}$ is considered more likely to be consistent with the current conceptual model of flow rather than either totally matrix- or fracture-dominated. In the current conceptual model, dominated fracture flow (that is not characterized by very sparse flow paths) occurs in the welded units (Section 6.1.9). In this case, matrix diffusion is important for radionuclide transport in the welded units (Section 6.2.2).

\subsection{NUMERICAL APPROACHES}

This section briefly reviews the currently available numerical approaches that can be used for modeling flow and transport in unsaturated fractured rocks, followed by a discussion of the appropriateness of these approaches for use in the UZ flow and transport model and other relevant issues.

\subsubsection{Available Numerical Schemes}

A variety of numerical approaches have been proposed in the literature to deal with flow and transport processes in fractured media at the field scale. When classified according to the manner in which fracture networks are treated in the model structure, the approaches fall into one of three groups: continuum approaches, discrete fracture-network approaches, and other approaches. Excellent reviews on these approaches, which have been developed and used in different fields (including oil-reservoir engineering, groundwater hydrology, geothermal engineering, and soil physics), can be found in Bear et al. (1993 [DIRS 116773], pp. 267-320 and 396-428) and the National Research Council (1996 [DIRS 139151], pp. 307-394). This section does not intend to give a comprehensive review of all the approaches, but will rather focus on those that can be used for unsaturated, fractured rock.

\subsubsection{Continuum Approaches}

\subsection{Basic Physical and Numerical Principles}

In continuum approaches, fractures are considered to be sufficiently ubiquitous and distributed in such a manner that they can be described statistically in a meaningful way (Bear et al. 1993 [DIRS 116773], pp. 395-396). The role of individual fractures in fractured media is considered to be similar to that of individual pores in porous media. Therefore, one can describe average fracture properties as macroscopic, and those associated with individual fractures as microscopic. Theoretically, the macroscopic scale is related to the so-called representative elementary volume (REV) (Bear et al. 1993 [DIRS 116773], pp. 3-10). A physical property value at a "point" in the fracture or matrix continuum is defined as that averaged over the corresponding REV. When the continuum approaches are valid, the size of a REV must be much larger than the scale of microscopic heterogeneity and much smaller than the scale of whole flow and/or transport domain.

In continuum approaches, connected fractures and rock matrix are viewed as two or more overlapping, interacting continua. In other words, at a "point," two or more continua are considered to co-exist. In this case, the continuum mechanics formulations, such as those used for porous media, can be used to describe flow and transport in each continuum. Coupling of processes between different continua is determined by interaction mechanisms at a subgrid scale. 
Depending on the number of continua and methodologies used to treat fracture-matrix interaction, continuum approaches can be further classified as effective-continuum, dual-continua, and multiple interacting continua (MINC) approaches.

\subsection{Effective Continuum Approach}

In the effective continuum method (ECM) approach, fractures and rock matrix are replaced with a single effective continuum (Figure 6-7(a)). In the traditional ECM (Pruess and Tsang 1994 [DIRS 117451], pp. 47-49), nonzero liquid saturation in the fracture does not occur until the matrix is fully saturated, which occurs at the so-called threshold saturation. Composite characteristic curves are constructed which embody matrix behavior when the saturation of the effective continuum is less than the threshold saturation, and fracture behavior when the saturation is larger than the threshold saturation. In the modified ECM (Wu et al. 1999 [DIRS 117161], p. 194), the concept of threshold saturation is not invoked. Instead, liquid saturation is partitioned into the matrix and fracture in accordance with the principle of local thermodynamic equilibrium, which requires capillary pressure in the matrix and fracture components of a gridblock to be equal. Thus, in the generalized ECM formulation, fracture flow occurs at all saturations, although small fracture flow is computed at low saturations. In each gridblock, ECM also assumes that water in the fractures and matrix have the same chemical concentration and temperature.

The ECM approach provides a substantial simplification for describing flow and transport in fractured porous media, and is computationally efficient in handling a large model grid. However, the assumptions on which ECM is based may break down when long times are needed to reach local equilibrium condition between the fracture and matrix continua. This is especially true for a very tight and low-permeability rock matrix with rapid fracture flow (Wu et al. 1999 [DIRS 117161], p. 195).

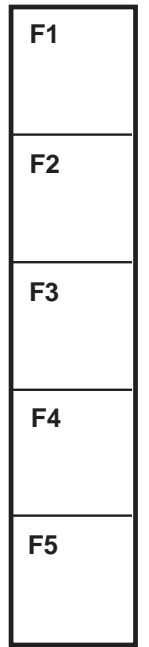

(a)

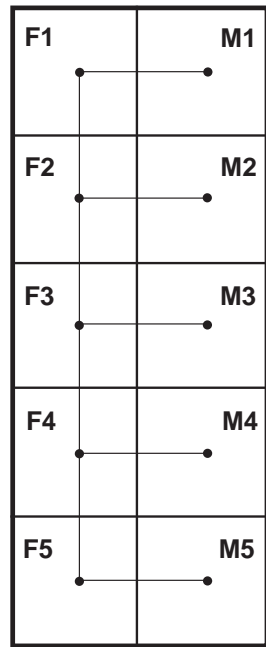

(b)

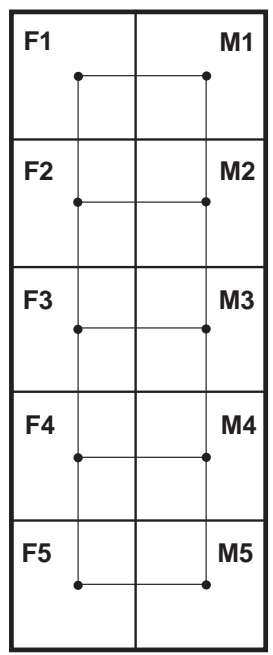

(c)

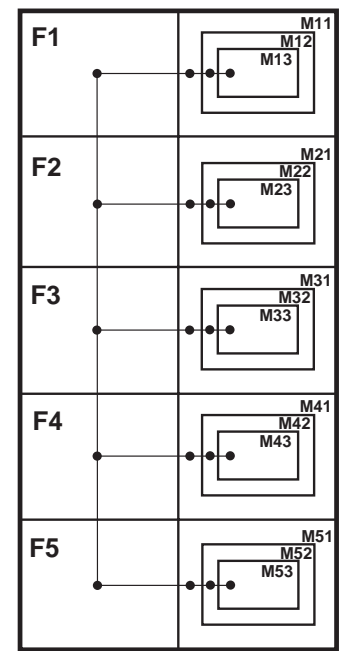

(d)

Figure 6-7. Schematic Diagram of One-Dimensional Column of Gridblock, Modeled as (a) ECM, (b) Dual-Porosity with One Matrix Gridblock, (c) Dual-Permeability with One Matrix Gridblock per Fracture Gridblock, and (d) MINC with Three Matrix Gridblocks per Fracture Gridblock 


\subsection{Dual-Continua Approaches}

In dual-continua approaches, fractures and matrix are treated as two separate, yet interacting continua, and each gridblock is subdivided into one fracture block and one matrix block (Figure 6-7). The fracture-matrix flow and transport are approximated as quasi-steady. This treatment is the numerical equivalent of the Warren and Root (1963 [DIRS 100611]) formulation. If global flow occurs only between fracture gridblocks, the approach is known as a dual-porosity approach, because fractures alone control large-scale fluid flow and the matrix only contributes an additional storage term. If global flow occurs within both fracture and matrix continua, the scheme is known as a dual-permeability approach (Doughty 1999 [DIRS 135997], p. 76).

Compared to ECM, dual-continua approaches can more accurately predict flow and transport, because nonequilibrium is allowed between fracture and matrix continua. The dual-porosity approach is valid only when matrix flow is not important. When both fracture flow and matrix flow are important, the dual-permeability scheme is more accurate. On the other hand, since only one matrix block is used for each gridblock and a quasi-steady fracture-matrix flow assumption is employed, gradients of matrix capillary pressures, temperature, and concentration near a fracture-matrix interface may be poorly predicted using dual-continua schemes. This is especially true during a rapid, transient flow or transport period in a system with large size and low-permeability matrix blocks. Therefore, the dual-continua approach could give rise to poor solutions to fracture-matrix flow for rapid, transient flow and transport. Under steady-state conditions, however, the gradients near the matrix surface become minimal, and the approaches are expected to produce acceptable solutions.

\subsection{Multiple Interacting Continua Approach}

As indicated previously, dual-continua approaches could give rise to poor solutions to fracture-matrix flow for rapid, transient flow and transport. A more general and rigorous approach, MINC, was developed by Pruess and Narasimhan (1985 [DIRS 101707]) to overcome this limitation. Specifically, MINC is based on the notion that changes in fluid pressures, temperature, and phase compositions will propagate rapidly through the fracture system, while invading the tight matrix blocks slowly. Therefore, changes in matrix conditions will be locally controlled by the distance from the fractures. In the MINC, all fractures are lumped into Continuum \#1; all matrix materials within a certain ("small") distance from the fractures are lumped into Continuum \#2; matrix materials at larger distance from the fractures become Continuum \#3; and so on. Therefore, the MINC approach can be considered a generalization of the dual-continua approach.

Compared with dual-continua approaches, the MINC approach can more accurately predict flow and transport in fractured media, but has larger computational requirements in both central processing unit times and storage space.

\subsubsection{Discrete Fracture-Network Approaches}

Discrete fracture-network approaches are based on an assumption that flow and transport behavior can be predicted from knowledge of the fracture geometry and data on hydraulic properties of individual fractures (National Research Council 1996 [DIRS 139151], p. 332). 
These approaches involve computational generation of synthetic fracture networks and subsequent modeling of flow and transport in each individual fracture. These approaches have been extensively used for single-phase flow and transport, with deterministic, stochastic, artificial, or site-specific fracture networks in two or three dimensions (National Research Council 1996 [DIRS 139151], pp. 333-350). Recently, the same approaches have also been applied to unsaturated conditions (e.g., Kwicklis and Healy 1993 [DIRS 100587]; Liu et al. 2002 [DIRS 160230]).

While discrete fracture-network approaches are useful as tools for concept evaluation or model-based process studies, they have several limitations. First, the approaches require geometric parameters that may strongly impact flow and transport, such as fracture apertures and conductivity, but typically cannot be well constrained from field observations (Pruess et al. 1999 [DIRS 117112], p. 308). Second, it is difficult to separate the conductive fracture geometry from the nonconductive fracture geometry (National Research Council 1996 [DIRS 139151], p. 350). Third, flow and transport models based on these approaches can be complex and computationally intensive for realistic fracture densities (National Research Council 1996 [DIRS 139151], p. 350). Fourth, so far, the studies based on discrete fracture-network approaches have rarely considered fracture-matrix interaction because of computational complexity (Pruess et al. 1999 [DIRS 117112], p. 308). Fracture-matrix interaction has important effects on flow and transport in unsaturated fractured rocks.

\subsubsection{Assessment of Numerical Approaches}

Several basic numerical approaches for unsaturated, fractured porous media have been briefly reviewed, and the advantages and limitations of these approaches have also been discussed. It needs to be indicated that several other numerical approaches are also available in the literature (e.g., Clemo and Smith 1997 [DIRS 139105], pp. 1763-1765). These additional approaches, however, can be considered as variations and/or combinations of the basic approaches mentioned above. The appropriateness of the currently available numerical approaches for the UZ flow and transport model depends on several important factors, including flow and transport behavior at the Yucca Mountain site, scale of the problem, data availability, and computational feasibility.

The overall flow and transport behavior in the UZ at Yucca Mountain may be characterized by two important features. The first feature is the existence of relatively uniform flow and transport along fractures (Section 6.1.7) which makes continuum approaches a reasonable choice for the UZ model. The second feature is the coexistence of matrix-dominant flow and transport in nonwelded units and fracture-dominant flow and transport in welded units. This feature can be easily handled by continuum approaches, but not by other approaches such as a fracture-network model. For example, as previously indicated, studies based on discrete fracture-network approaches have rarely considered fracture-matrix interaction because of computational complexity (Pruess et al. 1999 [DIRS 117112], p. 308). Consideration of this feature is important for correctly simulating flow and transport processes in the UZ of Yucca Mountain.

Scale of the problem is an important factor for assessing the appropriateness of numerical schemes for the UZ flow and transport model. Because continuum approaches are relatively simple and straightforward to implement, they are preferred for most applications that are 
encountered in practice (National Research Council 1996 [DIRS 139151], p. 331). There are estimated to be on the order of $10^{9}$ fractures at Yucca Mountain (Doughty 1999 [DIRS 135997], p. 77). It is practically impossible to construct and calibrate a discrete fracture network site-scale model with so many fractures, considering the data availability and computational feasibility.

Based on the above considerations, continuum approaches have been considered to be appropriate for use in the UZ flow and transport model. As a compromise between accuracy and feasibility, the dual-permeability method has become the main modeling approach currently used in the UZ model to simulate water flow, heat transfer, and chemical transport.

\subsubsection{Consistency Between Continuum-Approach-Based Simulation Results and Field Observations}

As discussed in Section 6.3.2, the continuum approach has been used for modeling flow and transport in the UZ. Recently, efforts have also been made to evaluate the performance of the continuum approach (e.g., Liu et al. 2003 [DIRS 162470]; BSC 2004 [DIRS 169861], Section 7.6). Given the complexity of the flow and transport processes in the unsaturated fractured rock, a direct comparison between numerical simulations (based on the continuum approach) and field experimental observations would be a useful and relatively simply way to evaluate the validity of the approach (Liu et al. 2003 [DIRS 162470], Section 1).

Field-scale experiment data of flow and transport through unsaturated fractured rock, obtained under controlled conditions, are very limited. However, two field-scale experiments (referred to as Alcove 1 test and Alcove 8/Niche 3 test, respectively) of this kind were recently conducted in the UZ. The Alcove 1 test site is located near the North Portal of the ESF (Liu et al. 2003 [DIRS 162470]). Alcove 1 was constructed for collecting seepage water originating from a controlled application of surface infiltration. The alcove is about $5.5 \mathrm{~m}$ high and $5.8 \mathrm{~m}$ wide, and about $20 \mathrm{~m}$ below the ground surface. Rocks between the ground surface and the alcove are intensely fractured and within the TCW unit. A bulkhead was installed in order to isolate the alcove from the ESF. The bulkhead was intended to raise the relative humidity in the alcove and reduce evaporation from the wall of the alcove. Maintaining relative humidity allows the determination of the wetting front arrival from the observation of dripping from the alcove ceiling and walls. During the infiltration test, water was applied at the ground surface directly over the end of the alcove. The size of the infiltration plot was $7.9 \mathrm{~m} \times 10.6 \mathrm{~m}$. During the late stage of the Alcove 1 test, a tracer, bromide, was introduced into the infiltrating water. Seepage into the alcove was collected as a function of time. Tracer concentrations were obtained by analyzing the seepage water.

Infiltration and tracer transport tests were also conducted at the cross-over test site, where Alcove 8 in the enhanced characterization of the repository block (ECRB) cross-drift is about $20 \mathrm{~m}$ directly above Niche 3 in the ESF main drift (BSC 2004 [DIRS 170004], Section 6.12). The test site is located in the upper lithophysal and middle nonlithophysal subunits of the TSw unit. The upper lithophysal subunit contains lithophysal cavities. Liquid water without and with tracers was released sequentially along a fault (line-release) and from a large $3 \mathrm{~m} \times 4 \mathrm{~m}$ plot (areal release) on the floor of Alcove 8. Water release locations are different for line-release and areal release. The test along the fault was conducted before the large plot test. Seepage rate and tracer concentration data were collected from Niche 3 . 
Comparisons between simulation results and field observations from these two tests are used to evaluate the continuum approach used in the site-scale UZ flow model. A three-dimensional submodel for the Alcove 8/Niche 3 test site was developed, and both model calibration and prediction analyses were performed (BSC 2004 [DIRS 169861], Section 7.6). Infiltration rate, seepage rate, and tracer concentration data from the tests were used to corroborate model simulations. It was found that the field observations are well represented by the modeling results. For example, Figure 6-8 shows a comparison between simulated and observed seepage rate as a function of time. A similar model evaluation approach is also used for Alcove 1 tests. Again, modeling results are found to be consistent with field observations (e.g., Figure 6-9). These comparisons demonstrate that a continuum-approach-based model is able to capture important features of the unsaturated flow and transport processes in the UZ.

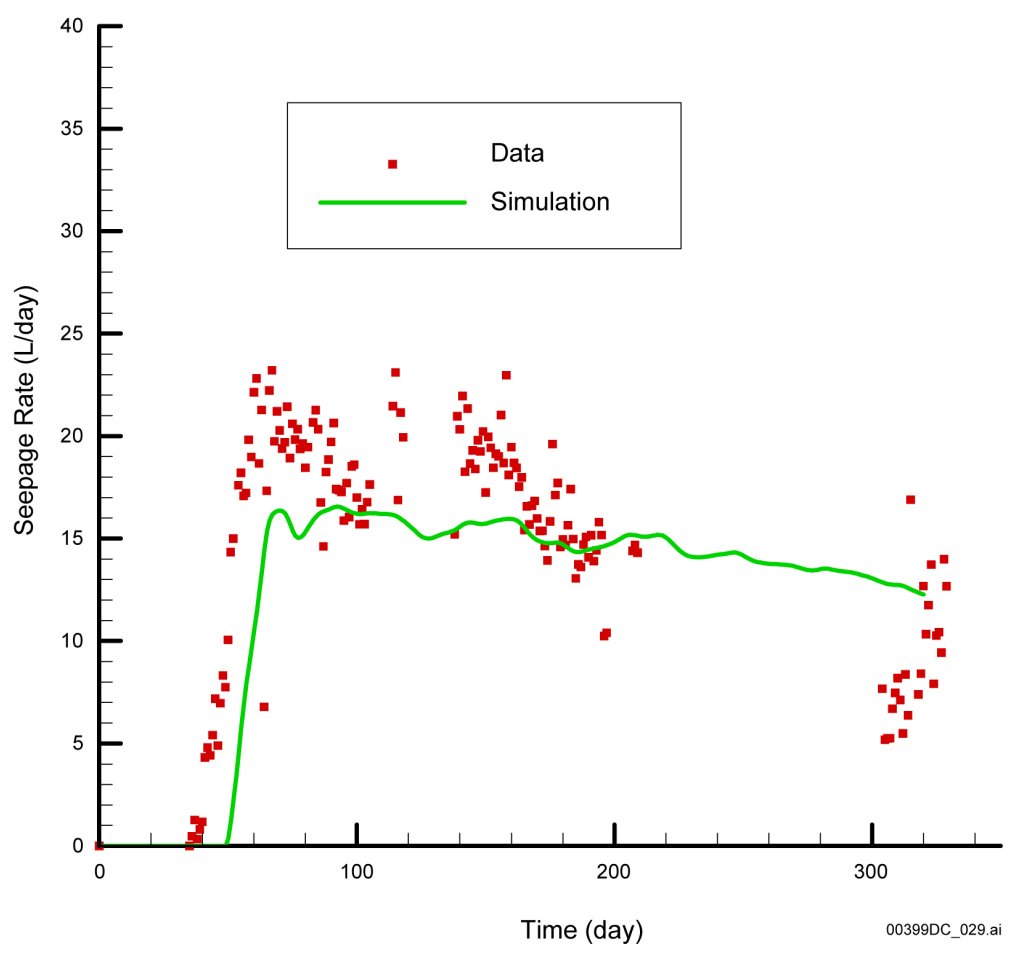

Source: BSC 2004 [DIRS 169861], Figure 7.6-8.

Figure 6-8. Comparison Between Simulated Seepage Rates as a Function of Time and Field Observations Collected from Alcove 8/Niche 3 Tests 


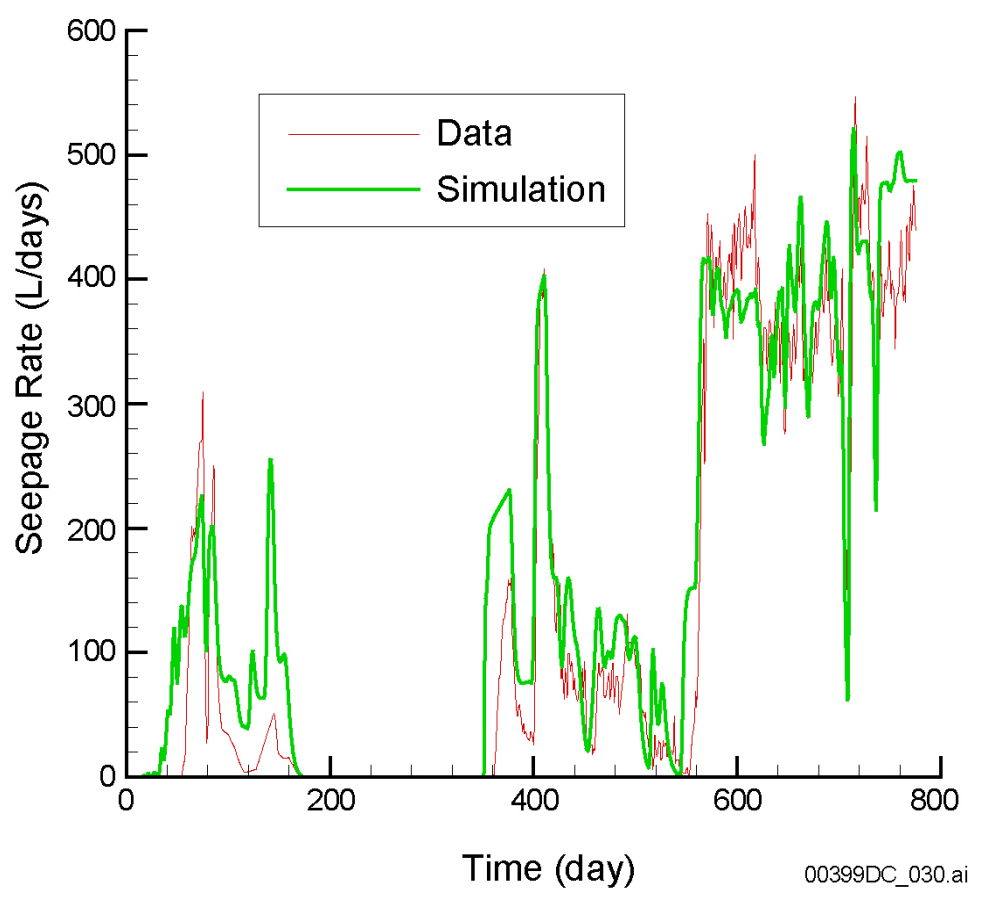

Source: Liu et al. 2003 [DIRS 162470], Figure 4.

Figure 6-9. Comparison Between Simulated Seepage Rates as a Function of Time and Field Observations Collected from Alcove 1 Tests

\subsubsection{Treatment of Heterogeneity}

Heterogeneities exist at different scales within both fracture and matrix continua in the UZ. Treatment of subsurface heterogeneity is important for modeling flow and transport processes. A geology-based deterministic approach, in which an entire model layer is assigned uniform properties, is used mainly for representing subsurface heterogeneity.

The key justification for the above approach is that the overall behavior of site-scale flow and transport processes is determined mainly by relatively large-scale heterogeneities associated with the geologic stratification and tectonic features (e.g., faults) of the mountain. Within the same geologic unit, hydrologic properties are relatively uniformly distributed because of the intrastrata homogenization induced by tuff depositional environments. This justification is also consistent with a field observation that matrix saturation distribution is relatively uniform within a given geologic unit (Flint 1998 [DIRS 100033], pp. 24 to 30). Displacement of strata along faults can result in units with different hydrologic properties being placed against each other across the fault, resulting in lateral heterogeneities within the UZ.

Zhou et al. (2003 [DIRS 162133]) recently demonstrated the validity of this approach in dealing with subsurface heterogeneity. They used a two-dimensional vertical cross section in the eastwest direction through Borehole USW UZ-14 to investigate the effect of multiscale heterogeneity on unsaturated flow and transport within the UZ. Specifically, they generated and used random fields of three selected properties: matrix permeability, $k_{m}$; matrix van Genuchten parameter, $\alpha_{m}$; and fracture permeability, $k_{f}$ (Zhou et al. 2003 [DIRS 162133], Figure 13). For comparison, they employed different sets of rock property distributions in three cases. In these 
cases, mean rock properties for a given geological layer are the same. In Case A, the layered approach mentioned above was used. In Case B, stochastically generated $k_{f}$ variability was considered within a geological layer. In Case $\mathrm{C}$, variabilities of all the selected rock properties were included, with the variabilities determined from the measured hydrologic properties. Thus, Case A only considers large-scale heterogeneity, while Cases B and C include small-scale heterogeneity within a geological unit.

Figure 6-10 shows comparisons of vertical water fluxes within the matrix and fractures along the repository zone for the three cases. Although relatively large differences exist for the water flux in the matrix, distributions of water fluxes in fractures are very similar for these three cases. Because the matrix flux corresponds to only a small percentage of total water flux, the three cases essentially provide similar water flow fields at the site scale. Zhou et al. (2003 [DIRS 162133], Figure 17) also compared simulated results for tracer transport from the repository to water table, and again found that the results are similar for the three cases. In summary, the study of Zhou et al. (2003 [DIRS 162133]) demonstrates that heterogeneities within each geological unit have only a minor effect on the site-scale flow processes.

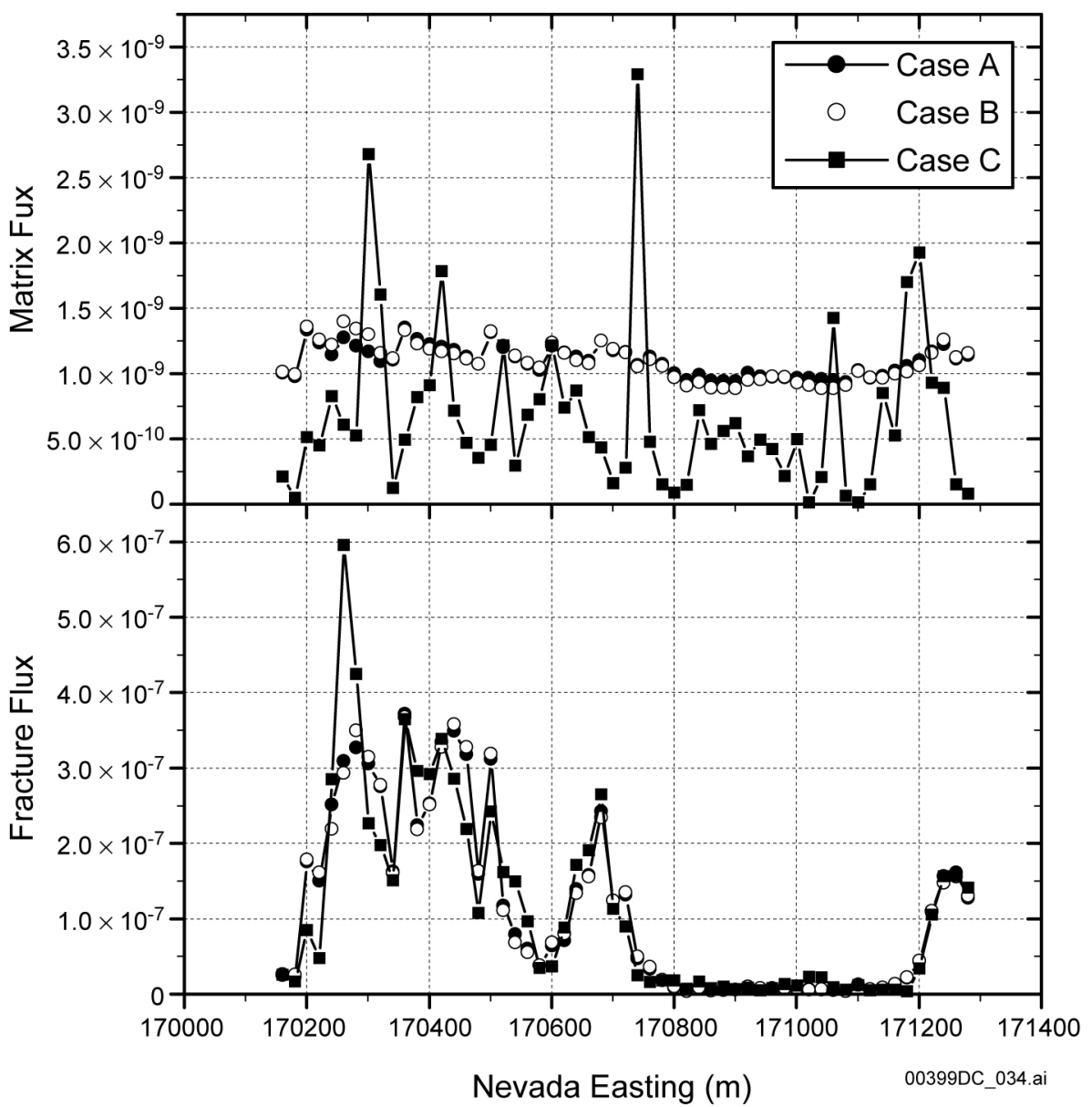

Source: Zhou et al. 2003 [DIRS 162133], Figure 16.

Figure 6-10. Comparison of Simulated Matrix and Fracture Flux $(\mathrm{m} / \mathrm{s})$ at the Repository Horizon in Cases $A, B$, and $C$ 


\subsection{5 van Genuchten Relations for Modeling Unsaturated Flow in Fractures}

In the dual-continua approach, porous-medium equivalence has been used for describing water flow in the fracture continuum (National Research Council 1996 [DIRS 139151], p. 380). Specifically, Darcy's law is used to determine water flux within the fracture continuum, and constitutive relations between relative permeability, capillary pressure, and saturation (van Genuchten 1980 [DIRS 100610]) are employed for modeling unsaturated water flow in fractures. The van Genuchten (1980 [DIRS 100610]) relations are given by

$$
\begin{gathered}
S_{e}=\left[1+\left|\alpha P_{c}\right|^{n}\right]^{-m} \\
k_{r}=\sqrt{S_{e}}\left[1-\left(1-S_{e}{ }^{1 / m}\right)^{m}\right]^{2}
\end{gathered}
$$

where $P_{c}$ is the capillary pressure; $k_{r}$ is the relative permeability; $\alpha, n$, and $m$ are empirical fitting parameters with $m$ equal to $1-1 / n$; and $S_{e}$ is the effective saturation given by

$$
S_{e}=\frac{S-S_{r}}{S_{S}-S_{r}}
$$

where $S$ is the water saturation, $S_{r}$ is the residual saturation, and $S_{S}$ is the satiated saturation. The parameter $\mathrm{m}$ is an index of pore size distribution.

Although van Genuchten (1980 [DIRS 100610]) relations have been widely used in porous media, their usefulness for fractures has not been fully established. To evaluate these relations, Liu and Bodvarsson (2001 [DIRS 160110]) performed numerical experiments for two-dimensional fracture networks. Figure 6-11 shows one of the fracture networks generated from fracture data collected in the UZ of Yucca Mountain.

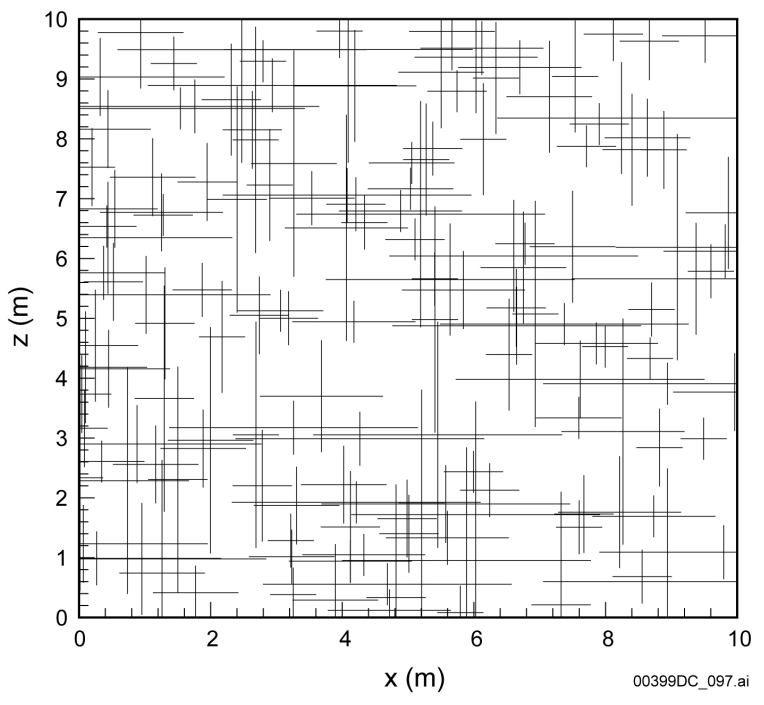

Source: Liu and Bodvarsson 2001 [DIRS 160110], Figure 1b.

Figure 6-11. A Computationally Generated Fracture Network 
The effective constitutive relations for fractures were determined by numerical simulations of steady-state unsaturated flow in fracture networks (Liu and Bodvarsson 2001 [DIRS 160110]). The rock matrix is treated as being impermeable for purposes of focusing on the fracture continuum. Different parameters (including aperture and van Genuchten parameters) were assigned to different groups of individual fractures. Liu and Bodvarsson (2001 [DIRS 160110]) imposed the same capillary pressures at the top and bottom boundaries of a fracture network and nonflow conditions at the side boundaries. The capillary pressures at the top and bottom boundaries were considered to be effective capillary pressures of the fracture network. Because the effective capillary pressure gradient is zero in the vertical direction (resulting from the same pressure values used as the top and bottom boundary conditions), the average vertical flux should (according to Darcy's law) be the same as the hydraulic conductivity of the corresponding fracture network. The network is considered to be a fracture continuum within the context of the dual continua approach. For a number of different uniform capillary pressures at the boundaries, the corresponding values of volumetric saturation and hydraulic conductivity (or relative permeability) can be obtained for a fracture network, resulting in the desired constitutive relations. This computational procedure is similar to laboratory procedures to determine constitutive relations for porous media. The relative permeability is determined from the ratio of the unsaturated conductivity to the saturated conductivity (Liu and Bodvarsson 2001 [DIRS 160110]).

Some evaluation results of Liu and Bodvarsson (2001 [DIRS 160110]) are given in Figures 6-12 and 6-13. These figures also show the results for Brooks-Corey relations (Brooks and Corey 1966 [DIRS 119392]), which can be expressed by

$$
\begin{gathered}
S_{e}=\left|P_{c} / P_{d}\right|^{-\lambda} \\
k_{r}=S_{e}^{\left(3+\frac{2}{\lambda}\right)}
\end{gathered}
$$

where $P_{d}$ is known as the air entry pressure and $\lambda$ is a dimensionless index of pore size distribution. If $P_{d}$ is approximated by $1 / \alpha$, the Brooks-Corey's capillary pressure-saturation relation is equivalent to that of the van Genuchten model with (van Genuchten 1980 [DIRS 100610]; Wang and Narasimhan 1993 [DIRS 106793])

$$
\lambda=n-1
$$

This relation allows use of the van Genuchten parameter $n$ to estimate relative permeability using the Brooks-Corey model that has been employed in this study to minimize the number of property parameters.

Figure 6-12 shows fairly good fits between the van Genuchten (1980 [DIRS 100610]) capillary pressure-effective saturation relations and the simulated retention curve, except for high saturations, for the fracture network in Figure 6-11. 


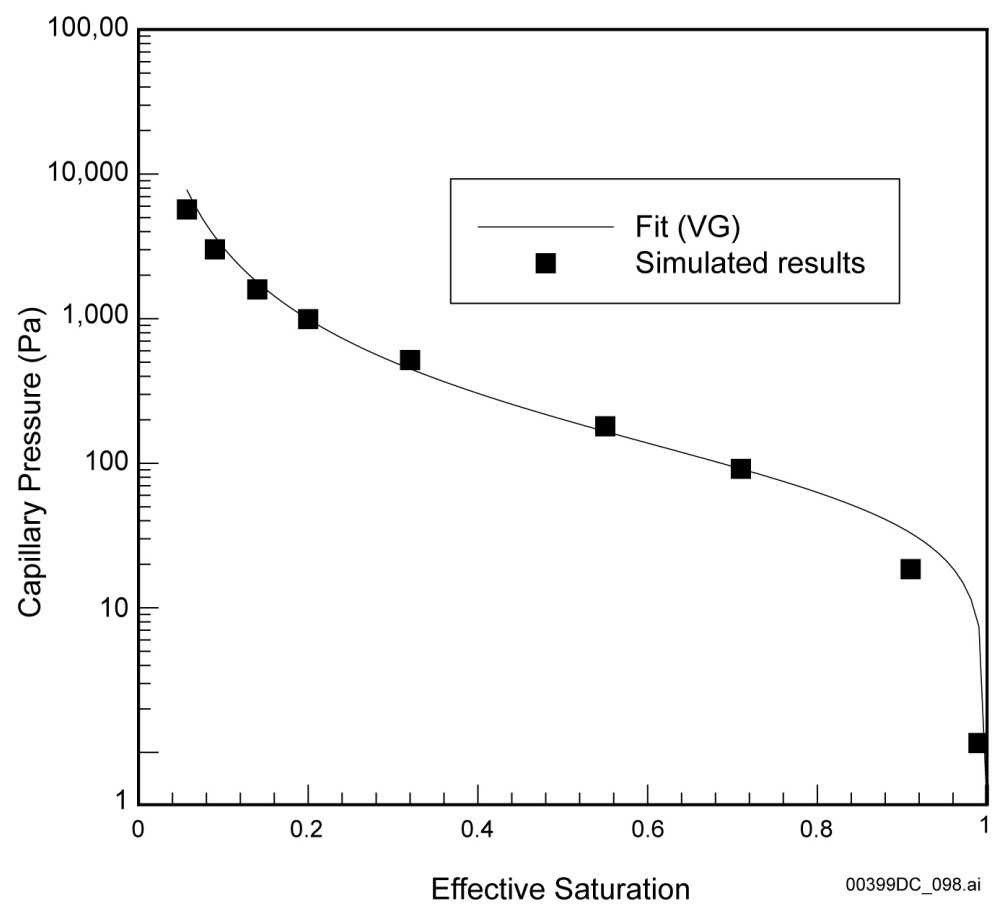

Source: Liu and Bodvarsson 2001 [DIRS 160110], Figure 2a.

Figure 6-12. Fit of the van Genuchten Model to the Simulated Capillary Pressure-Effective Saturation Relations

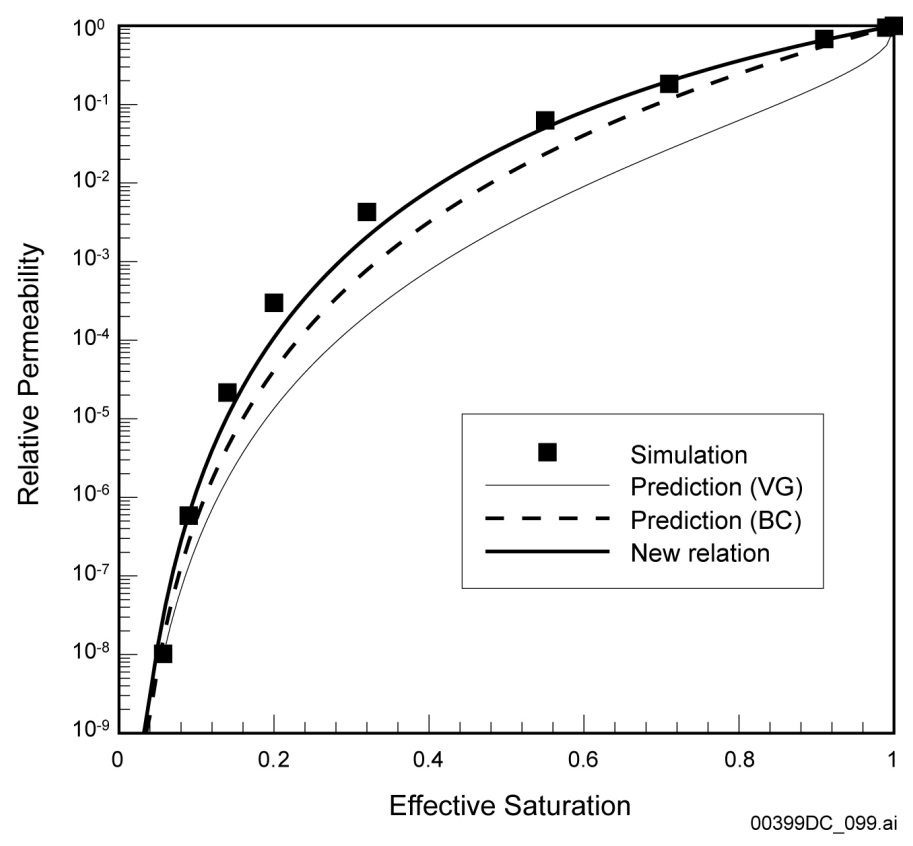

Source: Liu and Bodvarsson 2001 [DIRS 160110], Figure 3a.

Figure 6-13. Comparison between Simulated Relative Permeability-Effective Saturation Relations. The Curves Predicted Using the van Genuchten (VG) Relations, the Brooks-Corey (BC) Relations, and a New Relation (Equation 6-10) with the $m$ Values Determined from Figure 6-12. 
Figure 6-13 shows comparisons between the simulated relative permeability-effective saturation relations and curves predicted using the van Genuchten model and the Brooks-Corey model, with the $m$ values obtained from curve fitting in Figure 6-12. The predicted relative permeability values are consistently smaller than the simulated ones for a given saturation, while the Brooks-Corey model gives better results than the van Genuchten model. This may result from the different representations of pore geometry and their applications to fractures. First, the Brooks-Corey (Brooks and Corey 1966 [DIRS 119392]) relative permeability-saturation relation was derived from a model, in which pores are represented by a group of parallel capillary tubes with different radii, whereas the van Genuchten relation is based on the more complicated pore-geometry model of Mualem (1976 [DIRS 100599]). The Brooks-Corey model representing pores with a group of parallel capillary tubes may be more consistent with the unsaturated flow in a fracture network characterized by a number of major flow paths in the vertical direction (Kwicklis and Healy 1993 [DIRS 100587]). Second, because of the difference between fracture network geometry and pore space geometry, tortuosities of flow paths in a fracture network are considerably different from those in a porous medium. Because pore sizes in a porous medium are generally much smaller than fracture apertures, unsaturated flow in a fracture network is mainly gravity-driven (Liu et al. 1998 [DIRS 105729]), especially for a large fracture water saturation and, consequently, the capillary force is generally much stronger in a porous medium. The latter is expected to result in more tortuous flow paths around solid particles (through pores) in a porous medium. The following expression for tortuosity factor $\tau$ was assumed in deriving Equation 6-5 (Brooks and Corey 1966 [DIRS 119392]).

$$
\tau=S_{e}^{2}
$$

If $\tau$ is assumed to be its maximum value of 1, Equation 6-5 will become

$$
k_{r}=S_{e}\left(1+\frac{2}{\lambda}\right)
$$

Both the Brooks-Corey and van Genuchten models reasonably predict the simulated relative permeability-saturation relations for small water saturations (e.g., less than 0.10 in Figure 6-13). This may be because capillary force becomes important at low saturations, resulting in similar unsaturated flow behavior in both a porous media and a fracture network. These two models are, thus, approximately valid for modeling water flow in the Yucca Mountain UZ under ambient conditions, which generally involve very low fracture saturations as a result of low infiltration rates in that region. However, under disturbed conditions, the thermal-hydrologic response of the unsaturated rocks to the decay heat of nuclear wastes can give rise to relatively high fracture saturations around the repository. The van Genuchten and Brooks-Corey models may lead to considerable error in modeling flow processes under these conditions. To improve the accuracy of the Brooks-Corey model in predicting the relative permeability-effective saturation relation for a fracture network, Liu and Bodvarsson (2001 [DIRS 160110]) modify the tortuosity expression (Equation 6-7) for the Brooks-Corey model to

$$
\tau=S_{e}^{2\left(1-S_{e} e^{3 / 4}\right)}
$$


Compared with Equation 6-7, the above equation gives tortuosity factor values that are closer to 1 for large saturations and essentially the same as those calculated from Equation 6-7 for low saturations. Although Equation 6-9, like the expressions for tortuosity factor used in both the Brooks-Corey and the van Genuchten models, is empirical, it is consistent with the previous discussion. Following Brooks and Corey (1966 [DIRS 119392]), and using Equation 6-9 leads to

$$
\left.k_{r}=S_{e}^{\left(3-2 S_{e} 3 / 4\right.}+2 / \lambda\right)=S_{e}^{\left(3-2 S_{e} 3 / 4+\frac{2}{n-1}\right)}
$$

Improved matches between the simulated relative permeability-saturation relations and those calculated with Equation 6-10 are shown in Figure 6-13. Therefore, the new simulated constitutive relations can be represented by a combination of van Genuchten's capillary pressure-effective saturation relation and the modified Brooks-Corey relative permeability-effective saturation relation.

In summary, the results of Liu and Bodvarsson (2001 [DIRS 160110]) indicate that the van Genuchten (1980 [DIRS 100610]) relations are valid for modeling water flow in the Yucca Mountain UZ under the ambient conditions that generally involve very low fracture saturations resulting from low infiltration rates in that region.

\subsubsection{Special Issues for Flow and Transport Modeling}

\subsubsection{Gas Flow}

Gas (air) flow behavior is different from that of liquid water. No data are available to characterize gas relative permeability in the UZ of Yucca Mountain. It is reasonable to expect phase interference to reduce the mobility of the gas phase in both the matrix and the fractures. Indirect evidence of the reduction for gas flow between fractures and the matrix is found in pneumatic pressure data measured in the ESF (Rousseau et al. 1999 [DIRS 102097], pp. 77-110). These data show insignificant attenuation and lag of the pneumatic signal through the TSw, which can only occur in the presence of high permeability and/or low porosity. The very high gas saturation in the fractures indicates that the relative permeability of the gas phase in the fractures is also high. The effective porosity for the gas-phase system can be reduced by decreasing the mobility (or saturation) of the gas phase in the matrix, which provides a substantial portion of the gas-phase storage in the TSw. The widely used Brooks-Corey relationship for gas relative permeability, $k_{r g}$, is suitable for this problem and is given by (Brooks and Corey 1966 [DIRS 119392], p. 71)

$$
k_{r g}=\left(1-S_{e}\right)^{2}\left(1-S_{e}^{\frac{2+\lambda}{\lambda}}\right)
$$

where $\lambda$ is a pore-size distribution parameter and $S_{e}$ is effective saturation given by Equation 6-3. For the van Genuchten relationship, which is used to describe liquid relative permeability and water potential, pore-size distribution is determined from liquid desaturation data. The van Genuchten pore-size distribution parameters $n$ and $m$ can be related to the 
Brooks-Corey $\lambda$, as shown in Equation 6-6 (van Genuchten 1980 [DIRS 100610], p. 895). Substituting $m=1-1 / n$ into Equation 6-6 gives

$$
\lambda=\frac{m}{1-m}
$$

Substituting Equation 6-12 into Equation 6-11 gives

$$
k_{r g}=\left(1-S_{e}\right)^{2}\left(1-S_{e}^{\frac{2-m}{m}}\right)
$$

Equation 6-13 is used to describe the gas relative permeability in the fractures and matrix, and uses the same $m$ as the liquid relative-permeability and water-potential relationships.

\subsubsection{Particle-Tracking Algorithm for Chemical Transport}

In general, there are two kinds of numerical algorithms for modeling chemical transport in the subsurface. One is the conventional algorithm based on finite-difference and/or finite-element methods. Another is the particle-tracking algorithm. In a particle-tracking algorithm, chemical mass is divided into a large number of particles. Chemical transport is simulated by calculating particle movement, which is determined by velocity fields, dispersion/diffusion coefficients, and fracture-matrix interaction formulations. Compared with the conventional approaches, particle tracking has the following two advantages. First, it can significantly reduce or eliminate numerical dispersion. Numerical dispersion is a common numerical problem for coarse grid simulations of chemical transport problems. It artificially smears concentration fronts in simulations. Second, the particle-tracking algorithms can be computationally more efficient. However, one shortcoming of particle-tracking algorithms is that they can only be used for chemical transport with simple chemical reactions like linear adsorption and decay. The above considerations suggest that particle-tracking algorithms are appropriate for modeling chemical transport with simple reactions, and conventional algorithms are appropriate for transport with complex reactions. Note that both particle tracking and conventional algorithms should yield similar simulation results for transport with simple reactions when numerical dispersion is insignificant.

\subsubsection{Dispersion in Fractures}

Although it is generally recognized that dispersion in a fractured medium is physically different from dispersion in a porous medium, the porous medium form of the dispersion tensor is generally used for lack of a more appropriate expression (Bear et al. 1993 [DIRS 116773], p. 419). As discussed in Section 6.2.5, the dispersion may not be a major transport mechanism for the UZ of Yucca Mountain. It physically makes sense, because for a dual-continua system, chemical transport is mainly determined by the largest heterogeneity, the difference in properties between the matrix and fracture continua. In this case, heterogeneity in each continuum, resulting in the corresponding macroscopic dispersion process, becomes secondary. Therefore, a more accurate description of the fracture dispersion may not significantly improve the accuracy of transport simulations. This is supported by a tracer transport simulation study on the ESF Alcove 1 test (Liu et al. 2003 [DIRS 162470]). The 
Alcove 1 modeling study shows that the simulation results are sensitive to matrix diffusion, but not to dispersion in the fracture continuum.

\subsubsection{Use of the Dual-Continua Approach for Modeling Radionuclide Transport}

Since radionuclide transport is a transient process, the use of the dual-continua approach may result in some modeling errors for chemical transfer between fractures and the matrix. This is particular true when the chemical transfer occurs only within a portion of matrix close to the fracture-matrix interfaces. Generally, the dual-continua approach may underestimate the chemical concentration gradient at the fracture-matrix interface, and, therefore, may underestimate chemical transfer from fractures to matrix under certain conditions. This is supported by the modeling study of Doughty (1999 [DIRS 135997], pp. 94-95), showing that the dual-continua approach yields shorter travel times than the MINC approach. Since the matrix transport processes correspond to relatively long travel times to the water table compared with those in fractures, the dual-continua approach is expected to give conservative predictions of radionuclide transport in the UZ. This point is further confirmed in BSC (2004 [DIRS 164500], Section 6.19), which reported that the simulated breakthrough time for tracer transport from the repository to water table are significantly longer for the MINC model than that for the dual-continua model.

\subsubsection{Active Fracture Model}

In a dual-continua approach, the treatment of fracture-matrix interaction is important for accurate modeling of flow and transport because flow and transport behaviors in fractures and the matrix are very different. This subsection discusses the AFM used in the UZ Flow and Transport Model. The validation of the AFM will be presented in Section 7.

\subsubsection{Active Fracture Concept}

Although a number of mechanisms exist for limiting fracture-matrix interaction (Section 6.1.3), fingering flow at a fracture network scale is considered to be a key mechanism, and more important than that at a single fracture scale. We expect that for unsaturated fractured rock, the water-flow pattern should be characterized by significant preferential (fingering) flow at a fracture-network scale, because of a combination of the large nonlinearity involved in an unsaturated system and heterogeneities of fracture structure at different scales (Liu et al. 1998 [DIRS 105729]). The active fracture concept is based on the reasoning that as a result of fingering flow, only a portion of fractures in a connected, unsaturated fracture network contribute to liquid water flow, while others are simply by-passed. The portions of the connected fractures that actively conduct water are called active fractures. It is hypothesized that the number of active fractures in the UZ of Yucca Mountain is small compared to the total number of connected fractures. With this in mind, active fractures, rather than total connected fractures, must be used in numerical models. It is further hypothesized that the number of active fractures within a gridblock is large, such that a continuum approach is still valid for describing fracture flow. These hypotheses are consistent with the consideration that flowing fractures in the UZ are many and highly dispersed.

To use the active fracture concept to model flow and transport in fractures, we treat active fractures as a portion of the "homogeneous" fracture continuum for a given gridblock. 
It is important to note differences between the AFM and the conventional, capillary-equilibrium-based, fracture water distribution model. The latter assumes that liquid water occupies fractures with small apertures first, and then fractures with relatively large apertures as water potential (or water saturation) increases. In contrast, the AFM presumes gravity-dominated, nonequilibrium, preferential liquid water flow in fractures, which is expected to be similar to fingering flow in unsaturated porous media. A liquid finger can by-pass a large portion of a porous medium, which does not necessarily correspond to large pores. It is also consistent with the numerical study results of Kwicklis and Healy (1993 [DIRS 100587], pp. 4097-4099), showing that distribution of liquid water in a connected fracture network is not necessarily determined by fracture apertures.

Flow and transport conditions, and fractured rock properties should determine the fraction of active fractures in a connected fracture network, $f_{a}$. An expression for $f_{a}$ must satisfy the following conditions: all connected fractures are active $\left(f_{a}=1\right)$ if the system is fully liquid saturated; all fractures are inactive $\left(f_{a}=0\right)$ if the system is at residual saturation; and $f_{a}$ should be related to water flux in fractures. More fractures are considered to be conducive for a larger water flux (Liu et al. 1998 [DIRS 105729], pp. 2635-2636). The water flux in fractures is also considered to be mainly dependent on fracture saturation because fracture water flow is gravity-dominated. A simple expression for $f_{a}$ (Liu et al. 1998 [DIRS 105729], pp. 2635-2636) that meets these conditions and includes one parameter only is a power function of effective water saturation in connected fractures, $S_{e}$ :

$$
f_{a}=S_{e}^{\gamma}
$$

where $\gamma$ is a positive constant depending on properties of the corresponding fracture network, and the effective water saturation in connected fractures is given by

$$
S_{e}=\frac{S_{f}-S_{r}}{1-S_{r}}
$$

where $S_{f}$ is the water saturation of all connected fractures and $S_{r}$ is the residual fracture saturation. Equation 6-14 is used to determine the fraction of active fractures because it is mathematically simple. As discussed below, Equation 6-15 allows us to treat all the ramifications of the active fracture hypothesis (modified fracture capillarity, relative permeability, and fracture-matrix interaction reduction) in an integrated manner. As indicated in Section 7.2, this equation is also consistent with fractal flow patterns often observed in unsaturated flow systems. 


\subsubsection{Constitutive Relations}

Note that only the active fracture continuum, a portion of the total fracture continuum, contributes to flow and transport in fractures and fracture-matrix interaction. Therefore, fracture hydraulic properties should be defined for active fractures. The effective water saturation of active fractures, $S_{a e}$, is related to the effective water saturation in connected fractures, $S_{e}$, by (Liu et al. 1998 [DIRS 105729], p. 2636)

$$
S_{a e}=\frac{S_{e}}{f_{a}}=S_{e}^{1-\gamma}
$$

Because $S_{a e}$ is less than or equal to one, $\gamma$ should be less than or equal to one. The effective water saturation of active fractures is related to the actual water saturation in active fractures, $S_{a}$, by (Liu et al. 1998 [DIRS 105729], p. 2636)

$$
S_{a e}=\frac{S_{a}-S_{r}}{1-S_{r}}
$$

If all connected fractures are considered to be active in conducting water, the water capillary pressure for the fracture continuum may be described by the well-known van Genuchten (V-G) relation (Equation 6-1). In the AFM, however, the V-G capillary pressure relation is considered to be relevant for the active fracture continuum rather than for the whole fracture continuum. The capillary pressure for active fractures is determined by replacing $S_{e}$ in Equation 6-1 with $S_{a e}$ and rearranging to give

$$
P_{c}\left(S_{e}\right)=\frac{1}{\alpha}\left[S_{a e}^{-1 / m}-1\right]^{1 / n}=\frac{1}{\alpha}\left[S_{e}^{(\gamma-1) / m}-1\right]^{1 / n}
$$

Equation 6-18 rather than 6-1 should be used in flow simulations in the fracture continuum. Figure 6-14 shows fracture capillary pressure curves for several $\gamma$ values. For a given effective water saturation in connected fractures, a larger $\gamma$ value corresponds to a larger effective water saturation in active fractures, and, therefore, to a lower absolute value for capillary pressure.

The liquid-phase relative permeability for the active fracture continuum, $k_{a r}$, is directly determined by the effective water saturation of active fractures (Figure 6-14). However, as only a portion of the fractures are active, the relative permeability of the entire fracture continuum, $k_{r}$, should be the relative permeability of active fractures multiplied by $f_{a}$, or (Liu et al. 1998 [DIRS 105729], p. 2636).

$$
k_{r}=f_{a} k_{a r}=S_{e}^{\gamma} k_{a r}
$$

where $k_{a r}$ can be given by the following V-G permeability relation (Liu et al. 1998 [DIRS 105729], p. 2636):

$$
k_{a r}=S_{a e}{ }^{1 / 2}\left[1-\left\{1-S_{a e}{ }^{1 / m}\right\}^{m}\right]^{2}=S_{e}^{(1-\gamma) / 2}\left[1-\left\{1-S_{e}{ }^{(1-\gamma) / m}\right\}^{m}\right]^{2}
$$


Combining Equations 6-16 and 6-20 yields

$$
k_{r}=S_{e}^{(1+\gamma) / 2}\left[1-\left\{1-S_{e}^{(1-\gamma) / m}\right\}^{m}\right]^{2}
$$

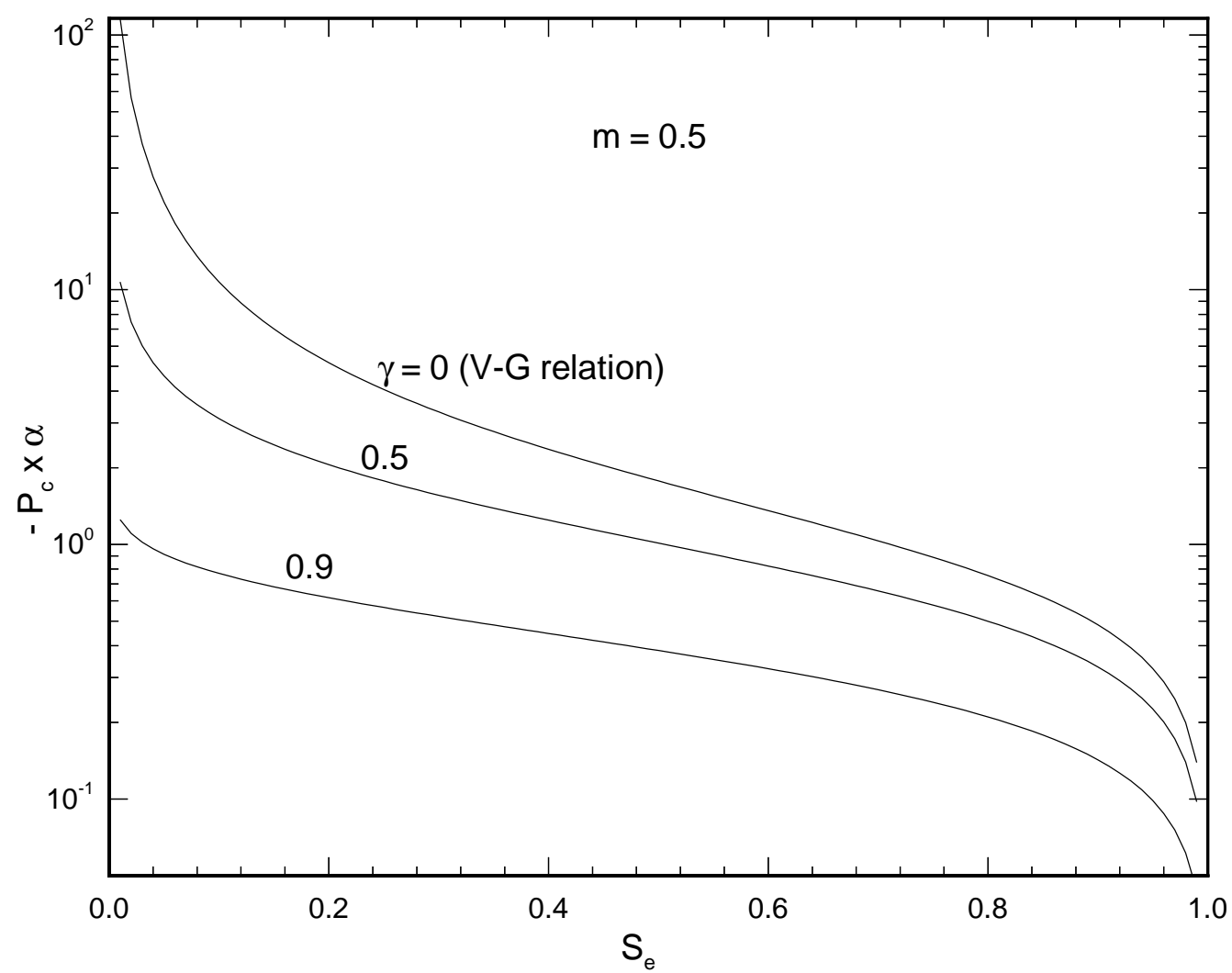

Source: Liu et al. 1998 [DIRS 105729], Figure 2.

Figure 6-14. Capillary Pressure Curves of Fracture Continuum for $\gamma=0,0.5$ and 0.9

Relative permeability $\left(k_{r}\right)$ curves are shown in Figure 6-15 for several $\gamma$ values. In general, the relative permeability $\left(k_{r}\right)$ is affected by $\gamma$ in a complicated manner for a given $S_{e}$. A larger $\gamma$ value, resulting in a higher effective water saturation in active fractures $\left(S_{a e}\right)$, gives rise to a larger value of $k_{a r}$. On the other hand, a larger $\gamma$ value corresponds to a smaller value of $f_{a}$. Because the former effect is dominant, a larger $\gamma$ value gives a larger relative permeability for a given effective water saturation of the fracture continuum, as indicated in Figure 6-15. 


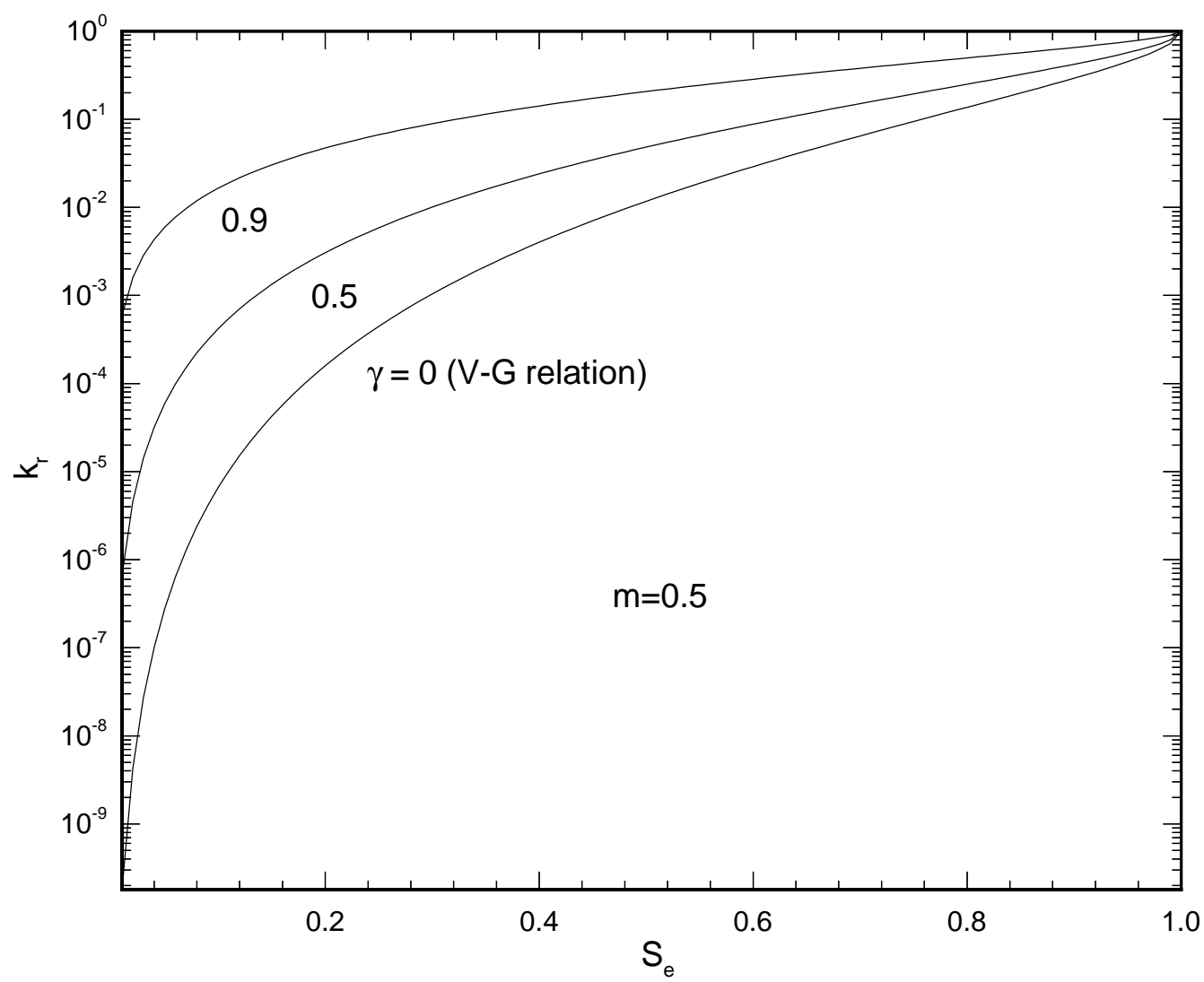

Source: Liu et al. 1998 [DIRS 105729], Figure 3.

Figure 6-15. Relative Permeability Curves of Fracture Continuum for $\gamma=0,0.5$ and 0.9

In the AFM, a term called the fracture-matrix interface-area reduction factor (R) accounts for three features of fingering flow that reduce fracture-matrix interaction. First, the average interface area between mobile water (saturated liquid water segments) in an active fracture and the surrounding matrix is smaller than the geometric interface area. Second, the number of active fractures is smaller than that of connected fractures. Conventionally, all the connected fractures were considered to contribute to fracture-matrix interaction. Third, average active fracture spacing is much larger than that for connected fractures. Under the quasi-steady-state condition, flow and transport between fractures and surrounding matrix is inversely proportional to the corresponding fracture spacing. Based on these considerations and Equation 6-14, Liu et al. (1998 [DIRS 105729], pp. 2636-2638) derived an approximate expression for the reduction factor:

$$
R \cong S_{e}^{1+\gamma}
$$

Note that the AFM uses a combination of the volume-averaged continuum method and a simple filter to deal with fracture flow and transport. Inactive fractures are filtered out in modeling fracture-matrix interaction, flow, and transport in the fracture continuum. Note that use of the filtering method adds a capability to continuum approaches for capturing dispersed fingering flow at a subgrid scale. This addresses a major limitation of continuum approaches, which was 
considered to be their inability to represent subgrid-scale fingering flow (Glass et al. 1996 [DIRS 139237], p. 7).

Note that the $\gamma$ factor may be interpreted as a measure of the "activity" of connected fractures. Generally speaking, a smaller $\gamma$ value corresponds to a larger number of active fractures in a connected fracture network. For example, $\gamma=0$ results in $f_{a}=1$ in Equation 6-14, corresponding to all connected fractures being active. On the other hand, $\gamma=1$ corresponds to zero fracture capillary pressure (Equation 6-18), indicating that all active fractures are saturated. In the latter case, the fraction of active fractures is very small for small percolation fluxes because relatively high fracture permeabilities measured at Yucca Mountain allow most of the water to flow through only a few fractures. The $\gamma$ value cannot be determined by laboratory measurements of fractured core samples, because $\gamma$ represents an inherently large-scale process. Instead, it must be inferred through inverse modeling using the site-scale UZ model and field-scale data collected at Yucca Mountain (Liu et al. 1998 [DIRS 105729], p. 2638). Note that preferential (fingering) flow in unsaturated fractures is captured by the AFM-based continuum approach even when a coarse numerical grid is used. For an extreme example, the fracture pore velocity simulated with the AFM (for a $\gamma$ value of 0.8 ) is about $10^{-4} \mathrm{~m} / \mathrm{s}$ (in the TSw unit) (Liu et al. 1998 [DIRS 105729], Figure 12), or 3,153.6 m/yr. This velocity corresponds to very fast preferential flow paths. (It should be emphasized that this velocity is not realistic for the UZ, and only used for demonstrating the capability of the AFM in capturing a large range of fast flow behavior.)

\subsection{MODEL UNCERTAINTY}

The objective of this report is to document the conceptual model and numerical approaches for UZ flow and transport under ambient conditions. These models have been developed mainly based on the geologic setting of the UZ and a variety of data collected from the UZ, in addition to theoretical and numerical studies conducted in the last two decades (Sections 6.1 to 6.3). However, these models are simplifications and/or approximations of the real-world system and subject to uncertainties.

Flow focusing - While the conceptual model for UZ flow has been supported by many field observations (as discussed in this report), some conceptual aspects related to focused flow at different scales are not fully understood. The flow focusing mechanism has been partially considered by the use of the AFM in site-scale models. The AFM considers only a portion of fractures in a connected, unsaturated fracture network to contribute to liquid water flow, while others are simply bypassed. The AFM has been implemented in the UZ flow and transport models (BSC 2004 [DIRS 169861]; BSC 2004 [DIRS 164500]).

Flow paths below the repository - Flow paths below the repository are critical for radionuclide transport from the repository to water table. Because the data available for characterizing these flow paths and the associated rock properties are very limited, the current conceptual model for flow below the repository (Section 6.1.2) is subject to uncertainty. However, the good matches between chloride and strontium data in samples below the repository and simulation results from the site-scale UZ flow model (BSC 2004 [DIRS 169861], Section 7) indicate that the UZ flow model (based on the current conceptual model) essentially captures important flow paths below the repository. 
The continuum approach - The UZ flow model is based on the continuum approach (that conceptualizes a fracture network as a continuum), as discussed in Section 6.3. The continuum approach is a practical approach for dealing with a large-scale, average UZ flow process, and it is generally supported by the consistency between continuum-approach-based model results and field observations (Section 6.3.3). However, it is uncertain that the continuum approach is adequate for capturing effects of highly localized (or focused) flow paths.

The AFM - The AFM is a key element of UZ flow and transport model (BSC 2004 [DIRS 169861]; BSC 2004 [DIRS 164500]). The validity of the AFM is presented in Section 7. The AFM-based simulation results are shown to be consistent with the relevant field observations and the AFM itself is also theoretically related to fractal flow patterns often observed in unsaturated systems (Section 7). However, it is uncertain that the AFM adequately captures the complex flow behavior in the unsaturated fractures.

A sensitivity study of the AFM parameter on flow and transport simulations is presented in BSC (2004 [DIRS 169861], Section 6.8). The study shows that values for the AFM parameter that are used in the current UZ flow and transport models likely underestimate radionuclide travel times from the repository to water table. Therefore, the current UZ flow and transport models (based on these parameter values) are conservative.

van Genuchten relations - UZ flow and transport models use van Genuchten (1980 [DIRS 100610]) relationships developed especially for porous media for describing unsaturated flow in fractures. Liu and Bodvarsson (2001 [DIRS 160110]) reported that van Genuchten (1980 [DIRS 100610]) relationships may be valid for low water saturations in the fracture continuum (corresponding to the ambient conditions), but underestimate fracture relative permeability for a large range of relatively high water saturations. 


\section{VALIDATION}

This section documents activities to validate the AFM and the corresponding model validation results.

\subsection{MODEL VALIDATION ACTIVITIES}

The AFM has been used in UZ flow and transport models. The AFM is a modification of the traditional dual-continua model that specifies a constitutive relationship for unsaturated flow in fractures. This modification is motivated by field observations showing that under unsaturated conditions, not all fractures in a connected fracture network actually carry water flow (Liu et al. 1998 [DIRS 105729]). The AFM has been reviewed and published by Liu et al. (1998 [DIRS 105729]), and several papers (e.g., Houseworth et al. 2003 [DIRS 164394]; Liu et al. 2003 [DIRS 162470]; Zhou et al. 2003 [DIRS 162133]; Xu et al. 2003 [DIRS 162124]) describing simulation results based on the AFM have been published in the Journal of Contaminant Hydrology, a peer-reviewed international journal publishing scientific articles pertaining to the contamination of groundwater. Section 7.2 shows that the AFM is approximately consistent with a fractal-distribution behavior for liquid water (characterized by a fractal dimension) in a fracture network. The fractal flow behavior has been often reported in the literature for unsaturated flow and multiphase flow systems. The fractal analysis is used to analyze the fracture coating data from UZ, indicating that the UZ may also exhibit fractal flow behavior. This consistency provides an important theoretical foundation for the AFM. Section 7.3 demonstrates that the AFM also captures behavior of film flow that has been regarded as a potentially important mechanism for water flow in unsaturated fractures (e.g., Tokunaga and Wan 1997 [DIRS 139195]; Tokunaga et al. 2000 [DIRS 152914]), which further supports the usefulness of the AFM. The validation of the AFM with field observations from the Yucca Mountain UZ, including fracture coating data and carbon-14 data, is documented in Section 7.4.

The criteria of model validation are given in the TWP (BSC 2004 [DIRS 169654], Section 2.2.1; BSC 2002 [DIRS 160819], Section I-1-3). The AFM is an element of the TSPA for the license application component model of UZ flow. As stated in the TWP (BSC 2004 [DIRS 169654], Section 2.2.1), models supporting that TSPA for the license application component require Level I validation. The criteria for model validation using carbon-14 data and fracture coating data are: (a) that simulated water travel times are sensitive to AFM parameters and within the range of measured data for the TSw unit; and (b) that the simulated active portion of the fractures is similar to the percentage of fractures with mineral coatings; or (c) that other factors, not directly related to the AFM, can explain any significant disparity between simulations and the observed results.

The model validation criteria mentioned above allow for evaluating the AFM by showing whether model results based on the AFM are consistent with different field observations simultaneously when the relevant results are sensitive to the AFM parameters. Because carbon-14 data and fracture coating data are signatures of past flow and transport processes in the UZ, these data provide important insight into the flow and transport processes under ambient conditions and are directly related to the intended use of the AFM. Consistency of the AFM with these field observations (and the fractal flow behavior often observed in unsaturated systems) is 
able to demonstrate that the AFM is sufficiently accurate for its intended use (for modeling UZ flow and transport) given the uncertainties represented in the UZ flow and transport models that implement the AFM. As shown in Section 7.4, the criteria ((a) and (b)) are met for the suitable AFM parameter values.

In numerical simulations reported in this section, codes TOUGH2 V1.4 (LBNL 2000 [DIRS 146496]) and T2R3D V1.4 (LBNL 1999 [DIRS 146654]) are used because they have been comprehensively tested and widely used for modeling UZ flow and transport.

The model validation activities documented in Sections 7.2 and 7.4 were published by Liu et al. (2003 [DIRS 166106]) in Vadose Zone Journal, a leading scientific journal for vadose zone hydrology. The film-flow model (Section 7.3) was published by Liu (2004 [DIRS 170129]) in Hydrogeology Journal, the official Journal of the International Association of Hydrogeologists. Both of these two journals are peer-reviewed scientific journals.

The key scientific notebooks and the data tracking numbers (DTNs) of the specific input data sets for the model validation activities in this section are presented in Tables 7-1 and 7-2, respectively.

Table 7-1. Scientific Notebooks

\begin{tabular}{|l|l|l|l|}
\hline LBNL Scientific Notebook ID & \multicolumn{1}{|c|}{ M\&O Scientific Notebook ID } & \multicolumn{1}{|c|}{ Relevant Pages } & \multicolumn{1}{c|}{ Citation } \\
\hline YMP-LBNL-HHL-GZ-1 & SN-LBNL-SCI-227-V1 & $\begin{array}{l}8-19,21-54,70-71,73-84, \\
87\end{array}$ & $\begin{array}{l}\text { Wang 2003 } \\
\text { [DIRS 161654] }\end{array}$ \\
\hline YMP-LBNL-YSW-3 & SN-LBNL-SCI-199-V1 & $92-99$ & $\begin{array}{l}\text { Wang 2003 } \\
\text { [DIRS 161654] }\end{array}$ \\
\hline
\end{tabular}

LBNL= Lawrence Berkeley National Laboratory; $\mathrm{M} \& \mathrm{O}=$ management and operating contractor; $\mathrm{YMP}=\mathrm{Yucca}$ Mountain Project

Table 7-2. Data Tracking Numbers for Input Data Used

\begin{tabular}{|l|l|}
\hline \multicolumn{1}{|c|}{ Data Description } & \multicolumn{1}{c|}{ DTN } \\
\hline 1-D site-scale calibrated properties: supporting files & LB02091DSSCP3I.001 [DIRS 161292] \\
\hline $\begin{array}{l}\text { 1-D Calibrated hydrologic properties for UZ model: Data } \\
\text { Summary }\end{array}$ & LB02091DSSCP3I.002 [DIRS 161433] \\
\hline $\begin{array}{l}\text { Supporting files of calibrated hydrologic properties for UZ } \\
\text { model: Mean Infiltration }\end{array}$ & LB0208UZDSCPMI.001 [DIRS 161285] \\
\hline Yucca Mountain Project borehole locations & MO9906GPS98410.000 [DIRS 109059] \\
\hline Diffusion of sorbing and non-sorbing radionuclides & LA000000000034.002 [DIRS 148603] \\
\hline Infiltration maps for Three Infiltration Scenarios & GS000308311221.005 [DIRS 147613] \\
\hline 3-D UZ numerical grid & LB03023DKMGRID.001 [DIRS 162354] \\
\hline $\begin{array}{l}\text { Line Survey information from ESF Obtained to Estimate } \\
\text { Secondary Mineral Abundance }\end{array}$ & GS980308315215.008 [DIRS 107355] \\
\hline Fracture Properties for UZ Model Layer & LB0205REVUZPRP.001 [DIRS 159525] \\
\hline Chemical \& Isotopic Composition of Pore Water and Gas & GS961108312271.002 [DIRS 121708] \\
\hline Carbon 13 and Carbon 14 Abundance in Water and Gas & MO0012CARB1314.000 [DIRS 153398] \\
\hline
\end{tabular}

1-D=one-dimensional; 3-D= three-dimensional; DTN=data tracking number; ESF=Exploratory Studies Facility; UZ=unsaturated zone 
Finally, AP-SIII.10Q and AP-2.27Q also require documentation of decisions or activities that are implemented to generate confidence in the model during model development, including the following:

(1) Selection of input parameters and/or input data, and a discussion of how the selection process builds confidence in the model [AP-SIII.10Q 5.3.2(b)(1) and AP-2.27Q Attachment 3 Level I (a)]

Because the AFM is a conceptual model describing fracture-matrix interaction, its development does not involve input parameter values or input data (See Section 6.3.7).

(2) Description of calibration activities, and/or initial boundary condition runs, and/or run convergences and a discussion of how the activity or activities build confidence in the model. Inclusion of a discussion of impacts of any non-convergence runs. [AP-SIII.10Q 5.3.2(b)(2) and AP-2.27Q Attachment 3 Level 1 (e)]

Because the AFM is a conceptual model describing fracture-matrix interaction, its development does not involve calibration activities and/or the use of initial boundary conditions (See Section 6.3.7).

(3) Discussion of the impacts of uncertainties to model results. [AP-SIII.10Q 5.3.2(b)(3) and AP-2.27Q Attachment 3 Level 1 (d) and (f)]

Because the AFM is not a process model, its development does not generate numerical model results (See Section 6.3.7).

(4) Formulation of defensible assumptions and simplifications. [AP-2.27Q Attachment 3 Level I (b)]

As discussed in Section 6.3.7, the development of the AFM is based on assumptions and simplifications accepted in the scientific community. The AFM was published in a peer-reviewed, highly regarded scientific journal Water Resources Research (Liu et al. 1998 [DIRS 105729])

(5) Consistency with physical principles, such as conservation of mass, energy, and momentum. [AP-2.27Q Attachment 3 Level I (c)]

As discussed in Section 6.3.7, the development of the AFM is consistent with fingering flow in unsaturated fractures.

\subsection{CONSISTENCY BETWEEN AFM AND FRACTAL FLOW BEHAVIOR IN UNSATURATED SYSTEMS}

\subsubsection{Evidence of Fractal Flow-Patterns in Unsaturated or Multiphase Flow Systems}

Fractals have been shown to be a common language for describing many different natural phenomena (Mandelbrot 1983 [DIRS 160848]). A vast literature exists for discussing the validity of the fractal concept in a great number of fields. Many recent studies show that complex flow 
patterns in unsaturated or multiphase flow systems can be described by fractals. For example, viscous fingering in porous media has been experimentally shown to be fractal (Feder 1988 [DIRS 160844], Chapter 4). (The problem of viscous fingering in porous media is of central importance in oil recovery.) Flury and Flühler (1995 [DIRS 160845]) fitted a diffusion-limited-aggregation (DLA) model for solute transport in one of three field plots under unsaturated conditions, and then predicted solute transport reasonably well for the other two. A detailed description of DLA is given in Flury and Flühler (1995 [DIRS 160845]). The DLA generates fractal patterns (Feder 1988 [DIRS 160844], pp. 53-56). Persson et al. (2001 [DIRS 160840]) further confirms the finding of Flury and Flühler (1995 [DIRS 160845]) by showing that flow patterns resulting from an unsaturated field site resemble fractals. Glass (1993 [DIRS 160751]) demonstrated that unsaturated flow patterns in individual fractures can be reasonably modeled by a percolation-based model. Percolation-based models generate fractal patterns (Feder 1988 [DIRS 160844], Section 7.8; Stauffer and Aharony 2001 [DIRS 160846], Section 6.6).

Although detailed experimental studies of unsaturated flow patterns in natural fracture networks are still lacking in the literature, unsaturated flow patterns in a fracture network are expected to be (at least approximately) fractal also. This expectation is supported by fracture coating data from the UZ of Yucca Mountain. As will be discussed in Section 7.4, fracture coating is generally a signature of water flow paths. Detailed line survey data for coated fracture is available from DTN: GS980308315215.008 [DIRS 107355]. Since the middle nonlithophysal (Tptpmn) unit (corresponding to UZ model layer tsw34) has the largest number of survey intervals, data from this unit are analyzed using the box counting method that will be discussed in Section 7.2.2. The locations of the coated fractures along the survey line form a set of points in a one-dimensional space. For a given box size (length of a segment) $l$, there are $30 / l$ small boxes (or segments) for a given survey interval that is $30 \mathrm{~m}$ long. $N$ in this subsection denotes total numbers of boxes that cover at least one location of the coated fractures (along the survey line) for all the survey intervals. The determination of $N$ as a function of $l$ is given in Appendix B. Figure 7-1 shows that the observed $N$ values as a function of $l$ can be fitted by a power function with a power of -0.5 that corresponds to a fractal dimension of 0.5 for the set of points. A more detailed discussion of fractal dimension will be given in Section 7.2.2. This indicates that the analysis result from coated fractures is consistent with a fractal flow pattern in the corresponding fracture network. Note that for a given spatial pattern, fractal dimensions are different for different Euclidean dimensions of a space. The curve fitting is performed using Tecplot. 


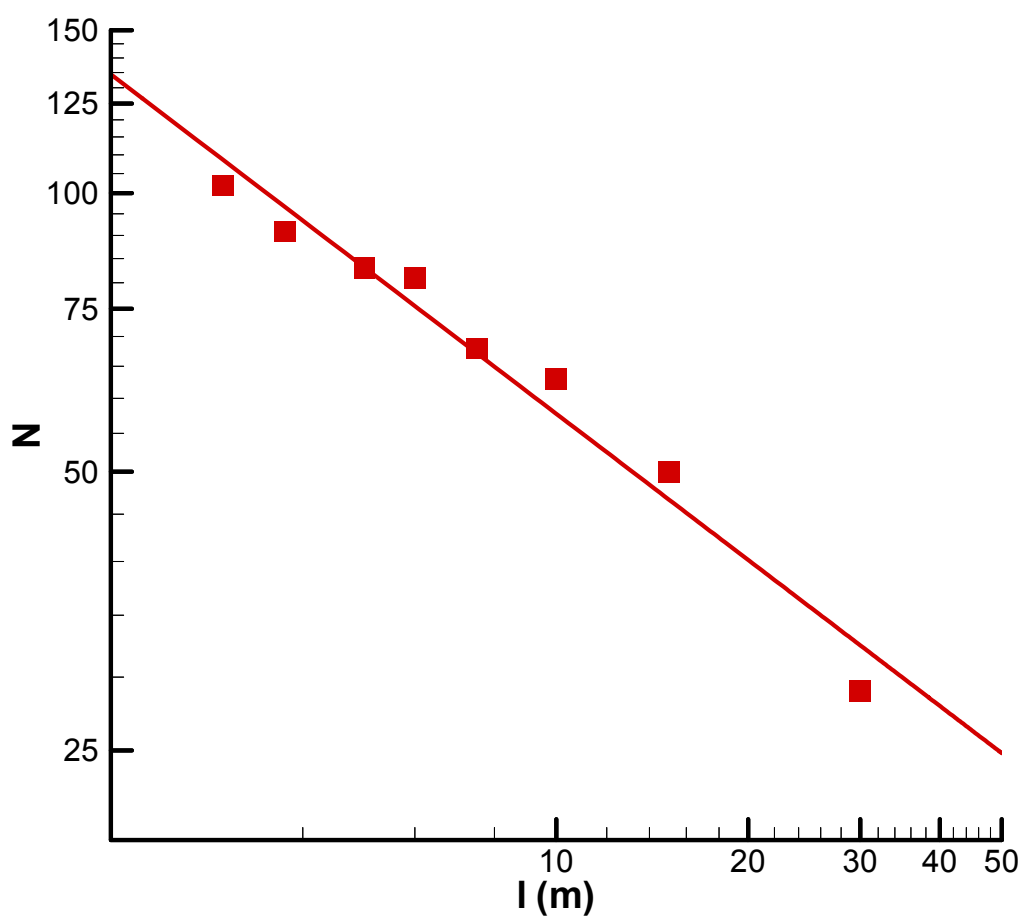

Source: DTN: GS9803083152115 [DIRS107355].

Figure 7-1. Relation Between N and I (Appendix B). The Data Points Correspond to Observed Values for the Tptpmn Unit

\subsubsection{Fractal Dimension}

A fractal pattern is characterized by the fractal dimension $\left(d_{f}\right)$ that is generally noninteger and less than the corresponding Euclidean dimension of a space, $D$. Among the different definitions for fractal dimension (Feder 1988 [DIRS 160844], Section 2.3), the most straightforward definition is based on "box counting." In this case, the fractal dimension is determined from the following equation by counting the number $(N)$ of "boxes" (e.g., square and cubic for two-dimensional and three-dimensional problems, respectively), needed to cover a spatial pattern, as a function of the box size (l) (Feder 1988 [DIRS 160844], pp. 14-15):

$$
N(l)=\left(\frac{L}{l}\right)^{d f}
$$

where $L$ refers to the size of whole spatial domain under consideration. Figure 7-2 shows a box-counting procedure for a spatial pattern with $d_{f}=1.6$ in a two-dimensional domain with size $L$ (Yamamoto et al. 1993 [DIRS 160843], Figure 3). 
(a) $\mathrm{I}=\mathrm{L}$

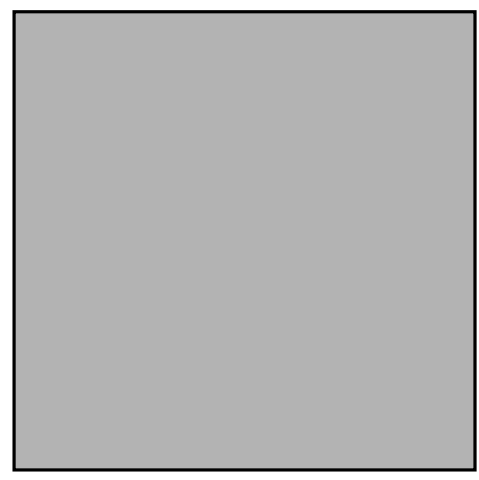

(c) $\mathrm{I}=\mathrm{L} / 4$

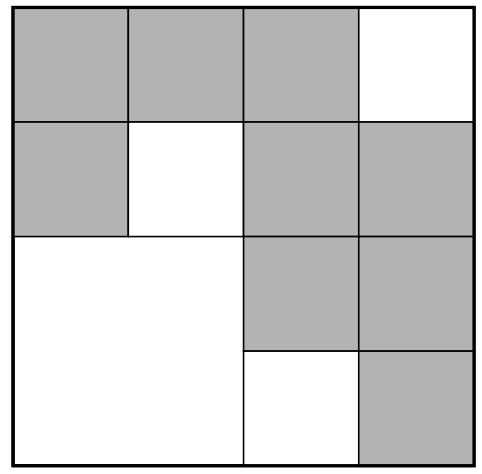

(b) $\mathrm{I}=\mathrm{L} / 2$

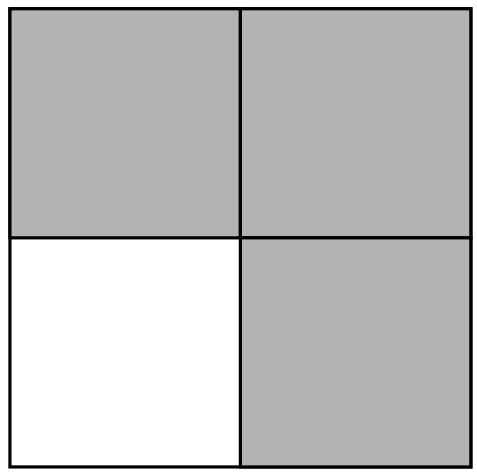

(d) $\mathrm{I}=\mathrm{L} / 8$

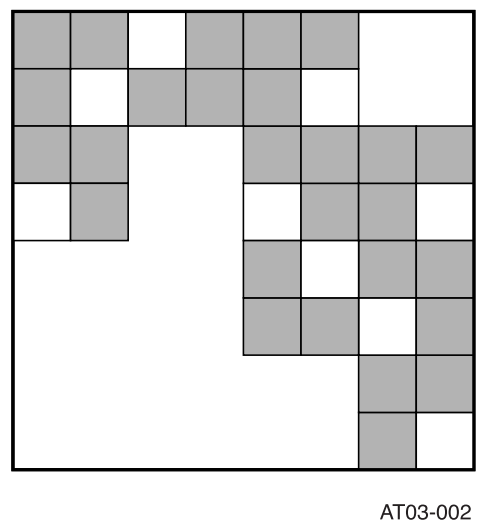

Figure 7-2. Schematic Showing Demonstration of "Box" Counting Procedure for Several Box Sizes, with the Shaded Areas Containing Saturation and Active Flow

Obviously, if a spatial pattern is uniformly distributed in space, the fractal dimension will be identical to the corresponding Euclidean dimension. In this case, the box number, $N^{*}$, and the box size $l$ have the following relation

$$
N *(l)=\left(\frac{L}{l}\right)^{D}
$$

\subsubsection{Consistency of the AFM and a Fractal Flow Pattern}

Consider Figure 7-2 to be a gridblock containing a fracture network and the corresponding flow pattern in the fracture network to be fractal. Only a portion of the medium within a gridblock contributes to water flow (Figure 7-2). This is conceptually consistent with the AFM (Liu et al. 1998 [DIRS 105729]). Note that in Figure 7-2, a box is shaded if it covers one or more fractures (or fracture segments) that conduct water. For simplicity, further consider that fractures are randomly distributed in space and thus the dimension for water saturation distribution is the corresponding Euclidean dimension when all the connected fractures actively conduct water. 
Combining Equations 7-1 and 7-2 gives

$$
[N(l)]^{1 / d} f=\left[N^{*}(l)\right]^{1 / D}
$$

The average water saturation $(S)$ for the whole gridblock (Figure 7-2) is determined as

$$
S=\frac{V}{l^{D} \phi N^{*}(l)}
$$

where $V$ is the total water volume (excluding residual water) in fractures within the gridblock (Figure 7-2), and $\phi$ is fracture porosity. Similarly, the average water saturation $\left(S_{b}\right)$ for shaded boxes with a size of $l$ is given as

$$
S_{b}=\frac{V}{l^{D} \phi N(l)}
$$

From Figure 7-2, it is obvious that there exists a box size $l_{l}<L$ satisfying:

$$
\frac{V}{l_{1}^{D} \phi}=1
$$

Based on Equations 7-3 to 7-6, the average saturation for shaded boxes with a size of $l_{l}, S_{b l}$, can be expressed by

$$
S_{b 1}=S^{\frac{d_{f}}{D}}
$$

Because a fractal is similar at different scales, the procedure for deriving Equation 7-7 from a grid-block with size $L$ can be applied to shaded boxes with a smaller size $l_{l}$. In this case, for a given box size smaller than $l_{l}$, the number of shaded boxes will be an averaged number for those within the relatively large shaded boxes with a size of $l_{1}$. Again, one can find a box size $l_{2}<l_{1}$ to obtain a saturation relation:

$$
S_{b 2}=\left(S_{b 1}\right)^{\frac{d_{f}}{D}}=S^{\left(\frac{d_{f}}{D}\right)^{2}}
$$

The procedure to obtain Equation 7-8 can be continued until it reaches an iteration level $n^{*}$ at which all the shaded boxes with a size of $l_{n}$ cover active fractures only. The resultant average saturation for these shaded boxes is

$$
S_{b n}=(S)^{\left(\frac{d_{f}}{D}\right)^{n^{*}}}
$$


By definition of active fractures, $S_{b n}$ should be equivalent to the effective saturation of active fractures. It is remarkable that Equation 7-9 is similar to Equation 6-15, obtained from a key hypothesis of the AFM that the fraction of active fractures in an unsaturated fracture network is a power function of the average effective saturation of the network. Comparing these two equations yields:

$$
\gamma=1-\left(\frac{d_{f}}{D}\right)^{n^{*}}
$$

Equation 7-10 provides the first theoretical relation between the parameter $\gamma$ and the fractal dimension for a fractal flow system, while $\gamma$ was initially developed as an empirical parameter (Liu et al. 1998 [DIRS 105729]). Therefore, the AFM essentially captures fractal flow behavior at the subgridblock scale $\left(d_{f}<D\right)$, whereas traditional continuum approaches assume a uniform flow pattern (or effective-saturation distribution) at that scale (corresponding to $d_{f}=D$ or $\gamma=0$ ). In other words, the AFM can be used for simulating fractal flow behavior in an unsaturated fracture network that cannot be handled by the traditional continuum approach.

Equation 7-10 implies that in the fractal flow model, $\gamma$ is not a constant, but a function of saturation, because both iteration level $n^{*}$ and $d_{f}$ may be dependent on water saturation for a given fracture network. However, a constant $\gamma$ is a reasonable treatment at least for a limited range of water saturations (or flow conditions), which is the case for the Yucca Mountain UZ where fracture saturation is typically less than 10 percent under ambient conditions. This is because $\gamma$ will not change significantly for a limited range of saturation. It is not totally clear how $\gamma$ depends on the other hydraulic parameters for a large range of water saturations. Experimental evidence suggests that $\gamma$ is a weak function of saturation (at least for porous media), which will be discussed below. It is obvious from the derivation of Equation 7-10 that the fractal flow concept and Equation 7-10 can be applied to porous media also, as long as fingering flow patterns in them are fractals. Therefore, results from porous media can be used to conceptually evaluate the relation between $\gamma$ and water saturation for unsaturated fracture networks.

Based on laboratory experimental observations collected by applying water at the top of the corresponding porous media, Wang et al. (1998 [DIRS 155770], pp. 2188-2189) reported a relation between flow conditions and a parameter, $F$, defined as the ratio of horizontal cross-sectional area occupied by fingers to the total cross-sectional area. $F$ corresponds to $f_{a}$, defined as the portion of active fractures in a fracture network (Liu et al. 1998 [DIRS 105729]). Wang et al. (1998 [DIRS 155770], pp. 2188-2189) related $F$ to the ratio of average water flux through the whole cross-sectional area, $q$, to saturated hydraulic conductivity of the porous medium, $K_{s}$, by

$$
F \approx\left(\frac{q}{K_{S}}\right)^{1 / 2}
$$


for $q / K_{s}=0.4-1.0$. By definition, the average water flux within fingers $\left(q_{F}\right)$ can be related to $q$ by

$$
q_{F}=\frac{q}{F}
$$

and the average water saturation of fingers, $S_{F}$, can be related to the average water saturation for the whole cross-section area, $S_{e}$, by

$$
S_{F}=\frac{S_{e}}{F}
$$

It is expected that flow within a gravitational finger is gravity dominated. In this case:

$$
\frac{q_{F}}{K_{S}}=k_{r}=S_{F}^{\beta^{*}}
$$

Equation 7-14 uses the Brooks-Corey (Brooks and Corey 1964 [DIRS 156915]) model for describing relative permeability $\left(k_{r}\right)$-saturation relationship. $\beta^{*}$ is a constant. Combining Equations 7-11 to 7-14 yields

$$
F=\left(S_{e}\right)^{\frac{\beta^{*}}{1+\beta^{*}}}
$$

Comparing the above equation with Equation 6-14 gives

$$
\gamma=\frac{\beta^{*}}{1+\beta^{*}}
$$

Therefore, $\gamma$ is a constant under certain conditions in porous media. Consequently, it is expected that $\gamma$ should be a weak function of saturation for unsaturated fracture networks if fingering flow patterns in a porous medium are considered to be an analogue of flow patterns in the networks.

Equation 7-16 cannot be directly used for estimating $\gamma$ values for fracture networks (in the AFM) because detailed flow mechanisms are different for unsaturated fractured rock and porous media. It also needs to be emphasized that Equation 7-16 is valid for porous media under a condition of $q / K_{s}=0.4-1.0$ (Wang et al. 1998 [DIRS 155770], pp. 2188-2189). The relation between $\gamma$ and other hydraulic properties has not been established for a fracture network.

\subsection{COMPARISON WITH A FILM-FLOW MODEL}

Film flow on fracture surfaces may be an important mechanism for fast flow in unsaturated fractured rocks (Tokunaga and Wan 1997 [DIRS 139195]), although the importance of the film flow in the UZ is still an issue of debate (Pruess 1999 [DIRS 104250]). As an alternative conceptual model for unsaturated flow in fractures, a model assuming pure film flow within unsaturated fractures is developed to compare with the AFM. The major objective of this 
comparison is to demonstrate that fast flow behavior caused by film flow is already essentially captured by the current version of the AFM.

\subsubsection{Film-Flow Model}

Tokunaga et al. (2000 [DIRS 152914], pp. 1743-1744) both conceptually and experimentally demonstrated similarities between film flow on rough fracture surfaces and unsaturated flow in porous media. They also found that measured film thickness-potential relation data could be fitted very well by a power function, which may be related to unsaturated flow in porous media with fractal pore-size distributions (Tokunaga et al. 2000 [DIRS 152914], p. 1743).

Constitutive relationships for porous media with fractal pore-size distributions have been extensively studied. The most commonly used constitutive-relationship model for these porous media is the Brooks-Corey model, although this model was not initially developed based on fractal concepts (Brooks and Corey 1964 [DIRS 156915]). The Brooks-Corey model can be formulated as follows (Liu and Bodvarsson 2001 [DIRS 160110])

$$
\begin{gathered}
S_{e}=\left|P_{c} / P_{d}\right|^{-\lambda} \\
k_{r}=\tau S_{e}{ }^{\left(1+\frac{2}{\lambda}\right)} \\
\tau=S_{e}{ }^{2}
\end{gathered}
$$

where $P_{c}$ is the capillary pressure, $P_{d}$ is the air entry pressure, $\lambda$ is a dimensionless index of pore size distribution, $k_{r}$ is the relative permeability, $\tau$ is the tortuosity factor, and $S_{\mathrm{e}}$ is the effective saturation. Note that Equation 7-17a is valid when absolute values of $P_{c}$ are larger that the absolute value of $P_{d}$.

Film flow is closely related to fracture surface roughness, which has also been studied extensively (National Research Council 1996 [DIRS 139151]). It has been found that the surface topographies for fractures could be represented in terms of fractal geometry. Although an equivalent "pore-size distribution" for a fracture surface has not been defined, it is conceptually reasonable to hypothesize (based on the conception of Tokunaga et al. (2000 [DIRS 152914], p. 1743)) that film flow on a fractal fracture surface is similar to an unsaturated water flow process in a porous medium with fractal pore-size distribution. Based on this hypothesis, the Brooks-Corey model can be adopted to develop a constitutive-relationship model for film flow. Considering average film thickness, $f$, and film transmissivity, $T$, to be analogues of effective water saturation and hydraulic conductivity (Brooks and Corey 1964 [DIRS 156915]), respectively, for a porous medium, one can obtain

$$
\frac{f}{f_{\text {ref }}}=\left|\frac{P_{c}}{P_{\text {ref }}}\right|^{-\lambda}
$$




$$
\begin{gathered}
\frac{T}{T_{r e f}}=\left(\frac{f}{f_{r e f}}\right)^{\left(\eta^{*}+1+\frac{2}{\lambda}\right)} \\
\tau \propto f^{\eta^{*}}
\end{gathered}
$$

where $f_{\text {ref }}$ and $T_{\text {ref }}$ are average film thickness and film transmissivity, respectively, for a reference capillary pressure $P_{\text {ref }}$, and $\eta^{*}$ is an empirical constant. Upper limits for $f$ and $T$, unlike their counterparts for porous media, cannot be defined for unbounded fracture surfaces (Tokunaga et al. 2000 [DIRS 152914]). Here, $\lambda$ is considered to be a parameter characterizing the geometry of the fracture surface. Since film flow is essentially two-dimensional and pore-scale water flow in a porous medium is essentially three-dimensional, different tortuosity factors are expected for the two different cases.

Experimental observations of Tokunaga and Wan (1997 [DIRS 139195]) and Tokunaga et al. (2000 [DIRS 152914]) are used to verify the proposed constitutive-relationship model for film flow. Specifically, we examine whether Equation 7-18 can match the data. Note that the two data sets used here are measured for very different fracture surfaces, corresponding to a natural fracture surface of Bishop Tuff (Tokunaga and Wan 1997 [DIRS 139195], p. 1298) and an artificially roughened surface (Tokunaga et al. 2000 [DIRS 152914], p. 1740). Comparisons with these two data sets provide a unique opportunity to examine the validity (or robustness) of the proposed model under different conditions.

Tokunaga et al. (2000 [DIRS 152914], p. 1743, Figure 6) showed that the measured film thickness - potential relation data could be fitted by a power function corresponding to $\lambda=0.37$ in Equation 7-18a. The curve fitting is performed using Tecplot for all the relevant figures in this subsection. Figure 7-3 shows a match of Equation 7-18b with the surface transmissivity-film thickness relation (Appendix A of this report) of Tokunaga et al. (2000 [DIRS 152914]), which was derived from their measurements, indicating that the relation can be represented by a power function with a power value of 6.91 . Using $\lambda=0.37$ and the power value of 6.91, we obtain $\eta^{*}=0.50$ from Equation 7-18b. Figure 7-4 shows matches of Equations 7-18a and 7-18b with the data of Tokunaga and Wan (1997 [DIRS 139195]), again indicating that the data are very well represented by power functions. The resultant $\lambda$ and $\eta^{*}$ values are 1.36 and -1 , respectively. Different $\lambda$ values are obtained for the two data sets, because of the differences between the corresponding fracture surfaces, as previously mentioned. Considerably different $\eta^{*}$ values are also obtained for the two surfaces as a potential result of different ranges of average film thickness involved in the two data sets (Figures 7-3 and 7-4). Further examination of the relation from Tokunaga et al. (2000 [DIRS 152914]) (Figure 7-3) seems to indicate that it can be more accurately represented by different power functions for different thickness ranges. For example, Figure 7-5 shows a match of Equation 7-18b to the data of Tokunaga et al. (2000 [DIRS 152914]) that exclude measurements below the thickness of 2 $\mu \mathrm{m}$, as compared with the match in Figure 7-3. The resultant power value is 5.67, corresponding to $\eta^{*}=-0.74$ (based on Equation $78 \mathrm{~b}$ and $\lambda=0.37$ given by Tokunaga et al. (2000 [DIRS 152914])). This is generally consistent with $\eta^{*}=-1$ for the data of Tokunaga and Wan (1997 [DIRS 139195]) (Figure 7-4), considering that their data involve larger values of average film thickness than those reported by Tokunaga et al. (2000 [DIRS 152914]). 
Theoretically, $\eta^{*}$ should be positive because a tortuosity factor should be smaller than one (Brooks and Corey 1964 [DIRS 156915]). The negative $\eta^{*}$ value results from the empirical nature of Equations 7-17 and 7-18. A similar situation was also reported for several different unsaturated porous media (Schaap and Leij 2000 [DIRS 160841]). Based on the above analyses, $\eta^{*}=-1$ seems to be reasonable for film flow with an average film thickness larger than $2 \mu \mathrm{m}$. In summary, while the proposed model may need to be further evaluated using more data sets, the excellent agreement between calculation results and experimental observations of Tokunaga and Wan (1997 [DIRS 139195]) and Tokunaga et al. (2000 [DIRS 152914]) supports the usefulness of the model for describing film flow in unsaturated fractures.

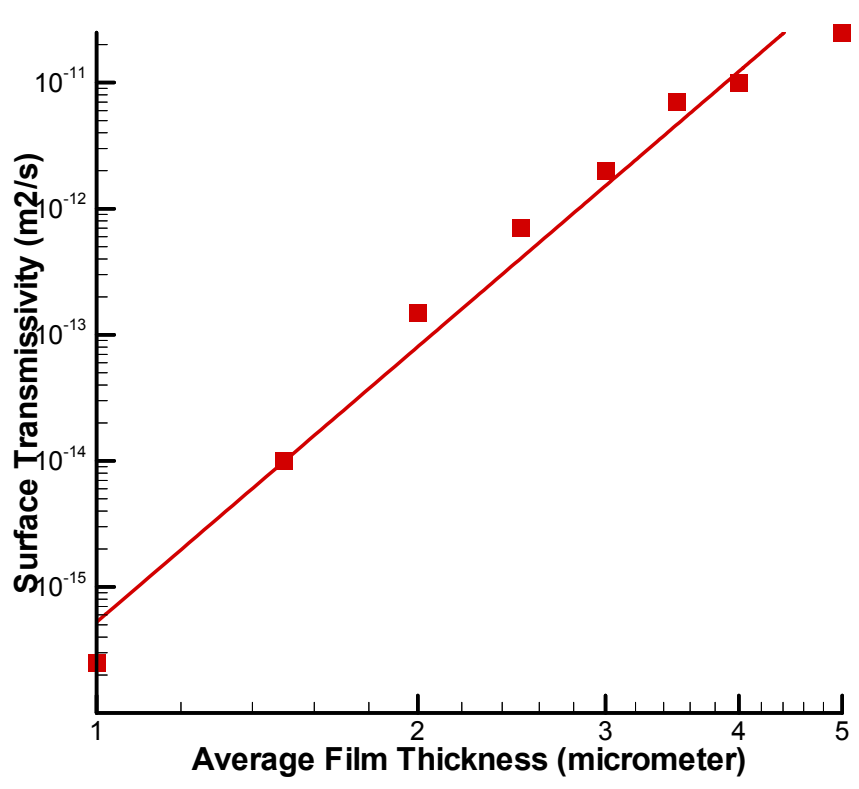

NOTE: Squares correspond to the surface transmissivity-film thickness relation (Appendix A) obtained from Figure 9 of Tokunaga et al. (2000 [DIRS 152914]).

Figure 7-3. Match of Equation 7-18b to Surface Transmissivity-Film Thickness Measurements 
(a)

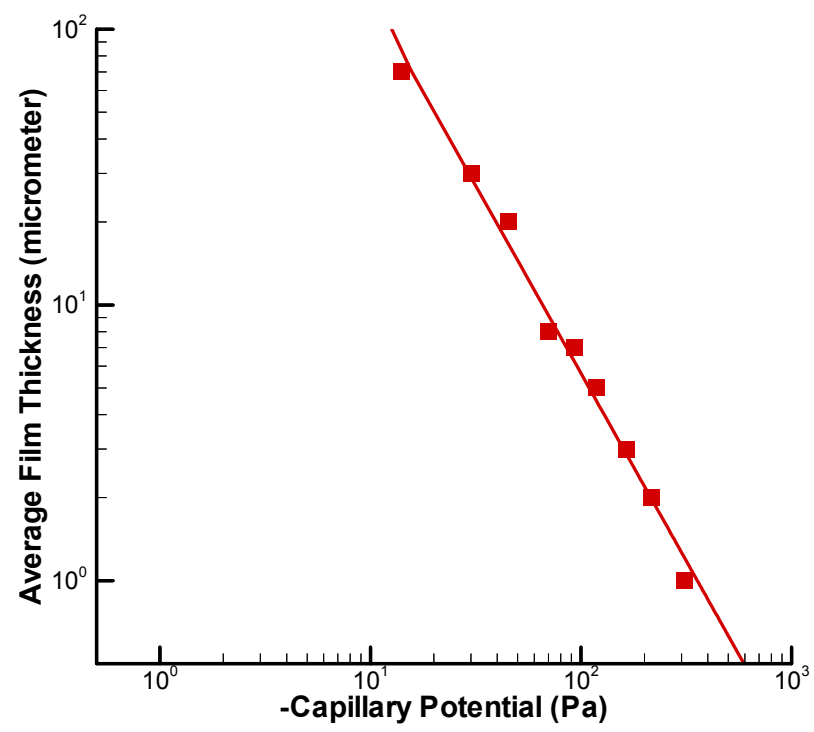

(b)

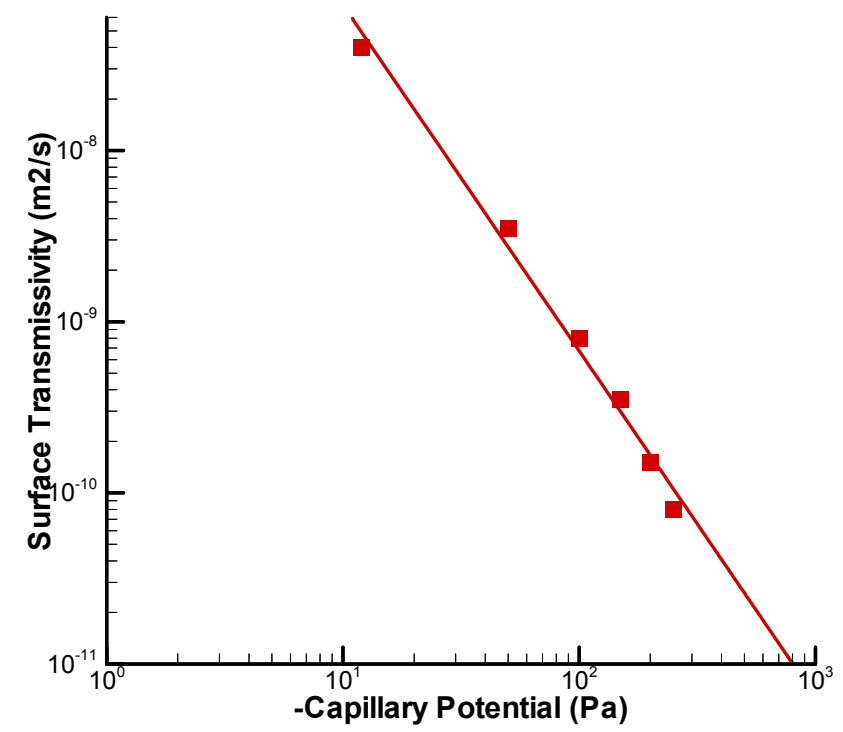

NOTE: Squares correspond to the measurements (Appendix A). (a) potential measurements given in Figure 7 of Tokunaga and Wan (1997 [DIRS 139195]); (b) potential measurements given in Figure 6 of Tokunaga and Wan (1997 [DIRS 139195]).

Figure 7-4. Matches of Equation 7-18 to (a) Film Thickness and (b) Surface Transmissivity-Film Thickness 


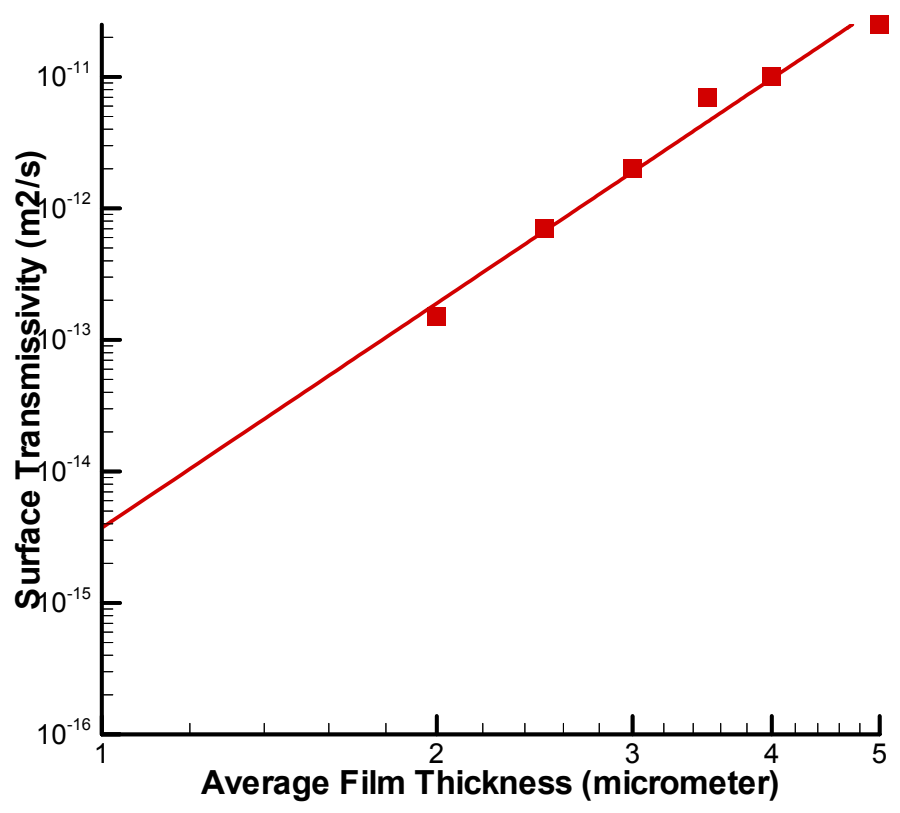

NOTE: Squares correspond to the surface transmissivity-film thickness relation (Appendix A) obtained from Figure 9 of Tokunaga et al. (2000 [DIRS 152914]) that exclude points below the thickness of $2 \mu \mathrm{m}$, as compared with the match in Figure 9.

Figure 7-5. Match of Equation 7-18b to Surface Transmissivity-Film Thickness Measurements

Assuming that film flow only occurs in unsaturated fractures, the fractures would become saturated when the average film thickness is equal to half the average aperture. In this case, the air entry value $P_{d}$ for fractures can be used as the reference capillary pressure. As a result, film thickness ratio and transmissivity ratio in Equation 7-18 are equivalent to the effective saturation $\left(S_{e}\right)$ and relative permeability $\left(k_{r}\right)$, respectively, for fractures. Equation 7-18 with $\eta=-1$ is then rewritten as

$$
\begin{gathered}
S_{e}=\left|\frac{P_{c}}{P_{d}}\right|^{-\lambda} \\
k_{r}=S_{e}^{2 / \lambda}
\end{gathered}
$$

Note that for the same $\lambda$ value, the ratio of relative permeability from the Brooks-Corey model (Equation 7-17) to that from Equation 7-19b is $S_{e}^{3}$, indicating that Equation 7-19b predicts much higher $k_{r}$ value than the Brooks-Corey model at low saturations. That also explains why film flow corresponds to fast flow in unsaturated fractures. Equation 7-19 can be used to describe film flow within the context of the continuum approach, if all fractures are assumed to be hydraulically the same within a gridblock. Note that effects of variability in fracture aperture are not considered in Equation 7-19. This issue may need further investigation in the future if film flow is determined to be a key flow mechanism. 


\subsubsection{Model Comparison}

This section provides a simple comparison between the film-flow model (Equation 7-19) and the AFM. In welded units, water mainly percolates through fractures (Liu et al. 1998 [DIRS 105729], Figure 7-6). For a given infiltration flux, pore velocity within fractures in a welded unit is proportional to the relative permeability, divided by the effective saturation, because fracture flow is gravity dominant (Liu et al. 1998 [DIRS 105729]). Therefore, for a given relative permeability, it will be determined whether the effective saturation predicted by the film model, using parameters derived from observations by Tokunaga and Wan (1997 [DIRS 139195]) and Tokunaga et al. (2000 [DIRS 152914]), is approximately within the range of saturations calculated by the AFM for a range of $\gamma$ values. If it is the case, pore velocity determined from the film-flow model should be approximately within the range of pore velocity predicted by the AFM. In other words, the fast flow behavior caused by fracture film flow is captured by the AFM.

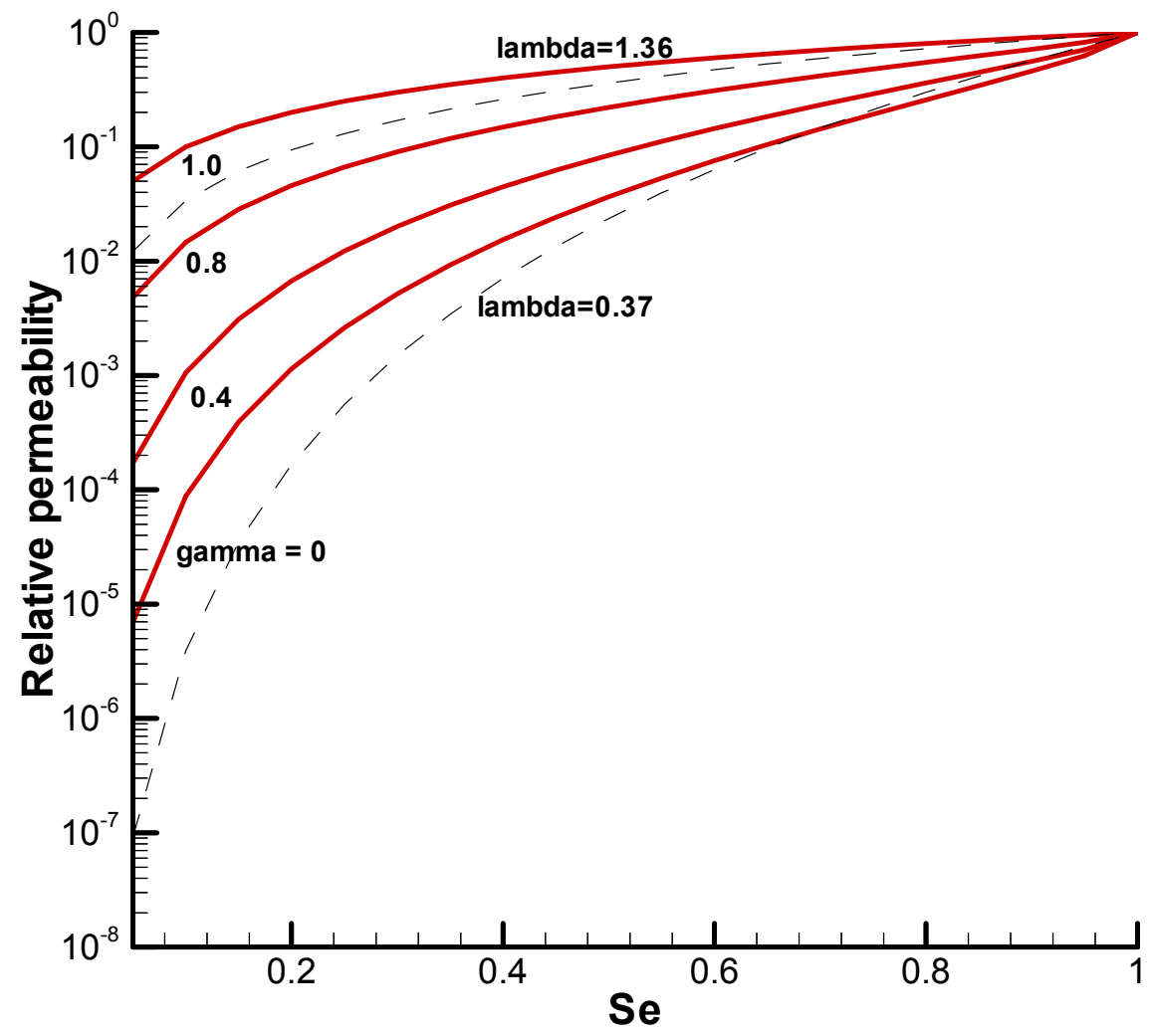

Source: From experimental results of Tokunaga and Wan (1997 [DIRS 139195]) and Tokunaga et al. (2000 [DIRS 152914]).

Figure 7-6. Comparison Between Relative Permeability-Saturation Relations Calculated Using the AFM with $\mathrm{m}=0.633$ (DTN: LB0205REVUZPRP.001 [DIRS 159525]) for Several $\gamma$ Values (Solid Red Lines) and Relations Calculated from the Film-Flow Model with $\lambda$ Values (Dashed Lines) 
Figure 7-6 shows a comparison between relative permeability-saturation relations calculated with the AFM and the film-flow model. For $\lambda=0.37$, even the AFM with $\gamma=0$ (i.e., all connected fractures are active) can predict larger pore velocity at low saturations compared to the film-flow model. For $\lambda=1.36$, the relative permeability-saturation relation given by the film-flow model is consistent with the AFM with a $\gamma$ value between 0.8 and 1.0. Therefore, fast flow predicted by the film-flow model with parameters obtained from observations by Tokunaga and Wan (1997 [DIRS 139195]) and Tokunaga et al. (2000 [DIRS 152914]) can be captured by the AFM with different $\gamma$ values. This largely results from the capability of the AFM to capture a large range of flow behaviors.

Although a typical $\lambda$ value for the UZ is not available, $\lambda$ should be bounded by the values used in Figure 7-6. This is based on the observation that water flow processes in the UZ described by the AFM are bounded by $\gamma$ values between 0 and 0.8 . As indicated by Liu et al. (1998 [DIRS 105729]), field observations support the concept that not all connected fractures are active in the UZ $(\gamma>0)$. On the other hand, Liu et al. (1998 [DIRS 105729], Figure 11) also showed that pore velocity within fractures in welded units is on the order of $1.0 \mathrm{E}-4 \mathrm{~m} / \mathrm{s}$ (or $3154 \mathrm{~m} / \mathrm{year}$ ) for $\gamma=0.8$. No evidence supports such a high pore velocity in the UZ. As a result, if film flow were indeed important in the UZ, the corresponding relative permeability-saturation relation would be bound by the relations for the two $\lambda$ values shown in Figure 7-6. Consequently, the above comparison is likely valid for the Yucca Mountain UZ.

Note also that derivation of Equation 7-19 implies a uniform film flow in all fractures. This is supported by the widespread nature of the film flow observed from small-scale laboratory experiments (Tokunaga and Wan 1997 [DIRS 139195]; Tokunaga et al. 2000 [DIRS 152914]). This uniform film-flow generally results in a much larger degree of matrix diffusion (resulting from a larger fracture-matrix interfacial area) than with the AFM, and therefore a larger degree of retardation for radionuclide transport in the UZ, even when pore velocity is the same for the two models. All these considerations support the idea that AFM does not overestimate the performance of the UZ, even if film flow were the main mechanism for fracture flow in the UZ.

\subsection{EVALUATION OF THE AFM WITH CARBON-14 AND MINERAL COATING DATA}

Carbon-14 and fracture coating data are used for evaluating the AFM. They contain useful information regarding water flow and fracture-matrix interaction in the UZ under ambient conditions. It is especially of interest to examine if the AFM can represent two different data sets for a similar range of the AFM parameter $\gamma$, which is an indication of whether the AFM is able to capture the large-scale UZ flow behavior. This model evaluation activity is documented in Scientific Notebooks (Wang 2003 [DIRS 161654], SN-LBNL-SCI-227-V1, pp. 8-19, 21-54, 70-71, 73-84; SN-LBNL-SCI-199-V1, pp. 92-99).

\subsubsection{Model Validation with Carbon-14 Data}

Carbon-14 data were collected from perched water, pore water, and gas samples from the Yucca Mountain UZ (BSC 2002 [DIRS 160247], Section 6.6.4). Pore-water carbon-14 data from various boreholes at Yucca Mountain were affected by contamination from atmospheric ${ }^{14} \mathrm{CO}_{2}$ during drilling, which may result in apparently younger residence times (Yang 2002 
[DIRS 160839], Section 4.1.2; BSC 2002 [DIRS 160247], Section 6.6.4.2). Carbon-14 data from gas samples are considered to be most representative of in situ conditions (Yang 2002 [DIRS 160839], Section 4.1.2). Gas samples were collected from different kinds of boreholes, including open surface-based boreholes and instrumented surface boreholes. The data from the latter boreholes (USW SD-12 and USW UZ-1) are the most reliable indicators of in situ conditions (BSC 2002 [DIRS 160247], Section 6.6.4.3). Carbon-14 residence ages (BSC 2002 [DIRS 160247], Table 20) calculated using the data from these two boreholes are used for validating the AFM. Water travel times from the ground surface to the perched water bodies are dominated by PTn where flow occurs mainly in the rock matrix and is, thus, insensitive to the AFM parameters (Wang 2003 [DIRS 161654], SN-LBNL-SCI-227-V1, pp. 49-50). Therefore, carbon-14 data collected from perched water are not used for validating the AFM.

Gas-phase Carbon-14 ages (DTN: GS961108312271.002 [DIRS 121708] for Borehole USW SD-12 and DTN: MO0012CARB1314.000 [DIRS 153398] for Borehole USW UZ-1) are interpreted to be representative of ages of the in situ pore water. The rationale for this interpretation is provided by Yang (2002 [DIRS 160839], Section 4.1.2). This interpretation presumes rapid exchange of gas-phase $\mathrm{CO}_{2}$ (in hours to days) with dissolved $\mathrm{CO}_{2}$ and $\left(\mathrm{HCO}_{3}{ }^{-}\right)$in pore water. Furthermore, the amount of $\mathrm{C}$ in an aqueous-phase pore water relative to $\mathrm{C}$ in the $\mathrm{CO}_{2}$ gas-phase reservoir is a hundred times greater. Consequently, the aqueous phase will dominate the gaseous phase when exchange occurs, indicating the reasonableness of the interpretation (Yang 2002 [DIRS 160839], Section 4.1.2).

One-dimensional numerical models are developed for Boreholes USW SD-12 and USW UZ-1. Numerical grids for these models are taken from DTN: LB02091DSSCP3I.001 [DIRS 161292]. The measurement elevations are determined from collar elevations of the boreholes (DTN: MO9906GPS98410.000 [DIRS 109059]) and depth information given in the DTNs in the above paragraph. The calibrated rock properties for present-day, mean infiltration maps are used except for the $\gamma$ values (DTN: LB02091DSSCP3I.002 [DIRS 161433]). The value of the AFM parameter $\gamma$ for model layers (tsw32 to tsw38) is varied for different simulations to check the sensitivity of this parameter to simulated water travel times. The top boundary condition corresponds to the present-day infiltration rate for flow simulations and a constant tracer concentration for transport simulations. Initial conditions for solute transport include zero concentration within the fractured rocks. Previous studies indicate that dispersion processes have an insignificant effect on overall solute transport behavior in unsaturated fractured rocks (Liu et al. 2003 [DIRS 162470]), and therefore they are ignored here. An effective-diffusion-coefficient value of $1.97 \mathrm{E}-10 \mathrm{~m} / \mathrm{s}$ is employed in this study and equal to the average value of measured coefficients for tritiated water (DTN: LA000000000034.002 [DIRS 148603]; TOUGH2 V1.4 (LBNL 2000 [DIRS 146496]); and T2R3D V1.4 (LBNL 1999 [DIRS 146654]) codes are used for simulating steady-state water flow and tracer transport processes. (The input and output files associated with these software items are described in Scientific Notebook (Wang 2003 [DIRS 161654], SN-LBNL-SCI-227-V1, pp. 8-19, 21-54, 70-71, and 73-84) and submitted to TDMS under Output DTNs: LB0212C14INFIL.001 and LB0212AFPGAMMA.001.) Simulated water travel times (or ages) for the rock matrix are compared with carbon-14 ages. A simulated water travel time at a given location is defined as the time when the matrix concentration reaches 50 percent of the top-boundary concentration. It represents the average travel time for water particles from the ground surface to the location. 
Figure 7-7 shows simulated water travel times (ages) for different $\gamma$ values of UZ Model layers tsw32 to tsw38. The considerable sensitivity of simulated results to $\gamma$ indicates that carbon-14 data are useful for validating the AFM and for constraining the $\gamma$ values for the TSw unit. For $\gamma$ values less than 0.4 , simulated results approximately match the observations. A larger $\gamma$ value generally corresponds to a larger travel time for the matrix because of a smaller degree of matrix diffusion, resulting from a smaller fracture-matrix interfacial area available for mass transport between fractures and the matrix.

Simulated water travel times change sharply at an elevation of about $1,100 \mathrm{~m}$ for two boreholes (Figure 7-7). This is because the upper portion of the TSw unit has relatively small fracture density values and, thus, corresponds to a smaller degree of matrix diffusion for a given $\gamma$ value (DTN: LB0205REVUZPRP.001 [DIRS 159525]). For the Borehole USW UZ-1, the simulated water travel time is generally longer than the observation for a given elevation. This may be a result of subsurface heterogeneity, which gives larger fracture densities (resulting in a larger degree of matrix diffusion) at the borehole location than what are used in the numerical model. Layer-averaged fracture properties are used in the UZ Model (Section 6.3.4). Also note that unlike the case for USW SD-12, the simulation result for $\gamma=0$ provides the best match to the data for USW UZ-1. This may again result from the spatial variability. Like many other hydraulic properties (e.g., permeability), $\gamma$ is spatially variable. Nevertheless, $\gamma \leq 0.4$ gives the reasonable matches to the data from the two boreholes simultaneously.

In summary, a comparison between simulated water travel times and observed carbon-14 ages indicates that the AFM with $\gamma$ values less than 0.4 (for UZ model layers tsw32-tsw38) can reasonably represent the data. The comparison satisfies the model validation criterion that simulated water travel times are sensitive to the AFM parameters and within the range of measured data for the TSw unit (Section 7.1). 
(a)

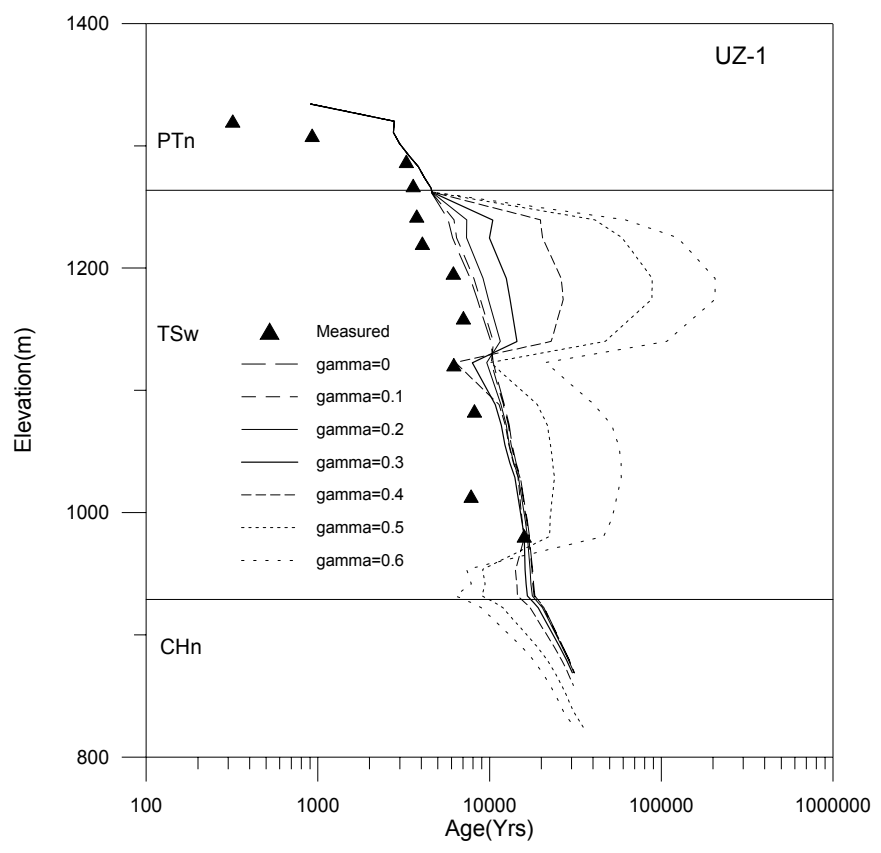

(b)

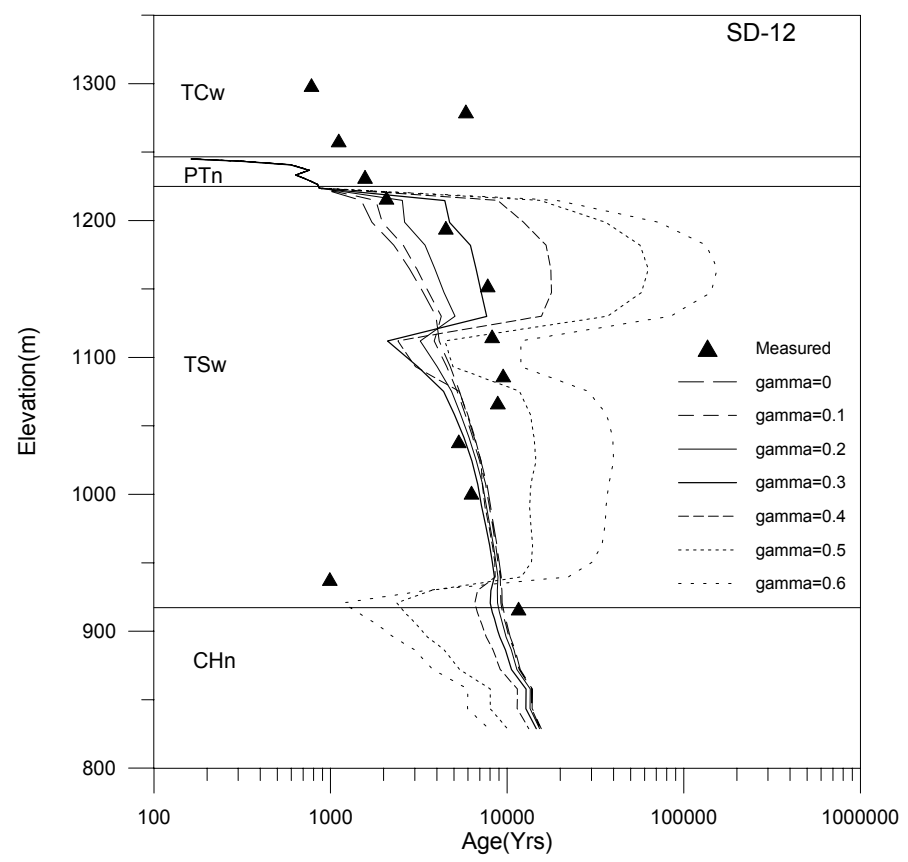

Source: Wang (2003 [DIRS 161654], SN-LBNL-SCI-227-V1, p. 87).

Output DTN: LB0212C14INFIL.002 (files: C14_UZ-1_age.doc and C14_SD-12_age.doc).

Figure 7-7. Comparisons Between Simulated Water Travel Times (Ages) for Rock Matrix at Boreholes (a) USW UZ-1 and (b) USW SD-12, as well as the Corresponding Carbon-14 Ages for Several $\gamma$ Values 


\subsubsection{Model Validation with Mineral Coating Data}

The process of UZ mineral deposition is initiated during infiltration. Here, meteoric water interacts with materials in the soil, after which a portion may then enter the bedrock fracture network. Fracture coating is generally a signature of water flow paths. Therefore, the coating data are useful for validating the AFM describing water flow in fractures.

Fracture coating data were collected in the ESF (DTN: GS980308315215.008 [DIRS 107355]). Observed spatial distribution of fractures with coatings is used to estimate the portion of active fractures in the UZ. For a given survey interval along ESF, a frequency of coated fractures can be estimated for a geologic unit, based on the total number of coated fractures. The ratio of coated-fracture frequency to total fracture frequency (DTN: LB0205REVUZPRP.001 [DIRS 159525]) will provide an estimate of the portion of active fracture for the given geologic unit (Wang 2003 [DIRS 161654], SN-LBNL-SCI-227-V1, pp. 70-71). The estimated average portion of the active fractures for the TSw is 7.2 percent. The abundance of mineral coating (coating volume divided by total rock volume), divided by the corresponding fracture porosity, gives another estimate of the portion of the active fractures in the UZ under ambient conditions. Abundance data for all intervals in welded tuffs have an arithmetic mean of 0.084 percent (BSC 2002 [DIRS 160247], Section 6.10.1.1), while a typical fracture porosity is 1 percent (DTN: LB0205REVUZPRP.001 [DIRS 159525]). Therefore, an estimate of the average portion of active fractures for welded units is $0.084 \% / 1 \%=8.4$ percent, close to the estimate determined from the frequency of coated fractures. Note that fracture coatings may not precisely represent active flow paths in the UZ and some flow paths may not have coatings (Liu et al. 1998 [DIRS 105729]). Nevertheless, these values at least give a rough estimate of lower limits for the portion of active fractures in the $\mathrm{UZ}-$ about 10 percent.

Mineral growth rate data imply that the UZ fracture network has maintained a large degree of hydrologic stability over time, and fracture flow paths in the deep UZ are buffered from climate-induced variations in precipitation and infiltration (BSC 2002 [DIRS 160247], Section 6.10.3.9). If the AFM actually represents water flow processes in the UZ, modeling results based on the AFM should be consistent with this important observation.

To check the consistency of the AFM against the coating data, a one-dimensional model for Borehole USW SD-12 is used. The model is the same as that described in Sections 6.3.7 and 7.2.1. USW SD-12 is chosen because it is located near the middle of the ESF, where coating data were collected. Two infiltration rates, present data mean infiltration rate and glacial maximum infiltration rate, are used for simulations. Again, uniform $\gamma$ distributions within model layers tsw32 to tsw38 are employed. The latter infiltration rate is about five times as large as the former rate and represents the maximum infiltration rate in past climates.

Figure 7-8 shows the simulated average portion of active fractures, $f_{a}$, for the relevant model layers (tsw32 to tsw38) as a function of infiltration rate and $\gamma$. The average portion is calculated from Equation 6-14 using the average effective saturation for model layers tsw32 to tsw38. The calculated $f_{a}$ values range about 10 percent for $\gamma$ values close to 0.4 , which are similar to those used for matching the carbon-14 data. For the same range of $\gamma$ values, the calculated $f_{a}$ values do not change significantly for the two infiltration rates (Figure 7-8), which is consistent with the 
observation of flow-path stability over time. The present day mean infiltration rate is obtained from file GENER_m_rad_200 in DTN: LB0208UZDSCPMI.001 [DIRS 161285]. The glacial maximum infiltration rate is determined using software routine infil2grid V1.7 (LBNL 2002 [DIRS 154793]) based on infiltration maps (BSC 2004 [DIRS 170007]; DTN: GS000308311221.005 [DIRS 147613]) and UZ numerical grid (DTN: LB03023DKMGRID.001 [DIRS 162354]; Wang 2003 [DIRS 161654], SN-LBNL-SCI199-V1, pp. 92-99; SN-LBNL-SCI-227-V1, pp. 8-9). The determined glacial maximum infiltration rate is $17.3108 \mathrm{~mm} /$ year (Wang 2003 [DIRS 161654], SN-LBNL-SCI-227-V1, p. 8). The simulation results satisfy the model validation criterion that simulated active portion of fractures is similar to the percentage of fractures with mineral coating (Section 7.1).

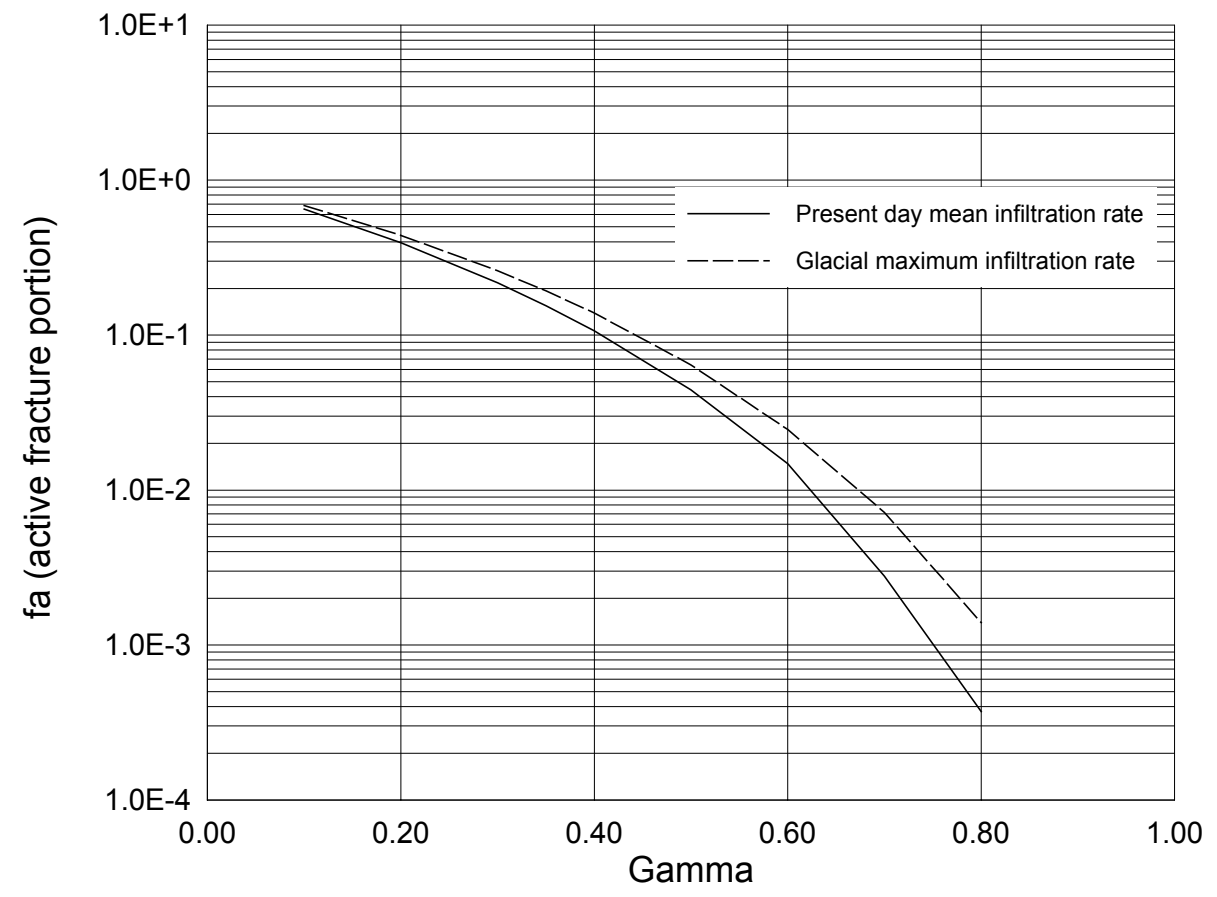

Output DTN: LB0212AFPGAMMA.002 (files: gamma_analysis.doc, FA_GA_GU.dat, and FA_GA_PM.dat).

Figure 7-8. Simulated Average Portion of Active Fracture for the Relevant Model Layers (tsw32 to tsw38) as a Function of Infiltration Rate and $\gamma$

In summary, the simulation results based on the AFM are consistent with both carbon-14 data and fracture coating data, for a similar range of $\gamma$ values. This result, together with the consistency of the AFM with fractal flow patterns and film-flow behavior (Sections 7.2 and 7.3, respectively), support the usefulness of the AFM.

\subsection{VALIDATION SUMMARY}

The AFM has been validated by applying acceptance criteria based on an evaluation of the model's relative importance to the potential performance of the repository system. All the validation requirements defined in TWP-MGR-HS-000001 REV 00 (BSC 2004 [DIRS 169654], Section 2.2.1) have been fulfilled, including corroboration of model results with experimental data (Section 7.4), publications in refereed professional journals (Section 7.1), and corroboration 
with alternative conceptual models (Sections 7.2 and 7.3). Confidence building during model development was obtained by publishing the AFM in Water Resources Research (Liu et al. 1998 [105729]). The model development activities and post-development validation activities described establish the scientific bases for the AFM. Based on these activities (that satisfy the model validation criteria), the AFM is considered to be sufficiently accurate and adequate for the intended purpose, and to the level of confidence required by the model's relative importance to the potential performance of the repository system. 


\section{CONCLUSIONS}

\subsection{CONCEPTUAL MODEL AND NUMERICAL APPROACHES}

A variety of flow and transport processes occur in the UZ of Yucca Mountain. The conceptual model and numerical modeling approaches used for modeling these processes are summarized in this report.

Flow processes are considered to be characterized by the following attributes (Section 6.1). The percolation processes below this unit are considered to be approximately in steady state under ambient conditions because of the expected attenuation effects of the PTn unit. Fracture liquid-water flow is dominant in the welded units and matrix flow in the nonwelded units. Fracture-matrix interaction in the welded units is limited. The existence of perched water bodies introduces three-dimensional lateral flow within the UZ.

Solute transport within the UZ of Yucca Mountain is closely tied to the conceptual model of flow (Section 6.2). Advective transport pathways coincide with flow pathways. Matrix diffusion is a major mechanism for mass transfer between fractures and the matrix, and contributes to the retardation of radionuclide transport when fracture flow is dominant. Sorption can also act to retard the movement of radionuclides in the UZ: radionuclides and reactive chemicals, which are strongly sorbed to rock matrix, are relatively immobile. On the other hand, sorptive interactions may enhance radionuclide transport if the aqueous species sorbs to colloids. Dispersion is not expected to be a major transport mechanism in the UZ. In addition, perched water bodies may dilute solute and radionuclide plumes.

Several basic numerical approaches are available for modeling flow and transport in unsaturated, fractured rock. Based on flow and transport behavior in the UZ of Yucca Mountain, the scale of the problem, data availability, and computational feasibility, the dual-permeability approach is considered the most appropriate approach for modeling flow and transport processes (Section 6.3). Relevant issues, such as the comparison between conventional approaches and particle-tracking methods for modeling transport processes, are also addressed.

This report also discusses model uncertainties related to understanding of focused flow at different scales, use of the continuum approach for dealing with UZ flow and transport processes, and the validity of the van Genuchten relationships and the AFM for describing unsaturated flow in fractures (Section 6.4).

\subsection{MODEL VALIDATION}

This report documents activities to validate the AFM and the corresponding model validation results (Section 7). The AFM is evaluated based on (fractal) flow patterns in unsaturated systems, the consistency with different types of field observations, and a comparison with an alternative (film-flow) model. The AFM is shown to be consistent with fractal distributions of flow patterns that have been often observed from unsaturated or multiphase flow systems (porous media). Simulation results based on the AFM, with a similar range of AFM-parameter values, match both the carbon-14 ages and fracture coating data collected from the UZ. Furthermore, a simple comparison between the AFM and the film-flow model, an alternative model, shows that the AFM would capture the fast flow behavior of water film if film flow were 
the major mechanism for fracture flow. All these support the usefulness of the AFM in describing flow and transport processes in the UZ. The model validation results were submitted to TDMS under DTNs: LB0212C14INFIL.001, LB0212C14INFIL.002, LB0212AFMGAMMA.001, and LB0212AFPGAMMA.002.

\subsection{HOW THE ACCEPTANCE CRITERIA ARE ADDRESSED}

The following information describes how this model report addresses the acceptance criteria in the YMRP (NRC 2003 [DIRS 163274], Sections 2.2.1.3.6.3 and 2.2.1.3.7.3). Only those acceptance criteria that are applicable to this report (see Section 4.2) are discussed. In most cases, the applicable acceptance criteria are not addressed solely by this report; rather, the acceptance criteria are fully addressed when this report is considered in conjunction with other analysis and model reports that describe flow and transport in the unsaturated zone.

\section{Acceptance Criteria from Section 2.2.1.3.6, Flow Paths in the Unsaturated Zone.}

\section{Acceptance Criterion 1, System Description and Model Integration Are Adequate.}

Subcriterion (1) The model described in this report adequately incorporates physical phenomena related to UZ flow including the various mechanisms involved in fracture-matrix interaction, perched water, major faults, transient flow, and focused flow (discussed in Sections 6.1.3, 6.1.4, 6.1.5, 6.1.6, and 6.1.7, respectively). The model described in this report is used by UZ flow and transport models that support TSPA.

Subcriterion (2) An adequate and detailed discussion of water flow paths and the associated processes is presented in Section 6.1. This discussion includes consideration of effects of rock properties, infiltration, major faults, perched water, flow focusing and fracture-matrix interaction on the UZ flow paths. Conditions and assumptions related to these processes are identified in the subsection discussing each and are consistently throughout the model development (Sections 6.1 and 6.3).

Subcriterion (3) The assumptions, technical bases, and models described in Sections 6.1, 6.2 and 6.3 are appropriate and consistent with other Yucca Mountain related abstractions regarding flow in the UZ and flow in the saturated zone. The descriptions and technical bases are transparent and traceable to site data through a discussion of the geologic features of Yucca Mountain (Sections 6.1 and 6.2).

Subcriterion (4) The bases and justification presented in Section 6 support the conclusion in Section 8 that fracture liquid-water flow is dominant in welded units and matrix flow, in nonwelded units. These approximations are employed in the numerical approaches described in Section 6.3 to represent radionuclide transport in the unsaturated zone and are consistent with the models and approaches in related abstracts.

Subcriterion (9) This report was developed in accordance with the QARD, which commits to NUREGs 1297 (Altman et al. 1988 [DIRS 103597]) and 1298 (Altman et al. 1998 [DIRS 103750]). Moreover, compliance with the DOE procedures, which are designed to ensure compliance with the QARD, is verified by audits by QA and 
other oversight activities. Accordingly, the guidance in NUREGs 1297 and 1298 has been followed as appropriate.

\section{Acceptance Criterion 2: Data Are Sufficient for Model Justification.}

Subcriterion (6) Approved QA procedures identified in the TWP (BSC 2004 [DIRS 169654], Section 4) have been used to conduct and document the activities described in this model report.

Subcriterion (7) The relatively uniform distribution of fracture flow paths at Yucca Mountain makes the continuum approach a reasonable choice for the UZ model as noted in Section 6.3.2. The continuum model adopted reflects a robust, complete mathematical model reflecting the most appropriate choices from a number of approaches suggested in the literature (Section 6.3.2). Approaches considered have been developed and used in different fields (including oil-reservoir engineering, groundwater hydrology, geothermal engineering and soil physics). Model validity was demonstrated by comparison of model simulations with field-scale results for the Alcove 8/Niche 3 test site (Section 6.3.3) where it was found that the field observations are well represented by the modeling results.

\section{Acceptance Criterion 3: Data Uncertainty is Characterized and Propagated Through the Model Abstraction.}

Subcriterion (1) The assumptions implicit in the model developed in this report are consistent with those for similar models in other applications (Sections 6.1 through 6.3). They reasonably account for uncertainties and variabilities by choice of the most appropriate model from a number of possibilities (Section 6.3) and, due to the conservative nature of the dual-continua model, do not result in an under-representation of the risk.

Subcriterion (6) Uncertainties and heterogeneity of the UZ are considered by adopting a geology-based deterministic approach, in which an entire model layer is assigned uniform properties. This approach is used mainly for representing subsurface heterogeneity because overall behavior of site-scale flow and transport processes is determined mainly by relatively large-scale heterogeneities associated with the geologic stratification and faults (Section 6.3.4).

\section{Acceptance Criterion 4, Model Uncertainty is Characterized and Propagated Through the Model Abstraction.}

Subcriterion (1) A number of alternate modeling approaches are considered in Section 6.3.1 and assessed in Section 6.3.2. The approaches fall into one of three groups: continuum approaches, discrete fracture-network approaches, and other approaches that can be considered as variations and/or combinations of the other two approaches. An extensive review of literature on each approach with a discussion of the limitations of each is presented in Section 6.3.2. A geology-based deterministic approach, in which an entire model layer is assigned uniform properties, is used mainly for representing subsurface heterogeneity because overall behavior of 
site-scale flow and transport processes is determined mainly by relatively large-scale heterogeneities associated with the geologic stratification and faults (Section 6.3.4).

Subcriterion (3) The conceptual model uncertainties were discussed in Section 6.4. Model validation in Section 7 provides comparisons between the AFM and alternate models and physical data (14C and mineral coating). Results of these comparisons indicate that the model matches the physical data and other models within expected limits. These results support the conclusion that the AFM is considered the appropriate approach for modeling flow and transport processes in the UZ (Section 8.1).

Acceptance Criteria from Section 2.2.1.3.7, Radionuclide Transport in the Unsaturated Zone).

\section{Acceptance Criterion 1: System Description and Model Integration Are Adequate.}

Subcriterion (1) The model described in this report adequately incorporates important physical phenomena related to UZ transport including the various advective transport, matrix diffusion, fracture and matrix sorption, colloid-facilitated transport, and other transport issues (discussed in Sections 6.2.1, 6.2.2, 6.2.3, 6.2.4, and 6.2.5, respectively). Assumptions that are consistent with other abstracts and appropriate for the physical phenomena expected in the UZ are applied throughout the report (especially in Section 6).

Subcriterion (2) The detailed discussion of radionuclide transport processes is presented in Section 6.2. This discussion includes effects of advection, matrix diffusion, sorption and colloid-facilitated transport on radionuclide transport behavior in the UZ. These conditions and assumptions are consistent with other documents supporting UZ transport (Section 6).

Subcriterion (3) This report uses assumptions, technical bases, data, and models that are appropriate and consistent with other related abstractions for flow and transport in the UZ. Related abstractions that use this model are the UZ flow model, model for radionuclide transport under ambient conditions, and particle tracking model for UZ. The descriptions and technical bases for the continuum model chosen provide transparent and traceable support for the TSPA abstraction through extensive literature cites and discussion (Sections 6.1 through 6.3).

Subcriterion (5) Sufficient technical bases have been presented in Sections 6.2 and 7 to support the extent to which FEPs have been addressed. These include the discussions of matrix diffusion (Section 6.2.2), fracture and matrix sorption (Section 6.2.3), and colloid-facilitated transport (Section 6.2.4).

Subcriterion (6) This report was developed in accordance with the QARD, which commits to NUREGs 1297 and 1298. Moreover, compliance with the DOE procedures, which are designed to ensure compliance with the QARD, is verified by audits by QA and other oversight activities. Accordingly, the guidance in NUREGs 1297 and 1298 has been followed as appropriate. 


\section{Acceptance Criterion 3: Data Uncertainty Is Characterized and Propagated Through the Model Abstraction.}

Subcriterion (1) The assumptions implicit in the model developed in this report are consistent with those for similar models in other applications (Sections 6.1 through 6.3). They reasonably account for uncertainties and variabilities by choice of the best model from a number of possibilities (Section 6.3) and, due to the conservative nature of the dual-continua model, do not result in an under-representation of the risk.

\section{Acceptance Criterion 4: Model Uncertainty Is Characterized and Propagated Through the Model Abstraction.}

Subcriterion (1) A number of alternate modeling approaches suggested in current scientific literature are considered in Section 6.3.1 and assessed in Section 6.3.2. An extensive review of literature on each approach with a discussion of the limitations of each is presented in Section 6.3.2.

Subcriterion (2) The model uncertainties are addressed in Section 6.4.

Subcriterion (3) The conceptual model uncertainties were discussed in Section 6.4. Model validation in Section 7 provides comparisons between the AFM and alternate models and physical data (14C and mineral coating). Results of these comparisons indicate that the model matches the physical data and other models within expected limits. These results support the conclusion that the AFM is considered the appropriate approach for modeling flow and transport processes in the UZ (Section 8.1).

Subcriterion (4) Appropriate alternative modeling approaches from current scientific literature have been investigated as discussed in Section 6.3. Validation using two alternative models: 1) Fractal flow in unsaturated systems (Section 7.2) and, 2) a film-flow model (Section 7.3) concludes that the AFM-based continuum model adopted does not overestimate the performance of the UZ for the conditions applicable to the other models. 


\section{INTENTIONALLY LEFT BLANK}




\section{INPUTS AND REFERENCES}

\subsection{DOCUMENTS CITED}

Abdel-Salam, A. and Chrysikopoulos, C.V. 1996. "Unsaturated Flow in a 132960 Quasi-Three-Dimensional Fractured Medium with Spatially Variable Aperture." Water Resources Research, 32, (6), 1531-1540. Washington, D.C.: American Geophysical Union. TIC: 239861.

Ahlers, C.F.; Finsterle, S.; and Bodvarsson, G.S. 1999. "Characterization and Prediction of Subsurface Pneumatic Response at Yucca Mountain, Nevada." Journal 109715 of Contaminant Hydrology, 38, (1-3), 47-68. New York, New York: Elsevier. TIC: 244160.

Altman, W.D.; Donnelly, J.P.; and Kennedy, J.E. 1988. Peer Review for High-Level 103597 Nuclear Waste Repositories: Generic Technical Position. NUREG-1297. Washington, D.C.: U.S. Nuclear Regulatory Commission. TIC: 200651.

Altman, W.D.; Donnelly, J.P.; and Kennedy, J.E. 1988. Qualification of Existing 103750 Data for High-Level Nuclear Waste Repositories: Generic Technical Position. NUREG-1298. Washington, D.C.: U.S. Nuclear Regulatory Commission. TIC: 200652.

Bandurraga, T.M. and Bodvarsson, G.S. 1999. "Calibrating Hydrogeologic 103949 Parameters for the 3-D Site-Scale Unsaturated Zone Model of Yucca Mountain, Nevada." Journal of Contaminant Hydrology, 38, (1-3), 25-46. New York, New York: Elsevier. TIC: 244160.

Bear, J.; Tsang, C.F.; and de Marsily, G., eds. 1993. Flow and Contaminant Transport in Fractured Rock. San Diego, California: Academic Press.

TIC: 235461.

Becker, M.W. and Shapiro, A.M. 2000. "Tracer Transport in Fractured Crystalline 169947 Rock: Evidence of Nondiffusive Breakthrough Tailing." Water Resources Research, 36, (7), 1677-1686. Washington, D.C.: American Geophysical Union.

TIC: 252313.

Bodvarsson, G.S.; Boyle, W.; Patterson, R.; and Williams, D. 1999. "Ovverview of Scientific Investigations at Yucca Mountain-The Potential Repository for High-Level Nuclear Waste." Journal of Contaminant Hydrology, 38, (1-3), 3-24. New York, New York: Elsevier. TIC: 244160. 
Bodvarsson, G.S.; Wu, Y-S.; and Zhang, K. 2003. "Development of Discrete Flow 163443 Paths in Unsaturated Fractures at Yucca Mountain." Journal of Contaminant Hydrology, 62-63, 23-42. New York, New York: Elsevier. TIC: 254205.

Brooks, R.H. and Corey, A.T. 1964. Hydraulic Properties of Porous Media. Hydrology Paper No. 3. Fort Collins, Colorado: Colorado State University. TIC: 217453.

Brooks, R.H. and Corey, A.T. 1966. "Properties of Porous Media Affecting Fluid 119392 Flow." Journal of the Irrigation and Drainage Division, Proceedings of the American Society of Civil Engineers, 92, (IR2), 61-89. Ann Arbor, Michigan: American Society of Civil Engineers. TIC: 216867.

BSC (Bechtel SAIC Company) 2002. Analysis of Geochemical Data for the Unsaturated Zone. ANL-NBS-HS-000017 REV 00 ICN 02. Las Vegas, Nevada: Bechtel SAIC Company. ACC: MOL.20020314.0051.

BSC (Bechtel SAIC Company) 2002. Technical Work Plan for: Performance Assessment Unsaturated Zone. TWP-NBS-HS-000003 REV 02. Las Vegas, Nevada: Bechtel SAIC Company. ACC: MOL.20030102.0108.

BSC (Bechtel SAIC Company) 2004. Analysis of Hydrologic Properties Data. 170038 ANL-NBS-HS-000042, Rev. 00. Las Vegas, Nevada: Bechtel SAIC Company.

BSC (Bechtel SAIC Company) 2004. Development of Numerical Grids for UZ Flow and Transport Modeling. ANL-NBS-HS-000015 REV 02. Las Vegas, Nevada: Bechtel SAIC Company. ACC: DOC.20040901.0001.

BSC (Bechtel SAIC Company) 2004. In Situ Field Testing of Processes. 170004 ANL-BS-HS-000005, Rev. 03. Las Vegas, Nevada: Bechtel SAIC Company.

BSC (Bechtel SAIC Company) 2004. Q-List. 000-30R-MGR0-00500-000-000 168361 REV 00 Las Vegas, Nevada: Bechtel SAIC Company. ACC: ENG.20040721.0007.

BSC (Bechtel SAIC Company) 2004. Radionuclide Transport Models Under Ambient Conditions. MDL-NBS-HS-000008, Rev. 02. Las Vegas, Nevada: Bechtel SAIC Company.

BSC (Bechtel SAIC Company) 2004. Simulation of Net Infiltration for Present-Day 170007 and Potential Future Climates. MDL-NBS-HS-000023, Rev. 00. Las Vegas, Nevada: Bechtel SAIC Company.

BSC (Bechtel SAIC Company) 2004. Technical Work Plan for: Unsaturated Zone Flow Analysis and Model Report Integration. TWP-MGR-HS-000001 REV 00. Las Vegas, Nevada: Bechtel SAIC Company. ACC: DOC.20040701.0005. 
BSC (Bechtel SAIC Company) 2004. UZ Flow Models and Submodels. 169861

MDL-NBS-HS-000006, Rev. 02. Las Vegas, Nevada: Bechtel SAIC Company.

Callahan, T.J.; Reimus, P.W.; Bowman, R.S.; and Haga, M.J. 2000. “Using

156648

Multiple Experimental Methods to Determine Fracture/Matrix Interactions and Dispersion of Nonreactive Solutes in Saturated Volcanic Tuff." Water Resources Research, 36, (12), 3547-3558. [Washington, D.C.]: American Geophysical Union. TIC: 250760.

Canori, G.F. and Leitner, M.M. 2003. Project Requirements Document. 166275 TER-MGR-MD-000001 REV 02. Las Vegas, Nevada: Bechtel SAIC Company. ACC: DOC.20031222.0006.

Clemo, T. and Smith, L. 1997. "A Hierarchical Model for Solute Transport in 139105 Fractured Media." Water Resources Research, 33, (8), 1763-1783. Washington, D.C.: American Geophysical Union. TIC: 239864.

de Marsily, G. 1986. Quantitative Hydrogeology: Groundwater Hydrology for Engineers. San Diego, California: Academic Press. TIC: 208450.

DOE (U.S. Department of Energy) 1998. Total System Performance Assessment.

Volume 3 of Viability Assessment of a Repository at Yucca Mountain.

DOE/RW-0508. Washington, D.C.: U.S. Department of Energy, Office of Civilian Radioactive Waste Management. ACC: MOL.19981007.0030.

DOE (U.S. Department of Energy) 2004. Quality Assurance Requirements and 171539 Description. DOE/RW-0333P, Rev. 16. Washington, D.C.: U.S. Department of Energy, Office of Civilian Radioactive Waste Management.

ACC: DOC.20040907.0002.

Domenico, P.A. and Schwartz, F.W. 1990. Physical and Chemical Hydrogeology. 100569 New York, New York: John Wiley \& Sons. TIC: 234782.

Doughty, C. 1999. "Investigation of Conceptual and Numerical Approaches for 135997 Evaluating Moisture, Gas, Chemical, and Heat Transport in Fractured Unsaturated Rock." Journal of Contaminant Hydrology, 38, (1-3), 69-106. New York, New York: Elsevier. TIC: 244160.

Feder, J. 1988. Fractals. New York, New York: Plenum Press. TIC: $253584 . \quad 160844$

Fetter, C.W. 1993. Contaminant Hydrogeology. Upper Saddle River, New 102009 Jersey: Prentice Hall. TIC: 240691.

Flint, A.L.; Hevesi, J.A.; and Flint, L.E. 1996. Conceptual and Numerical Model of 100147 Infiltration for the Yucca Mountain Area, Nevada. Milestone 3GUI623M. Denver, Colorado: U.S. Geological Survey. ACC: MOL.19970409.0087. 
Flint, L.E. 1998. Characterization of Hydrogeologic Units Using Matrix Properties,

100033

Yucca Mountain, Nevada. Water-Resources Investigations Report 97-4243. Denver, Colorado: U.S. Geological Survey. ACC: MOL.19980429.0512.

Flint, L.E.; Flint, A.L.; and Hevesi, J.A. 1994. "Shallow Infiltration Processes in Arid Watersheds at Yucca Mountain, Nevada." High Level Radioactive Waste Management, Proceedings of the Fifth Annual International Conference, Las Vegas, Nevada, May 22-26, 1994. 4, 2315-2322. La Grange Park, Illinois: American Nuclear Society. TIC: 210984.

Flury, M. and Flühler, H. 1995. "Modeling Solute Leaching in Soils by 160845 Diffusion-Limited Aggregation: Basic Concepts and Application to Conservative Solutes." Water Resources Research, 31, (10), 2443-2452.

[Washington, D.C.]: American Geophysical Union. TIC: 253609.

Freeze, R.A. and Cherry, J.A. 1979. Groundwater. Englewood Cliffs, New Jersey: Prentice-Hall. TIC: 217571.

Glass, R.J. 1993. "Modeling Gravity-Driven Fingering in Rough-Walled Fractures 160751 Using Modified Percolation Theory." High Level Radioactive Waste Management, Proceedings of the Fourth Annual International Conference, Las Vegas, Nevada, April 26-30, 1993. 2, 2042-2052. La Grange Park, Illinois: American Nuclear Society. TIC: 208542.

Glass, R.J.; Nicholl, M.J.; and Tidwell, V.C. 1996. Challenging and Improving Conceptual Models for Isothermal Flow in Unsaturated, Fractured Rock Through Exploration of Small-Scale Processes. SAND95-1824. Albuquerque, New Mexico: Sandia National Laboratories. ACC: MOL.19970520.0082.

Hevesi, J.A.; Ambos, D.S.; and Flint, A.L. 1994. "A Preliminary Characterization of 125315 the Spatial Variability of Precipitation at Yucca Mountain, Nevada." High Level Radioactive Waste Management, Proceedings of the Fifth Annual International Conference, Las Vegas, Nevada, May 22-26, 1994. 4, 2520-2529. La Grange Park, Illinois: American Nuclear Society. TIC: 210984.

Ho, C.K. 1997. "Models of Fracture-Matrix Interactions During Multiphase Heat and Mass Flow in Unsaturated Fractured Porous Media." Proceedings of the ASME Fluids Engineering Division, November 16-21, 1997, Dallas, Texas. FED-Vol. 244. Pages 401-412. New York, New York: American Society of Mechanical Engineers. TIC: 241082.

Houseworth, J.E.; Finsterle, S.; and Bodvarsson, G.S. 2003. "Flow and Transport in 164394 the Drift Shadow in a Dual-Continuum Model." Journal of Contaminant Hydrology, 62-63, 133-156. New York, New York: Elsevier. TIC: 254205. 
Jardine, P.M.; Sanford, W.E.; Gwo, J.P.; Reedy, O.C.; Hicks, D.S.; Riggs, J.S.; and 169950 Bailey, W.B. 1999. "Quantifying Diffusive Mass Transfer in Fractured Shale Bedrock." Water Resources Research, 35, (7), 2015-2030.

[Washington, D.C.]: American Geophysical Union. TIC: 256151.

Kwicklis, E.M. and Healy, R.W. 1993. "Numerical Investigation of Steady Liquid 100587 Water Flow in a Variably Saturated Fracture Network." Water Resources Research, 29, (12), 4091-4102. Washington, D.C.: American Geophysical Union.

TIC: 226993.

Liu, H.H. 2004. "A Constitutive-Relationship Model for Film Flow on Rough 170129 Fracture Surfaces." Hydrogeology Journal, [12], ([2]), 237-240. New York, New York: Springer-Verlag. TIC: 256149.

Liu, H.H. and Bodvarsson, G.S. 2001. "Constitutive Relations for Unsaturated Flow in a Fracture Network." Journal of Hydrology, 252, ([1-4]), 116-125. [New York, New York]: Elsevier. TIC: 253269.

Liu, H.H.; Bodvarsson, G.S.; and Finsterle, S. 2002. "A Note on Unsaturated Flow 160230 in Two-Dimensional Fracture Networks." Water Resources Research, 38, (9), 15-1 to 15-9. [Washington, D.C.]: American Geophysical Union. TIC: 253307.

Liu, H.H.; Bodvarsson, G.S.; and Zhang, G. 2004. "Scale Dependency of the 169948 Effective Matrix Diffusion Coefficient." Vadose Zone Journal, 3, ([1]), 312-315. Madison, Wisconsin: Soil Science Society of America. TIC: 256150.

Liu, H.H.; Doughty, C.; and Bodvarsson, G.S. 1998. "An Active Fracture Model for 105729 Unsaturated Flow and Transport in Fractured Rocks." Water Resources Research, 34, (10), 2633-2646. Washington, D.C.: American Geophysical Union.

TIC: 243012.

Liu, H-H.; Haukwa, C.B.; Ahlers, C.F.; Bodvarsson, G.S.; Flint, A.L.; and Guertal, 162470 W.B. 2003. "Modeling Flow and Transport in Unsaturated Fractured Rock: An Evaluation of the Continuum Approach." Journal of Contaminant Hydrology, 62-63, 173-188. New York, New York: Elsevier. TIC: 254205.

Liu, H-H.; Zhang, G.; and Bodvarsson, G.S. 2003. "The Active Fracture Model: Its Relation to Fractal Flow Patterns and an Evaluation Using Field Observations." Vadose Zone Journal, 2, ([2]), 259-269. [Madison, Wisconsin: Soil Science Society of America]. TIC: 255196.

Maloszewski, P. and Zuber, A. 1993. "Tracer Experiments in Fractured Rocks: 101460 Matrix Diffusion and the Validity of Models." Water Resources Research, 29, (8), 2723-2735. Washington, D.C.: American Geophysical Union. TIC: 222353.

Mandelbrot, B.B. 1983. The Fractal Geometry of Nature. New York, 160848 New York: W.H. Freeman. TIC: 253583. 
Montazer, P. and Wilson, W.E. 1984. Conceptual Hydrologic Model of Flow in the 100161 Unsaturated Zone, Yucca Mountain, Nevada. Water-Resources Investigations Report 84-4345. Lakewood, Colorado: U.S. Geological Survey.

ACC: NNA.19890327.0051.

Moridis, G.J.; Hu, Q.; Wu, Y-S.; and Bodvarsson, G.S. 2003. "Preliminary 3-D

Site-Scale Studies of Radioactive Colloid Transport in the Unsaturated Zone at Yucca Mountain, Nevada.” Journal of Contaminant Hydrology, 60, ([3-4]), 251-286.

New York, New York: Elsevier. TIC: 253921.

Mualem, Y. 1976. "A New Model for Predicting the Hydraulic Conductivity of

100599 Unsaturated Porous Media." Water Resources Research, 12, (3), 513-522.

Washington, D.C.: American Geophysical Union. TIC: 217339.

National Research Council. 1996. Rock Fractures and Fluid Flow, Contemporary Understanding and Applications. Washington, D.C.: National Academy Press. TIC: 235913.

Neretnieks, I. 1993. "Solute Transport in Fractured Rock - Applications to 123099 Radionuclide Waste Repositories." Chapter 2 of Flow and Contaminant Transport in Fractured Rock. Bear, J.; Tsang, C.F.; and de Marsily, G., eds. p. 39-127.

San Diego, California: Academic Press. TIC: 235461.

Neretnieks, I. 2002. "A Stochastic Multi-Channel Model for Solute Transport-Analysis of Tracer Tests in Fractured Rock." Journal of Contaminant Hydrology, 55, ([3-4]), 175-211. New York, New York: Elsevier. TIC: 253977.

Nitao, J. and Buscheck, T. 1991. "Infiltration of a Liquid Front in an Unsaturated, Fractured Porous Medium." Water Resources Research, 27, (8), 2099-2112. Washington, D.C.: American Geophysical Union. TIC: 224848.

NRC (U.S. Nuclear Regulatory Commission) 2003. Yucca Mountain Review Plan, 163274 Final Report. NUREG-1804, Rev. 2. Washington, D.C.: U.S. Nuclear Regulatory Commission, Office of Nuclear Material Safety and Safeguards. TIC: 254568.

Paces, J.B.; Neymark, L.A.; Marshall, B.D.; Whelan, J.F.; and Peterman, Z.E. 1998.107408 "Inferences for Yucca Mountain Unsaturated-Zone Hydrology from Secondary Minerals." High-Level Radioactive Waste Management, Proceedings of the Eighth International Conference, Las Vegas, Nevada, May 11-14, 1998. Pages 36-39.

La Grange Park, Illinois: American Nuclear Society. TIC: 237082.

Persson, M.; Yasuda, H.; Albergel, J.; Berndtsson, R.; Zante, P.; Nasri, S.; and 160840 Ohrstrom, P. 2001. "Modeling Plot Scale Dye Penetration by a Diffusion Limited Aggregation (DLA) Model.” Journal of Hydrology, 250, ([1-4]), 98-105.

[New York, New York]: Elsevier. TIC: 253606. 
Peters, R.R. and Klavetter, E.A. 1988. "A Continuum Model for Water Movement 100604 in an Unsaturated Fractured Rock Mass." Water Resources Research, 24, (3), 416-430. Washington, D.C.: American Geophysical Union. TIC: 223603.

Pruess, K. 1999. “A Mechanistic Model for Water Seepage Through Thick Unsaturated Zones in Fractured Rocks of Low Matrix Permeability." Water 104250 Resources Research, 35, (4), 1039-1051. Washington, D.C.: American Geophysical Union. TIC: 244913.

Pruess, K. and Narasimhan, T.N. 1985. "A Practical Method for Modeling Fluid and 101707 Heat Flow in Fractured Porous Media." Society of Petroleum Engineers Journal, 25, (1), 14-26. Dallas, Texas: Society of Petroleum Engineers. TIC: 221917.

Pruess, K. and Tsang, Y. 1994. Thermal Modeling for a Potential High-Level Nuclear Waste Repository at Yucca Mountain, Nevada. LBL-35381. Berkeley, California: Lawrence Berkeley National Laboratory. ACC: NNA.19940427.0248.

Pruess, K.; Faybishenko, B.; and Bodvarsson, G.S. 1999. "Alternative Concepts and 117112 Approaches for Modeling Flow and Transport in Thick Unsaturated Zones of Fractured Rocks." Journal of Contaminant Hydrology, 38, (1-3), 281-322.

New York, New York: Elsevier. TIC: 244160.

Rousseau, J.P.; Kwicklis, E.M.; and Gillies, D.C., eds. 1999. Hydrogeology of the 102097 Unsaturated Zone, North Ramp Area of the Exploratory Studies Facility, Yucca Mountain, Nevada. Water-Resources Investigations Report 98-4050. Denver, Colorado: U.S. Geological Survey. ACC: MOL.19990419.0335.

Salve, R.; Oldenburg, C.M.; and Wang, J.S.Y. 2003. "Fault-Matrix Interactions in 164470 Nonwelded Tuff of the Paintbrush Group at Yucca Mountain." Journal of Contaminant Hydrology, 62-63, 269-286. New York, New York: Elsevier. TIC: 254205.

Schaap, M.G. and Leij, F.J. 2000. "Improved Prediction of Unsaturated Hydraulic 160841 Conductivity with the Mualem-van Genuchten Model." Soil Science Society of America Journal, 64, ([3]), 843-851. [Madison, Wisconsin]: Soil Science Society of America. TIC: 253607.

Shapiro, A.M. 2001. "Effective Matrix Diffusion in Kilometer-Scale Transport in Fractured Crystalline Rock.” Water Resources Research, 37, (3), 507-522.

[Washington, D.C.]: American Geophysical Union. TIC: 253979. 
Sharp, J.M., Jr.; Kreisel, I.; Milliken, K.L.; Mace, R.E.; and Robinson, N.I. 1996.

"Fracture Skin Properties and Effects on Solute Transport: Geotechnical and Environmental Implications." Rock Mechanics, Tools and Techniques, Proceedings of the 2nd North American Rock Mechanics Symposium, NARMS '96, A Regional Conference of ISRM, Montreal, Quebec, Canada, 19-21 June 1996. Aubertin, M.; Hassani, F.; and Mitri, H., eds. 2, 1329-1335. Brookfield, [Vermont]: A.A. Balkema. TIC: 239941.

Sonnenthal, E.L. and Bodvarsson, G.S. 1999. "Constraints on the Hydrology of the 117127 Unsaturated Zone at Yucca Mountain, NV from Three-Dimensional Models of Chloride and Strontium Geochemistry." Journal of Contaminant Hydrology, 38, (1-3), 107-156. New York, New York: Elsevier. TIC: 244160.

Stauffer, D. and Aharony, A. 2001. Introduction to Percolation Theory. 2nd 160846 Edition. Philadelphia, Pennsylvania: Tayler \& Francis. TIC: 253585.

Thoma, S.G.; Gallegos, D.P.; and Smith, D.M. 1992. "Impact of Fracture Coatings 139189 on Fracture/Matrix Flow Interactions in Unsaturated, Porous Media." Water Resources Research, 28, (5), 1357-1367. Washington, D.C.: American Geophysical Union. TIC: 237509.

Thorstenson, D.C.; Weeks, E.P.; Haas, H.; and Woodward, J.C. 1990. "Physical and 100831 Chemical Characteristics of Topographically Affected Airflow in an Open Borehole at Yucca Mountain, Nevada." Proceedings of the Topical Meeting on Nuclear Waste Isolation in the Unsaturated Zone, Focus '89, September 17-21, 1989, Las Vegas, Nevada. Pages 256-270. La Grange Park, Illinois: American Nuclear Society. TIC: 212738.

Tokunaga, T.K. and Wan, J. 1997. "Water Film Flow Along Fracture Surfaces of 139195 Porous Rock." Water Resources Research, 33, (6), 1287-1295. Washington, D.C.: American Geophysical Union. TIC: 242739.

Tokunaga, T.K.; Wan, J.; and Sutton, S.R. 2000. "Transient Film Flow on Rough 152914 Fracture Surfaces." Water Resources Research, 36, (7), 1737-1746. [Washington, D.C.]: American Geophysical Union. TIC: 249028.

Triay, I.R.; Meijer, A.; Conca, J.L.; Kung, K.S.; Rundberg, R.S.; Strietelmeier, B.A.; 100422 and Tait, C.D. 1997. Summary and Synthesis Report on Radionuclide Retardation for the Yucca Mountain Site Characterization Project. Eckhardt, R.C., ed. LA-13262-MS. Los Alamos, New Mexico: Los Alamos National Laboratory. ACC: MOL.19971210.0177.

van Genuchten, M.T. 1980. "A Closed-Form Equation for Predicting the Hydraulic 100610 Conductivity of Unsaturated Soils." Soil Science Society of America Journal, 44, (5), 892-898. Madison, Wisconsin: Soil Science Society of America. TIC: 217327. 
Wang, J.S. 2003. "Scientific Notebooks Referenced in Model Report U0090, 161654 Analysis of Hydrologic Properties Data, MDL-NBS-HS-000014 REV 00" Interoffice correspondence from J.S. Wang (BSC) to File, February 28, 2003, with attachments. ACC: MOL.20030306.0535.

Wang, J.S.Y. and Narasimhan, T.N. 1993. "Unsaturated Flow in Fractured Porous 106793 Media." Chapter 7 of Flow and Contaminant Transport in Fractured Rock. Bear, J.; Tsang, C-F.; and de Marsily, G., eds. San Diego, California: Academic Press. TIC: 235461.

Wang, Z.; Feyen, J.; and Elrick D.E. 1998. "Prediction of Fingering in Porous 155770 Media." Water Resources Research, 34, (9), 2183-2190. [Washington, D.C.]: American Geophysical Union. TIC: 250733.

Warren, J.E. and Root, P.J. 1963. "The Behavior of Naturally Fractured Reservoirs." Society of Petroleum Engineers Journal, 3, (3), 245-255. Dallas, Texas: Society of Petroleum Engineers. TIC: 233671.

Weeks, E.P. 1987. "Effect of Topography on Gas Flow in Unsaturated Fractured Rock: Concepts and Observations." Flow and Transport Through Unsaturated Fractured Rock. Evans, D.D. and Nicholson, T.J., eds. Geophysical Monograph 42. Pages 165-170. Washington, D.C.: American Geophysical Union. TIC: 223605.

Wu, Y.S.; Haukwa, C.; and Bodvarsson, G.S. 1999. "A Site-Scale Model for Fluid 117161 and Heat Flow in the Unsaturated Zone of Yucca Mountain, Nevada." Journal of Contaminant Hydrology, 38, (1-3), 185-215. New York, New York: Elsevier. TIC: 244160.

Wu, Y.S.; Liu, H.H.; Bodvarsson, G.S.; and Zellmer, K.E. 2001. A Triple-Continuum Approach for Modeling Flow and Transport Processes in Fractured Rock. LBNL-48875. Berkeley, California: Lawrence Berkeley National Laboratory. TIC: 251297.

Wu, Y.S.; Ritcey, A.C.; and Bodvarsson, G.S. 1999. “A Modeling Study of Perched 117167 Water Phenomena in the Unsaturated Zone at Yucca Mountain." Journal of Contaminant Hydrology, 38, (1-3), 157-184. New York, New York: Elsevier. TIC: 244160.

Wu, Y-S.; Zhang, W.; Pan, L.; Hinds, J.; and Bodvarsson, G.S. 2002. "Modeling 161058 Capillary Barriers in Unsaturated Fractured Rock." Water Resources Research, 38, (11), 35-1 through 35-12. [Washington, D.C.]: American Geophysical Union. TIC: 253854

Xu, T.; Sonnenthal, E.; and Bodvarsson, G. 2003. "A Reaction-Transport Model for 162124 Calcite Precipitation and Evaluation of Infiltration Fluxes in Unsaturated Fractured Rock." Journal of Contaminant Hydrology, 64, ([1-2]), 113-127. New York, New York: Elsevier. TIC: 254008. 
Yamamoto, H.; Kojima, K.; and Tosaka, H. 1993. "Fractal Clustering of Rock 160843

Fractures and Its Modeling Using Cascade Process." Scale Effects in Rock Masses, [Proceedings of the Second International Workshop on Scale Effects in Rock Masses, Lisbon, Portugal, June 25, 1993]. da Cunha, P., ed. Pages 81-86. Rotterdam, The Netherlands: A.A. Balkema. TIC: 253608.

Yang, I.C. 2002. "Percolation Flux and Transport Velocity in the Unsaturated Zone, 160839 Yucca Mountain, Nevada.” Applied Geochemistry, 17, ([6]), 807-817. [New York, New York]: Elsevier. TIC: 253605.

Yang, I.C.; Rattray, G.W.; and Yu, P. 1996. Interpretation of Chemical and Isotopic 100194 Data from Boreholes in the Unsaturated Zone at Yucca Mountain, Nevada. Water-Resources Investigations Report 96-4058. Denver, Colorado: U.S. Geological Survey. ACC: MOL.19980528.0216.

Zhou, Q.; Liu, H-H.; Bodvarsson, G.S.; and Oldenburg, C.M. 2003. "Flow and 162133 Transport in Unsaturated Fractured Rock: Effects of Multiscale Heterogeneity of Hydrogeologic Properties." Journal of Contaminant Hydrology, 60, ([1-2]), 1-30. New York, New York: Elsevier. TIC: 253978.

\subsection{CODES, STANDARDS, REGULATIONS, AND PROCEDURES}

10 CFR 63. Energy: Disposal of High-Level Radioactive Wastes in a Geologic 156605 Repository at Yucca Mountain, Nevada. Readily available.

AP-2.22Q, Rev. 1, ICN 1. Classification Analyses and Maintenance of the Q-List. Washington, D.C.: U.S. Department of Energy, Office of Civilian Radioactive Waste Management. ACC: DOC.20040714.0002.

AP-2.27Q, Rev. 1, ICN 4. Planning for Science Activities. Washington, D.C.: U.S. Department of Energy, Office of Civilian Radioactive Waste Management. ACC: DOC.20040610.0006.

AP-SIII.10Q, Rev. 2, ICN 7. Models. Washington, D.C.: U.S. Department of Energy, Office of Civilian Radioactive Waste Management. ACC:

DOC.20040920.00002.

LP-SI.11Q-BSC, Rev. 0, ICN 0. Software Management. Washington, D.C.: U.S. Department of Energy, Office of Civilian Radioactive Waste Management. ACC: DOC.20040225.0007.

\subsection{SOURCE DATA, LISTED BY DATA TRACKING NUMBER}

GS000308311221.005. Net Infiltration Modeling Results for 3 Climate Scenarios for 147613 FY99. Submittal date: 03/01/2000. 
GS961108312271.002. Chemical and Isotopic Composition of Pore Water and Pore 121708 Gas, 1994-96, from Boreholes USW UZ-1, USW UZ-14, UE-25 UZ\#16, USW NRG-6, USW NRG-7A, USW SD-7, USW SD-9, ESF-AL\#3-RBT\#1, and ESF-AL\#3-RBT\#4, and ESF Rubble. Submittal date: 12/04/1996.

GS980308315215.008. Line Survey Information from the Exploratory Studies 107355 Facility Obtained to Estimate Secondary Mineral Abundance. Submittal date: $03 / 24 / 1998$.

LA000000000034.002. Diffusion of Sorbing and Non-Sorbing Radionuclides. 148603 Submittal date: 06/22/1993.

LB0205REVUZPRP.001. Fracture Properties for UZ Model Layers Developed from 159525 Field Data. Submittal date: 05/14/2002.

LB0208UZDSCPMI.001. Drift-Scale Calibrated Property Sets: Mean Infiltration Supporting Files. Submittal date: 08/27/2002.

LB02091DSSCP3I.001. 1-D Site Scale Calibrated Properties: Supporting Files. Submittal date: 09/18/2002.

LB02091DSSCP3I.002. 1-D Site Scale Calibrated Properties: Data Summary. 161433 Submittal date: 09/18/2002.

LB03023DKMGRID.001. UZ 3-D Site Scale Model Grids. Submittal date: $02 / 26 / 2003$.

MO0012CARB1314.000. Water - Carbon 13 and Carbon 14 Abundance. Submittal 153398 date: $12 / 01 / 2000$.

MO0407SEPFEPLA.000. LA FEP List. Submittal date: 07/20/2004. 170760 MO9906GPS98410.000. Yucca Mountain Project Borehole Locations. Submittal date: $06 / 23 / 1999$.

\subsection{OUTPUT DATA, LISTED BY DATA TRACKING NUMBER}

LB0212C14INFIL.001. 1-D Simulation and Sensititvity Analyses of Groundwater Age by Matching to C14 Age Data: 1. Supporting Files. Submittal date: $12 / 19 / 2002$.

LB0212C14INFIL.002. 1-D Simulation and Sensititvity Analyses of Groundwater Age by Matching to C14 Age Data: 2. Data Summaries. Submittal date: 12/19/2002.

LB0212AFPGAMMA.001. Active Fracture Parameter Analysis: 1. Supporting Files. Submittal date: 12/23/2002. 
LB0212AFPGAMMA.002. Active Fracture Parameter Analysis: 2. Data

Summaries. Submittal date: 12/23/2002.

\subsection{SOFTWARE CITED}

LBNL (Lawrence Berkeley National Laboratory) 1999. Software Code: T2R3D. 146654 V1.4. FORTRAN 77, SUN, DEC/ALPHA. 10006-1.4-00.

LBNL (Lawrence Berkeley National Laboratory) 2000. Software Code: TOUGH2. 146496 V1.4. Sun Workstation and DEC/ALPHA. 10007-1.4-01.

LBNL (Lawrence Berkeley National Laboratory) 2002. Software Code: infil2grid. 154793 V1.7. DEC-Alpha, PC. 10077-1.7-00. 
APPENDIX A

DATA POINT VALUES IN FIGURES 7-3 AND 7-4 
Data point values in Figure 7-3 (estimated from Figure 9 of Tokunaga et al. (2000 [DIRS 152914])):

Average film thickness $(\mu \mathrm{m})$

1.2

1.5

2.0

2.5

3.0

3.5

4.0

5.0
Surface transmissivity $\left(\mathrm{m}^{2} / \mathrm{s}\right)$

$2.5 \mathrm{E}-16$

$1.0 \mathrm{E}-14$

$1.5 \mathrm{E}-13$

7.0E-13

$2.0 \mathrm{E}-12$

7.0E-12

$1.0 \mathrm{E}-11$

$2.5 \mathrm{E}-11$

Data point values in Figure 7-4 (a) (estimated from Figure 7 of Tokunaga and Wan (1997 [DIRS 139195])):

Capillary potential $(\mathrm{Pa})$

$-310$

$-215$

$-165$

$-118$

$-93$

$-70$

$-45$

$-30$

$-14$
Average film thickness $(\mu \mathrm{m})$

1.0

2.0

3.0

5.0

7.0

8.0

20.0

30.0

70.0 
Data point values in Figure 7-4 (b) (estimated from Figure 6 of Tokunaga and Wan (1997 [DIRS 139195])):

Capillary pressure $(\mathrm{Pa})$

$-250$

$-200$

$-150$

$-100$

$-50$

$-12$
Surface transmissivity $\left(\mathrm{m}^{2} / \mathrm{s}\right)$

8.0E-11

$1.5 \mathrm{E}-10$

$3.5 \mathrm{E}-10$

$8.0 \mathrm{E}-10$

$3.5 \mathrm{E}-9$

$4.0 \mathrm{E}-8$ 
APPENDIX B

DATA POINT VALUES IN FIGURE 7-1 
Coating data from DTN: GS980308315215.008 [DIRS 107355] are used to determine the data point values. Since Tptpmn unit has the largest number of survey intervals, data from this unit are analyzed using the box counting method. There are 29 survey intervals $(30 \mathrm{~m}$ long) for this unit that include coated fractures. The total number of coated fractures is 134 . The locations of the coated fractures along the survey line form a set of points in a one-dimensional space. For a given box size (length of a segment) $l$, there are 30/l small boxes (or segments) for a given survey interval. $N$ denotes total numbers of boxes that cover at least one location of the coated fractures (along the survey line) for all the survey intervals. The determined $N$ values as a function of $l$ are given as follows:

$\mathrm{N} \quad l(\mathrm{~m})$

$102 \quad 3$

$91 \quad 3.75$

$83 \quad 5$.

$81 \quad 6$.

$68 \quad 7.5$

$63 \quad 10$

$50 \quad 15$

$29 \quad 30$ 


\section{INTENTIONALLY LEFT BLANK}

